Supporting Information

\title{
Enantioselective NHC-catalyzed [3+3] Annulation of a-Bromoenals with 2-Aminobenzimidazoles
}

\author{
Yangxi Xie, ${ }^{\mathrm{b}}$ Luoyuan Li, ${ }^{\mathrm{b}}$ Shaofa Sun, ${ }^{\mathrm{a}, *}$ Zijun Wu, ${ }^{\mathrm{b}}$ Ming Lang, ${ }^{\mathrm{b}}$ Di Jiang ${ }^{\mathrm{b}}$ and Jian \\ Wang ${ }^{\mathrm{a}, \mathrm{b}, *}$ \\ ${ }^{a}$ College of Chemistry and Biological Sciences, Hubei University of Science and \\ Technology, Hubei, 437100, China \\ ${ }^{b}$ School of Pharmaceutical Sciences, Tsinghua University, Beijing, 100084, China \\ e-mail: wangjian2012@tsinghua.edu.cn
}

Contents:

General Information

General Procedure for the Synthesis of $\alpha$-bromoenals and 2-aminobenzimidazole 3

General Procedure for NHC-catalyzed annulation of $\alpha$-bromoenals and 2-aminobenzimidazoles

Gram-scale synthesis 4

Synthetic transformation $\quad 4$

Crystal Structure of $\mathbf{3 m} \quad 5$

Biological test 6

$\begin{array}{ll}\text { Characterization data } & 10\end{array}$

References $\quad 23$

$\begin{array}{ll}\text { NMR Spectra } & 24\end{array}$

$\begin{array}{ll}\text { HPLC Spectra } & 59\end{array}$ 


\section{General Information}

Chemicals were purchased from commercial suppliers and used as received. Solvents were dried on alumina columns using a solvent dispensing system or using reported methods. Thin-layer chromatography (TLC) was conducted on plates (GF254) supplied by Yantai Chemicals (China) and visualized using a UV light at $254 \mathrm{~nm} .{ }^{1} \mathrm{H}$ NMR, ${ }^{13} \mathrm{C}$ NMR, ${ }^{19} \mathrm{~F}$ NMR, spectra were recorded on a Bruker ACF400 (400 MHz) spectrometer. Chemical shifts were reported in parts per million (ppm), and the residual solvent peak was used as an internal reference: proton (chloroform $\delta$ 7.26, menthol $\delta 3.31$, dimethyl sulfoxide $\delta 2.50$ ), carbon (chloroform $\delta 77.16$, menthol $\delta$ 49.00, dimethyl sulfoxide $\delta 39.52$ ) or tetramethylsilane (TMS $\delta 0.00$ ) was used as a reference. Multiplicity was indicated as follows: s (singlet), d (doublet), t (triplet), $q$ (quartet), m (multiplet), dd (doublet of doublet), td (doublet of triplet), bs (broad singlet). Coupling constants were reported in Hertz $(\mathrm{Hz})$. All high resolution mass spectra were obtained from the Tsinghua University Mass Spectrometry Facility. Flash chromatography separations were performed on Silica gel (300-400 mesh) supplied by Qingdao Haiyang Chemicals (China). The enantiomeric excesses of products were determined on a Shimadzu LC-20AT Chiral HPLC. Optical rotations were recorded on Optical rotations were recorded on SGW-1 autopolarimeter. 
General procedure for the synthesis of $\alpha$-bromoenals and

\title{
2-aminobenzimidazoles
}

\author{
A: Substituted 2-aminobenzimidaoles were prepared according to known \\ procedures $^{1}$.
}

B: General procedure for Synthesis of $\alpha$-bromoenals ${ }^{2}$

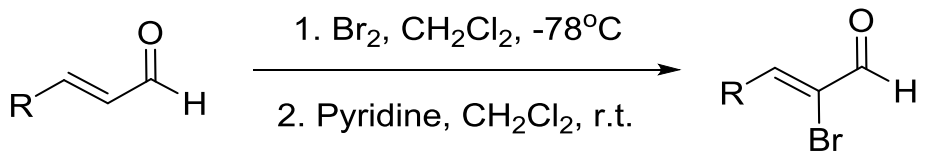

A round bottom flask was charged with enal (20 mmol, 1.0 equiv) and $\mathrm{CH}_{2} \mathrm{Cl}_{2}, \mathrm{Br}_{2}$ (24 mmol, 1.2 equiv) was added slowly at $-78^{\circ} \mathrm{C}$, then it was stirred for $30-60 \mathrm{~min}$ at $-78^{\circ} \mathrm{C}$. Pyridine ( $80 \mathrm{mmol}, 4.0$ equiv) was added slowly, then it was allowed to warm to room temperature and stirred for $2-3 \mathrm{~h}$ until it was completed. The mixture was washed by saturated aqueous $\mathrm{Na}_{2} \mathrm{~S}_{2} \mathrm{O}_{3}$ and saturated aqueous $\mathrm{NaHCO}_{3}$, dried over $\mathrm{Mg}_{2} \mathrm{SO}_{4}$, filtrated and concentrated, purified by flash column chromatography to give the product.

(When $\mathrm{R}=\mathrm{CO}_{2} \mathrm{Et}$, $\alpha$-bromoenal was synthesized according to another method using $\mathrm{NaOAc/HOAc} \mathrm{system.}{ }^{3}$ )

\section{General Procedure for NHC-catalyzed annulation of $\alpha$-bromoenals and 2-aminobenzimidazoles}

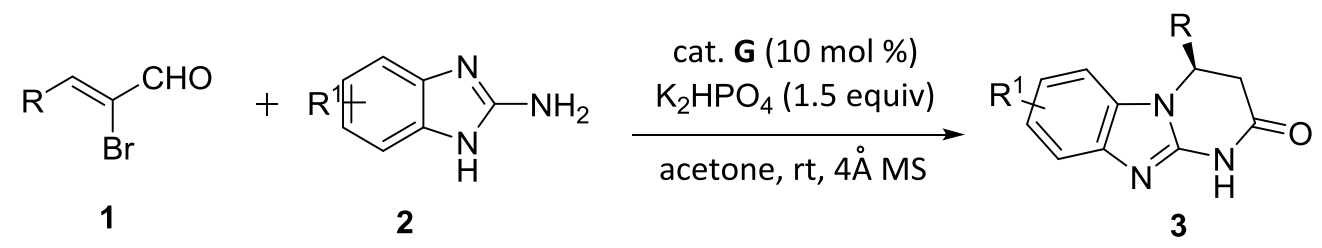

Method A: To a Schlenk tube with a stir bar, $\alpha$-bromoenal ( $0.15 \mathrm{mmol}, 1.5$ equiv), 2-aminobenzimidazole ( $0.1 \mathrm{mmol}, 1.0$ equiv), catalyst (0.01 mmol, 0.1 equiv), $\mathrm{K}_{2} \mathrm{HPO}_{4}(0.15 \mathrm{mmol}, 1.5$ equiv $)$ and $4 \AA$ molecular sieve were added, then the tube 
was closed with a septum, evacuated, back-filled with argon. Dry acetone was added (in case $\alpha$-bromoenal was liquid, it was added at this step) and the mixture was stirred at $\mathrm{rt}$ until the reaction was completed (generally 12-72h). After the reaction was completed, the mixture was diluted with $\mathrm{CH}_{2} \mathrm{Cl}_{2}$, filtered and concentrated, purified by column chromatography on silica gel using $\mathrm{CH}_{2} \mathrm{Cl}_{2} / \mathrm{MeOH}$ or $\mathrm{CHCl}_{3} / \mathrm{MeOH}$ (gradient increased slowly to 10:1) as eluent to afford the products.

\section{Method B:}

In a nitrogen-filled glovebox, to a dried Schlenk tube with a stir bar, $\alpha$-bromoenal ( $0.15 \mathrm{mmol}, 1.5$ equiv), 2-aminobenzimidazole ( $0.1 \mathrm{mmol}, 1.0$ equiv), catalyst $(0.01$ mmol, 0.1 equiv), $\mathrm{K}_{2} \mathrm{HPO}_{4}(0.15 \mathrm{mmol}, 1.5$ equiv) and $4 \AA$ molecular sieve were added, then dry acetone was added (in case $\alpha$-bromoenal was liquid, it was added at this step) and the mixture was stirred at rt until the reaction was completed (generally 12-72h). After the reaction was completed, the mixture was diluted with $\mathrm{CH}_{2} \mathrm{Cl}_{2}$, filtered and concentrated, purified by column chromatography on silica gel using $\mathrm{CH}_{2} \mathrm{Cl}_{2} / \mathrm{MeOH}$ or $\mathrm{CHCl}_{3} / \mathrm{MeOH}$ (gradient increased slowly to $10: 1$ ) as eluent to afford the products.

\section{Gram-scale synthesis}

In a nitrogen-filled glovebox, to a dried Schlenk tube with a stir bar, 1a (15 mmol, 1.5 equiv), $2 \mathbf{a}$ (10 mmol, 1.0 equiv), catalyst $\mathbf{G}$ ( $1 \mathrm{mmol}, 0.1$ equiv), $\mathrm{K}_{2} \mathrm{HPO}_{4}(15 \mathrm{mmol}$, 1.5 equiv) and $4 \AA$ molecular sieve were added, dry acetone was added and the mixture was stirred at $\mathrm{rt}$ until the reaction was completed $(\sim 24 \mathrm{~h})$. After the reaction was completed, the mixture was diluted with $\mathrm{CH}_{2} \mathrm{Cl}_{2}$, filtered and concentrated, purified by column chromatography on silica gel using $\mathrm{CH}_{2} \mathrm{Cl}_{2} / \mathrm{MeOH}$ or $\mathrm{CHCl}_{3} / \mathrm{MeOH}$ (gradient increased slowly to $10: 1$ ) as eluent to afford the products.

\section{Synthetic transformation}

To a dried Schlenk tube with a stir bar, $3 \mathbf{a}(0.3 \mathrm{mmol}, 1.0$ equiv) was added and the tube was closed with a septum, evacuated, back-filled with argon. Then dry THF (3 
$\mathrm{ml}$ ) was added, the mixture was cooled to $-10^{\circ} \mathrm{C}, \mathrm{LiAlH}_{4}$ (2.5 equiv) was added in 3 batches. The reaction was stirred at $0^{\circ} \mathrm{C}$ for $1 \mathrm{~h}$, then stirred at $\mathrm{rt}$ for $7 \mathrm{~h}$. After completed, the mixture was quenched by ice-water and extracted by $\mathrm{CH}_{2} \mathrm{Cl}_{2}$, organic phase was collected, dried over $\mathrm{Mg}_{2} \mathrm{SO}_{4}$, concentrated, purified by column chromatography on silica gel using $\mathrm{CH}_{2} \mathrm{Cl}_{2} / \mathrm{MeOH}$ (gradient increased slowly to 10:1, with few drops of $\mathrm{AcOH}$ ) as eluent to afford the products.

\section{Crystal Structure of 3m}

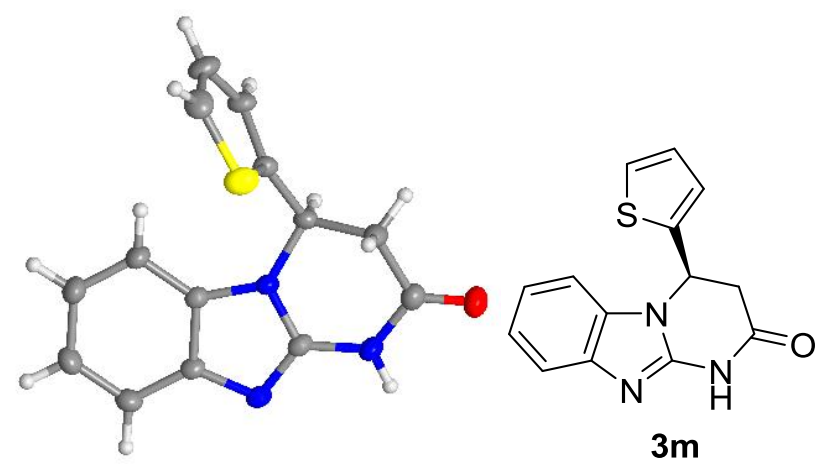

Table S1 Crystal data and structure refinement for $\mathbf{3 m}$

\begin{tabular}{cc}
\hline CCDC code & 1963978 \\
\hline Empirical formula & $\mathrm{C}_{14} \mathrm{H}_{11} \mathrm{~N}_{3} \mathrm{OS}$ \\
Formula weight & 269.32 \\
Temperature/K & $173.01(10)$ \\
Crystal system & triclinic \\
Space group & $\mathrm{P} 1$ \\
$\mathrm{a} / \AA$ & $8.0231(3)$ \\
$\mathrm{b} / \AA$ & $9.2045(3)$ \\
$\mathrm{c} / \AA$ & $9.8491(3)$ \\
$\alpha /{ }^{\circ}$ & $112.219(3)$ \\
$\beta /{ }^{\circ}$ & $102.171(3)$ \\
$\gamma /{ }^{\circ}$ & $103.048(3)$ \\
Volume $/ \AA^{3}$ & $619.56(4)$ \\
$\mathrm{Z}$ & 2 \\
$\rho_{\text {calc }} / \mathrm{cm}^{3}$ & 1.444 \\
$\mu / \mathrm{mm}^{-1}$ & 2.279 \\
\hline
\end{tabular}




\begin{tabular}{cc}
\hline $\mathrm{F}(000)$ & 280 \\
Crystal size/mm ${ }^{3}$ & $0.4 \times 0.35 \times 0.25$ \\
Radiation & $\mathrm{CuK \alpha}(\lambda=1.54184)$ \\
$2 \Theta$ range for data collection/ ${ }^{\circ}$ & 10.272 to 142.754 \\
Index ranges & $-9 \leq \mathrm{h} \leq 9,-11 \leq \mathrm{k} \leq 11,-12 \leq 1 \leq 12$ \\
Reflections collected & 8412 \\
Independent reflections & $4327\left[\mathrm{R}_{\text {int }}=0.0206, \mathrm{R}_{\text {sigma }}=0.0239\right]$ \\
Data/restraints/parameters & $4327 / 532 / 343$ \\
Goodness-of-fit on $\mathrm{F}^{2}$ & 1.042 \\
Final R indexes [I $>=2 \sigma(\mathrm{I})]$ & $\mathrm{R}_{1}=0.0329, \mathrm{wR}_{2}=0.0922$ \\
Final R indexes [all data] & $\mathrm{R}_{1}=0.0331, \mathrm{wR}_{2}=0.0925$ \\
Largest diff. peak/hole / e $\AA^{-3}$ & $0.35 /-0.24$ \\
Flack parameter & $0.013(7)$ \\
\hline
\end{tabular}

\section{Biological Test}

\section{Cell culture}

CT26 (murine colon carcinoma cell line), A549 (human lung cancer cell line), HeLa (human cervical cancer cell line), U87MG (human malignant glioblastoma cell line) and HEK 293T (human renal epithelial cell line) cells were provided by the Institute of Basic Medical Sciences, Chinese Academy of Medical Sciences (Beijing, China). The cells were cultured in high-glucose DMEM (Dulbecco's modified Eagle's medium, Solarbio, China) supplemented with $10 \%$ (v/v) fetal bovine serum (FBS), $1 \%$ penicillin and streptomycin. All the cell lines were cultured at $37{ }^{\circ} \mathrm{C}$ under a humidified atmosphere containing $5 \% \mathrm{CO}_{2}$.

\section{Cell viability assay and cell staining with Trypan blue}

Cell viability after treated with these compounds was assessed by using the MTT assay. Cancer cells $\left(10^{4} /\right.$ well for each cell lines) were seeded in 96 -well plates and cultured for 24 hours. $20 \mu \mathrm{M}$ of selected compounds (3a, 3g, 3k, 3m, 3i, 3o, 4a, 4d, 4e, 5) were prepared using culturing medium and added into the corresponding 96-well plates (100 $\mu \mathrm{L} /$ well), in which cells were incubated for 24 and 48 hours. Then, 
$10 \mu \mathrm{L}$ fresh media containing $5 \mathrm{mg} / \mathrm{mL}$ MTT was added. After incubated for $4 \mathrm{~h}$ at $37{ }^{\circ} \mathrm{C}, 100 \mu \mathrm{L}$ DMSO was added to each well for additional 2-hours incubation. The absorbance of the each well was measured at $490 \mathrm{~nm}$ in a Multi-mode Microplate Reader. The cell viability was calculated by the following equation. When the compound 3o was identified the most potential molecular, the dose-dependent $(1,5$, $15,20,25,40,60 \mu \mathrm{M})$ studies were carried out to determine the exact IC50 values against U87MG. And then, cells, after treating with compounds 3o of different concentrations $(0,5,20 \mu \mathrm{M})$, were stained with Trypan blue (staining dead cells) for 9 min, washed three times with PBS. The cell-staining images were observed by an Olympus IX71 microscopy.

Cell viability $(\%)=[($ mean of Abs. value of experiment $) /($ mean Abs. value of blank)] $\times 100 \%$.

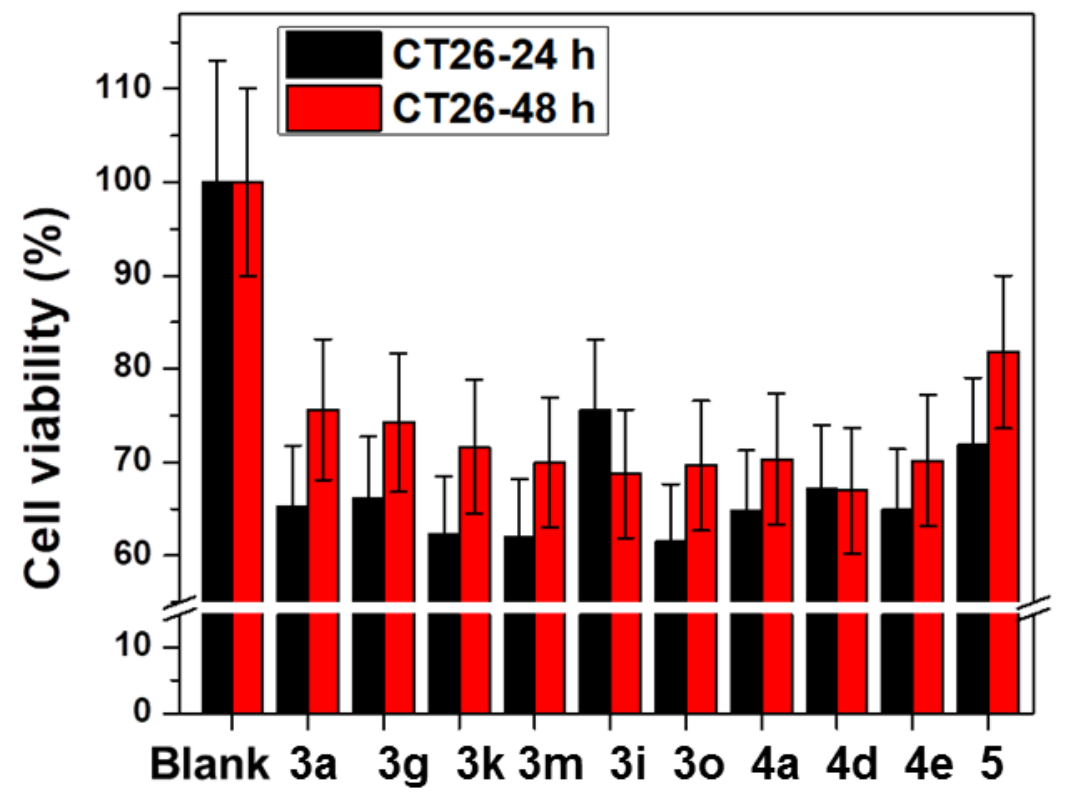

Figure S1. The cell viability of CT26 cell lines after treating with selected compounds $(20 \mu \mathrm{M})$ for 24 and $48 \mathrm{~h}$. 


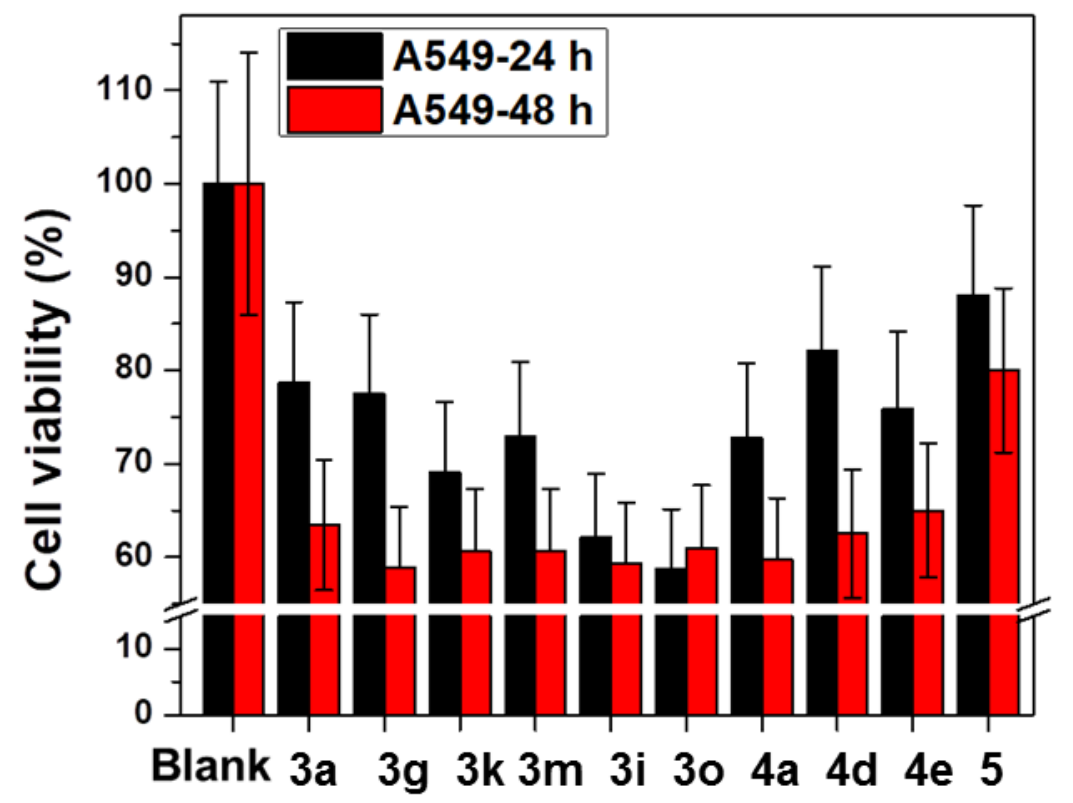

Figure S2. The cell viability of A549 cell lines after treating with selected compounds $(20 \mu \mathrm{M})$ for 24 and $48 \mathrm{~h}$.

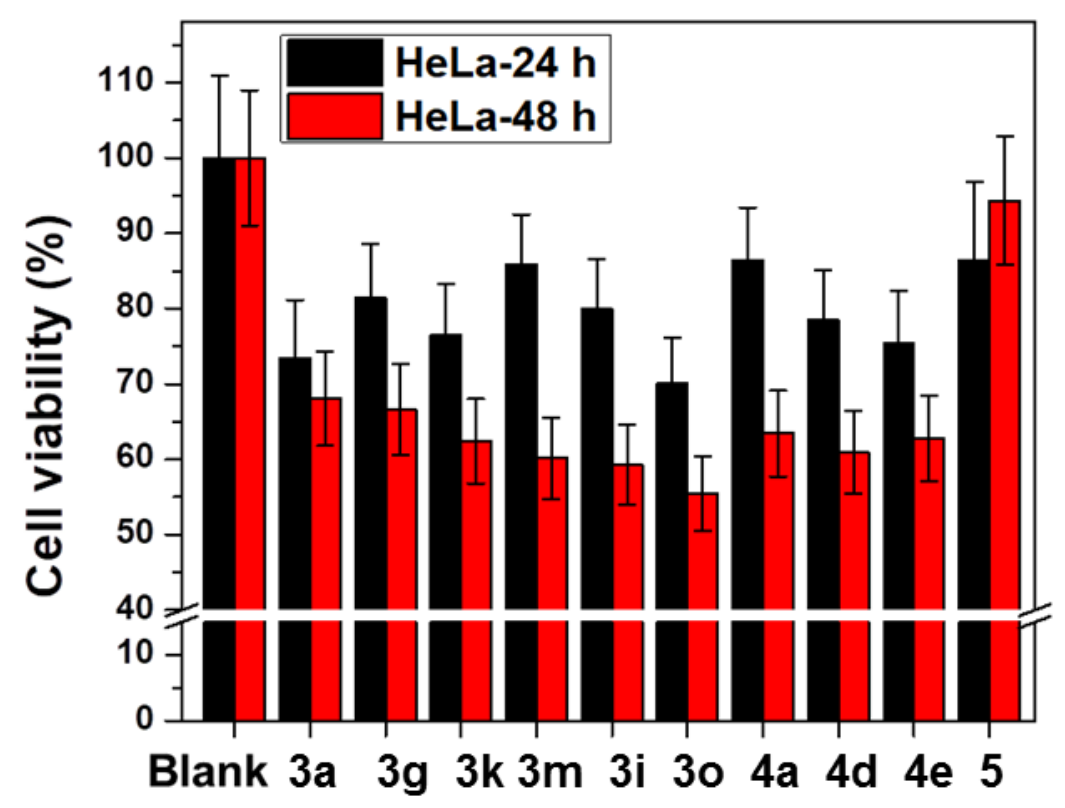

Figure S3. The cell viability of HeLa cell lines after treating with selected compounds $(20 \mu \mathrm{M})$ for 24 and $48 \mathrm{~h}$. 


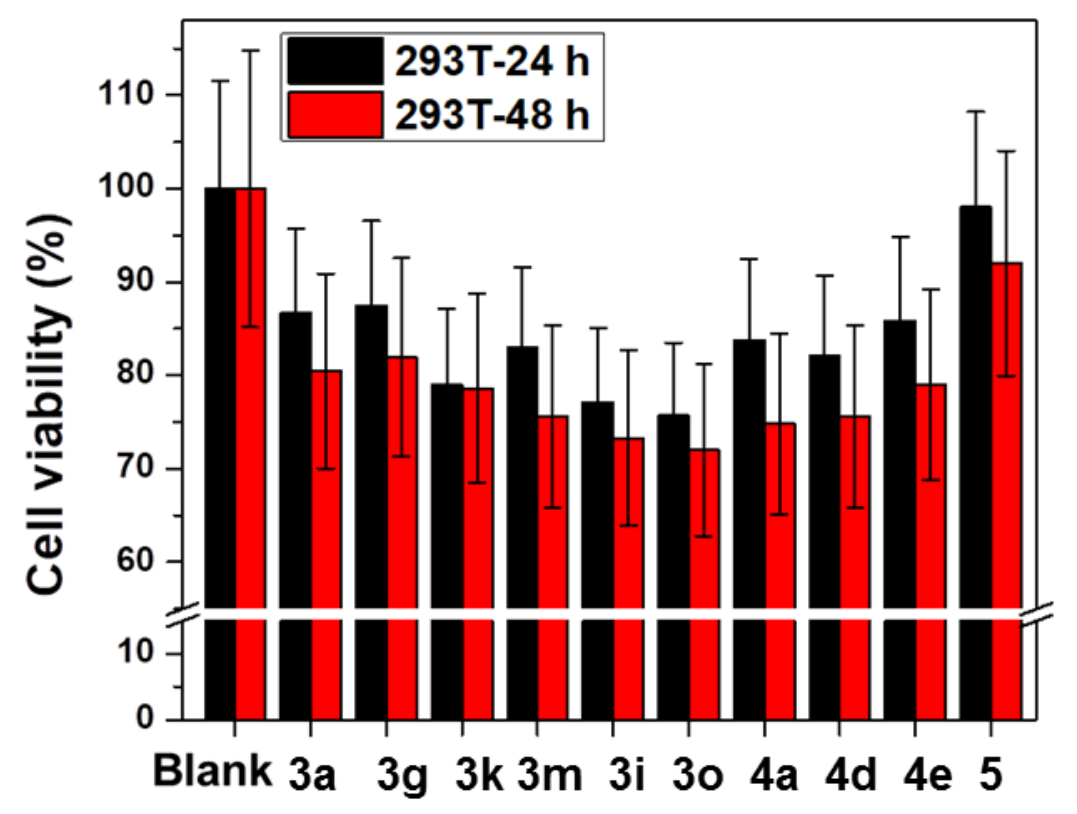

Figure S4. The cell viability of HEK 293T cell lines after treating with selected compounds $(20 \mu \mathrm{M})$ for 24 and $48 \mathrm{~h}$.
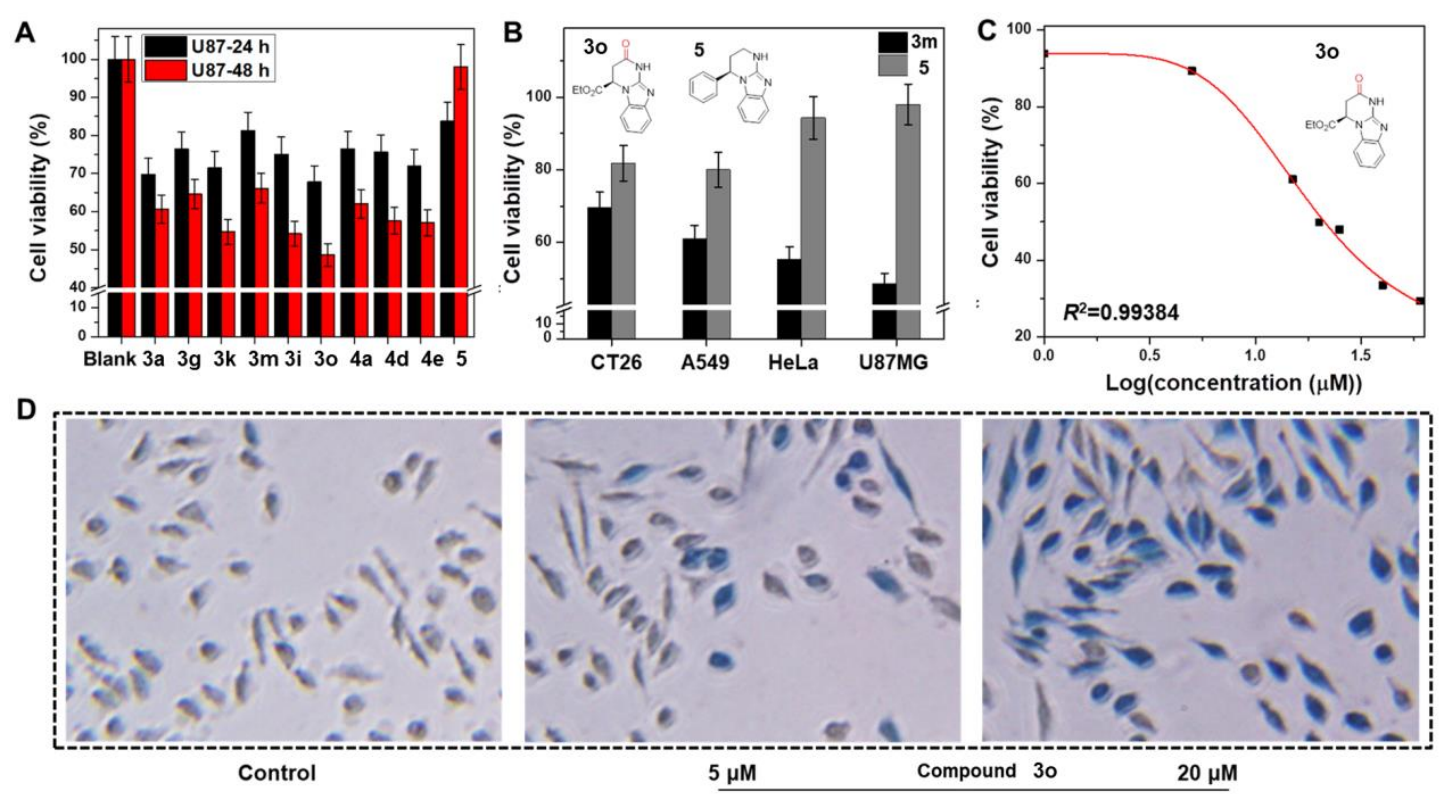

Figure 1. Biological Test: A) The cell viability of U87MG cell lines after treating with selected compounds $(20 \mu \mathrm{M})$ for $24 \mathrm{~h}$ and $48 \mathrm{~h}$; B) The cell viability of four cancer cell lines after treating with compound 3o or $5(20 \mu \mathrm{M})$ for $48 \mathrm{~h}$; C) $\mathrm{IC}_{50}$ values of compound 30 against U87MG cell lines measured by MTT assay; D) The micrographs of U87MG cells stained with Trypan blue after treated with 30 (5 and 20 $\mu \mathrm{M})$ for $24 \mathrm{~h}$, and the cells treated with PBS as the control 


\section{Characterization data}<smiles>O=C1C[C@H](c2ccccc2)n2c(nc3ccccc32)N1</smiles>

3a: light yellow solid, $80 \%$ yield; ${ }^{1} \mathbf{H}$ NMR (400 MHz, $\left.\mathrm{CDCl}_{3}: \mathrm{CD}_{3} \mathrm{OD}=2: 1\right) \delta 7.57$ $(\mathrm{d}, J=8.0 \mathrm{~Hz}, 1 \mathrm{H}), 7.40-7.30(\mathrm{~m}, 3 \mathrm{H}), 7.19(\mathrm{t}, J=7.4 \mathrm{~Hz}, 1 \mathrm{H}), 7.16-7.09(\mathrm{~m}, 2 \mathrm{H})$, $7.06(\mathrm{t}, J=7.7 \mathrm{~Hz}, 1 \mathrm{H}), 6.82(\mathrm{~d}, J=8.0 \mathrm{~Hz}, 1 \mathrm{H}), 5.68(\mathrm{dd}, J=7.1,4.5 \mathrm{~Hz}, 1 \mathrm{H}), 3.39$ $(\mathrm{dd}, J=16.7,7.1 \mathrm{~Hz}, 1 \mathrm{H}), 3.07(\mathrm{dd}, J=16.7,4.4 \mathrm{~Hz}, 1 \mathrm{H}) ;{ }^{13} \mathbf{C}$ NMR (100 MHz, $\left.\mathrm{CDCl}_{3}: \mathrm{CD}_{3} \mathrm{OD}=2: 1\right) \delta 168.3,148.3,141.2,138.3,132.4,129.8,129.3,126.2,123.1$, 122.5, 117.9, 110.1, 54.0, 39.3; HRMS (ESI): m/z: calculated for $\mathrm{C}_{16} \mathrm{H}_{14} \mathrm{~N}_{3} \mathrm{O}[\mathrm{M}+$ $\mathrm{H}]^{+}:$264.1137, found: 264.1140; HPLC (Chiralpak AD-H, $i$-propanol/hexane $=20 / 80$, flow rate $\left.1.0 \mathrm{~mL} / \mathrm{min}, 30{ }^{\circ} \mathrm{C}, \lambda=254 \mathrm{~nm}\right): t_{\mathrm{R}}($ major $)=15.2 \mathrm{~min}, t_{\mathrm{R}}($ minor $)=12.7$ $\min , e e=92 \% ;[\alpha]^{22}=+156.6\left(\mathrm{c}=1, \mathrm{CHCl}_{3} / \mathrm{MeOH}=2: 1\right)$.

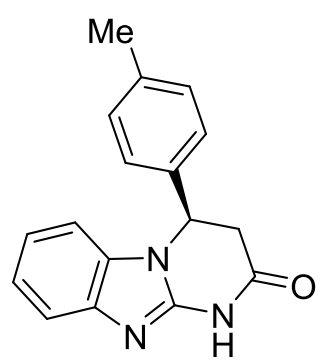

3b

3b: white solid, 80\% yield; ${ }^{1} \mathbf{H}$ NMR (400 MHz, $\left.\mathrm{CDCl}_{3}: \mathrm{CD}_{3} \mathrm{OD}=2: 1\right) \delta 7.55(\mathrm{~d}, J=$ $8.0 \mathrm{~Hz}, 1 \mathrm{H}), 7.26-7.12(\mathrm{~m}, 3 \mathrm{H}), 7.09-6.92(\mathrm{~m}, 3 \mathrm{H}), 6.82$ (d, J=8.0 Hz, 1H), 5.64 $(\mathrm{dd}, J=7.0,4.6 \mathrm{~Hz}, 1 \mathrm{H}), 3.49-3.25(\mathrm{~m}, 1 \mathrm{H}), 3.04(\mathrm{dd}, J=16.6,4.6 \mathrm{~Hz}, 1 \mathrm{H}), 2.33$ (s, $3 \mathrm{H}) ;{ }^{13} \mathrm{C}$ NMR $\left(100 \mathrm{MHz}, \mathrm{CDCl}_{3}: \mathrm{CD}_{3} \mathrm{OD}=2: 1\right) \delta 168.6,148.4,141.2,139.3,135.4$, 132.5, 130.4, 126.2, 123.1, 122.5, 117.9, 110.3, 53.9, 39.5, 21.2; HRMS (ESI): m/z: calculated for $\mathrm{C}_{17} \mathrm{H}_{16} \mathrm{~N}_{3} \mathrm{O}[\mathrm{M}+\mathrm{H}]^{+}:$278.1293, found: 278.1294; HPLC (Chiralpak IA, $i$-propanol $/$ hexane $=20 / 80$, flow rate $1.0 \mathrm{~mL} / \mathrm{min}, 30{ }^{\circ} \mathrm{C}, \lambda=254 \mathrm{~nm}$ ): $t_{\mathrm{R}}$ (major) $=11.7 \mathrm{~min}, t_{\mathrm{R}}($ minor $)=10.3 \mathrm{~min}, e e=91 \% ;[\alpha]^{23} \mathrm{D}=+189(\mathrm{c}=0.2, \mathrm{DMSO})$. 


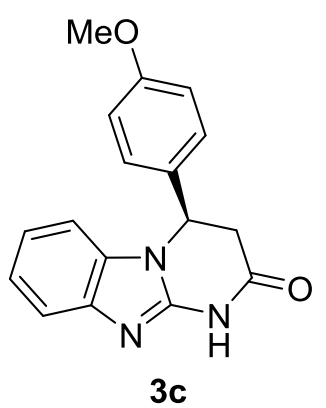

3c: white solid, $82 \%$ yield; ${ }^{1} \mathbf{H}$ NMR $\left(400 \mathrm{MHz}, \mathrm{CDCl}_{3}: \mathrm{CD}_{3} \mathrm{OD}=2: 1\right) \delta 7.54(\mathrm{~d}, J=$ $7.9 \mathrm{~Hz}, 1 \mathrm{H}), 7.18(\mathrm{t}, J=7.2 \mathrm{~Hz}, 1 \mathrm{H}), 7.13-7.01(\mathrm{~m}, 3 \mathrm{H}), 6.89(\mathrm{~d}, J=8.7 \mathrm{~Hz}, 2 \mathrm{H})$, $6.81(\mathrm{~d}, J=7.9 \mathrm{~Hz}, 1 \mathrm{H}), 5.64(\mathrm{dd}, J=6.8,4.9 \mathrm{~Hz}, 1 \mathrm{H}), 3.79(\mathrm{~s}, 3 \mathrm{H}), 3.39-3.27(\mathrm{~m}$, $1 \mathrm{H}), 3.04(\mathrm{dd}, J=16.6,4.9 \mathrm{~Hz}, 1 \mathrm{H}) ;{ }^{13} \mathbf{C}$ NMR $\left(100 \mathrm{MHz}, \mathrm{CDCl}_{3}: \mathrm{CD}_{3} \mathrm{OD}=2: 1\right) \delta$ 168.6, 160.4, 148.4, 141.2, 132.5, 130.3, 127.7, 123.1, 122.5, 117.9, 115.1, 110.3, 55.6, 53.8, 39.6; HRMS (ESI): $\mathrm{m} / \mathrm{z}$ : calculated for $\mathrm{C}_{17} \mathrm{H}_{16} \mathrm{~N}_{3} \mathrm{O}_{2}[\mathrm{M}+\mathrm{H}]^{+}: 294.1243$, found: 294.1238; HPLC (Chiralpak IA, $i$-propanol/hexane $=20 / 80$, flow rate 1.0 $\left.\mathrm{mL} / \mathrm{min}, 30{ }^{\circ} \mathrm{C}, \lambda=254 \mathrm{~nm}\right): t_{\mathrm{R}}($ major $)=16.7 \mathrm{~min}, t_{\mathrm{R}}($ minor $)=14.4 \mathrm{~min}, e e=94 \%$; $[\alpha]^{24}=+225.5(\mathrm{c}=0.22$, DMSO $)$.

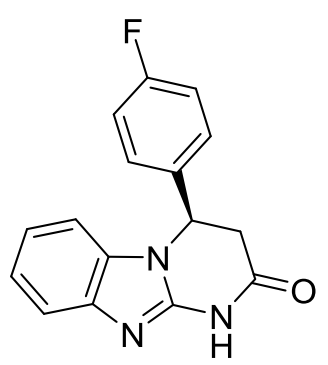

3d

3d: white solid, 81\% yield; ${ }^{\mathbf{1}} \mathbf{H}$ NMR $\left(400 \mathrm{MHz}, \mathrm{CDCl}_{3}\right) \delta 13.91(\mathrm{~s}, 1 \mathrm{H}), 7.78(\mathrm{~d}, J=$ $7.9 \mathrm{~Hz}, 1 \mathrm{H}), 7.20-7.09(\mathrm{~m}, 3 \mathrm{H}), 7.08-7.00(\mathrm{~m}, 2 \mathrm{H}), 6.95(\mathrm{t}, J=7.7 \mathrm{~Hz}, 1 \mathrm{H}), 6.54(\mathrm{~d}$, $J=8.0 \mathrm{~Hz}, 1 \mathrm{H}), 5.52(\mathrm{dd}, J=6.9,5.1 \mathrm{~Hz}, 1 \mathrm{H}), 3.43(\mathrm{dd}, J=16.6,6.9 \mathrm{~Hz}, 1 \mathrm{H}), 3.01$ $(\mathrm{dd}, J=16.6,5.1 \mathrm{~Hz}, 1 \mathrm{H}) ;{ }^{13} \mathbf{C} \mathbf{N M R}\left(100 \mathrm{MHz}, \mathrm{CDCl}_{3}\right) \delta 166.9,162.9(\mathrm{~d}, J=248.5$ Hz), 148.5, 141.2, 134.1 (d, $J=3.3 \mathrm{~Hz}), 131.7,128.0(\mathrm{~d}, J=8.4 \mathrm{~Hz}), 122.8,121.9$, 118.0, $116.6(\mathrm{~d}, J=22.0 \mathrm{~Hz}), 109.6,53.6,39.4 ;{ }^{19} \mathbf{F}$ NMR $\left(376 \mathrm{MHz}, \mathrm{CDCl}_{3}\right) \delta$ -112.4; HRMS (ESI): m/z: calculated for $\mathrm{C}_{16} \mathrm{H}_{13} \mathrm{~N}_{3} \mathrm{OF}[\mathrm{M}+\mathrm{H}]^{+}: 282.1043$, found: 282.1046; HPLC (Chiralpak AD-H, $i$-propanol $/$ hexane $=20 / 80$, flow rate $1.0 \mathrm{~mL} / \mathrm{min}$, $\left.30{ }^{\circ} \mathrm{C}, \lambda=254 \mathrm{~nm}\right): t_{\mathrm{R}}($ major $)=12.1 \mathrm{~min}, t_{\mathrm{R}}($ minor $)=10.3 \mathrm{~min}, e e=92 \% ;[\alpha]^{20}{ }_{\mathrm{D}}=$ $+237.6\left(\mathrm{c}=0.5, \mathrm{CHCl}_{3}\right)$. 


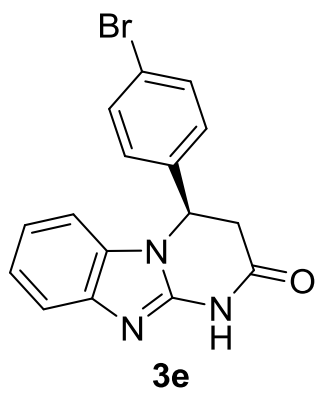

3e: yellow solid, 77\% yield; ${ }^{1} \mathbf{H}$ NMR (400 MHz, $\left.\mathrm{CDCl}_{3}: \mathrm{CD}_{3} \mathrm{OD}=2: 1\right) \delta 7.56(\mathrm{~d}, J=$ $8.0 \mathrm{~Hz}, 1 \mathrm{H}), 7.51-7.44(\mathrm{~m}, 2 \mathrm{H}), 7.21(\mathrm{td}, J=7.7,1.1 \mathrm{~Hz}, 1 \mathrm{H}), 7.10(\mathrm{td}, J=7.8,1.1$ $\mathrm{Hz}, 1 \mathrm{H}), 7.02(\mathrm{~d}, J=8.5 \mathrm{~Hz}, 2 \mathrm{H}), 6.89(\mathrm{~d}, J=8.0 \mathrm{~Hz}, 1 \mathrm{H}), 5.71(\mathrm{dd}, J=7.2,4.0 \mathrm{~Hz}$, $1 \mathrm{H}), 3.42(\mathrm{dd}, J=16.7,7.2 \mathrm{~Hz}, 1 \mathrm{H}), 3.03(\mathrm{dd}, J=16.6,4.1 \mathrm{~Hz}, 1 \mathrm{H}) ;{ }^{13} \mathbf{C}$ NMR $(100$ $\left.\mathrm{MHz}, \mathrm{CDCl}_{3}: \mathrm{CD}_{3} \mathrm{OD}=2: 1\right) \delta 168.0,148.3,141.2,137.6,133.0,132.3,128.0,123.3$, 123.3, 122.7, 118.0, 110.0, 53.4, 39.1; HRMS (ESI): $\mathrm{m} / \mathrm{z}$ : calculated for $\mathrm{C}_{16} \mathrm{H}_{13} \mathrm{BrN}_{3} \mathrm{O}[\mathrm{M}+\mathrm{H}]^{+}:$342.0242, found: 342.0237; HPLC (Chiralpak IA, $i$-propanol/hexane $=20 / 80$, flow rate $\left.1.0 \mathrm{~mL} / \mathrm{min}, 30{ }^{\circ} \mathrm{C}, \lambda=254 \mathrm{~nm}\right): t_{\mathrm{R}}$ (major) $=$ $13.8 \mathrm{~min}, t_{\mathrm{R}}($ minor $)=10.7 \mathrm{~min}, e e=91 \% ;[\alpha]_{\mathrm{D}}^{24}=+203.2(\mathrm{c}=0.25, \mathrm{DMSO})$.

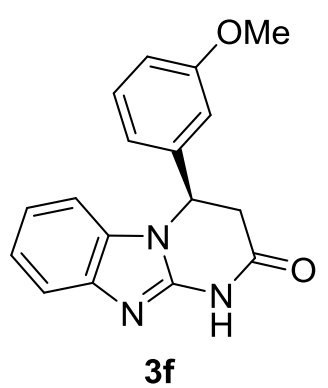

3f: white solid, 80\% yield; ${ }^{1} \mathbf{H}$ NMR $\left(400 \mathrm{MHz}, \mathrm{CDCl}_{3}\right) \delta 13.93(\mathrm{~s}, 1 \mathrm{H}), 7.80(\mathrm{~d}, J=$ $7.9 \mathrm{~Hz}, 1 \mathrm{H}), 7.29-7.20(\mathrm{~m}, 1 \mathrm{H}), 7.14(\mathrm{t}, J=8.0 \mathrm{~Hz}, 1 \mathrm{H}), 6.95$ (t, $J=7.7 \mathrm{~Hz}, 1 \mathrm{H}), 6.85$ $(\mathrm{dd}, J=8.2,1.9 \mathrm{~Hz}, 1 \mathrm{H}), 6.74-6.66(\mathrm{~m}, 2 \mathrm{H}), 6.58(\mathrm{~d}, J=8.0 \mathrm{~Hz}, 1 \mathrm{H}), 5.46(\mathrm{dd}, J=$ 7.0, $5.2 \mathrm{~Hz}, 1 \mathrm{H}), 3.74$ (s, 3H), $3.42(\mathrm{dd}, J=16.7,7.0 \mathrm{~Hz}, 1 \mathrm{H}), 3.04(\mathrm{dd}, J=16.7,5.2$ $\mathrm{Hz}, 1 \mathrm{H}) ;{ }^{13} \mathrm{C}$ NMR $\left(100 \mathrm{MHz}, \mathrm{CDCl}_{3}\right) \delta 167.0,160.3,148.7,141.2,139.9,131.9$, 130.6, 122.7, 121.7, 118.3, 118.0, 113.9, 112.3, 109.7, 55.4, 54.1, 39.2 ; HRMS (ESI): $\mathrm{m} / \mathrm{z}$ : calculated for $\mathrm{C}_{17} \mathrm{H}_{16} \mathrm{~N}_{3} \mathrm{O}_{2}[\mathrm{M}+\mathrm{H}]^{+}$: 294.1243, found: 294.1243; HPLC (Chiralpak AD-H, $i$-propanol/hexane $=20 / 80$, flow rate $1.0 \mathrm{~mL} / \mathrm{min}, 30{ }^{\circ} \mathrm{C}, \lambda=254$ $\mathrm{nm}): t_{\mathrm{R}}($ major $)=19.9 \min , t_{\mathrm{R}}($ minor $)=18.2 \mathrm{~min}, e e=92 \% ;[\alpha]^{20}{ }_{\mathrm{D}}=+121.8(\mathrm{c}=1$, $\left.\mathrm{CHCl}_{3}\right)$. 


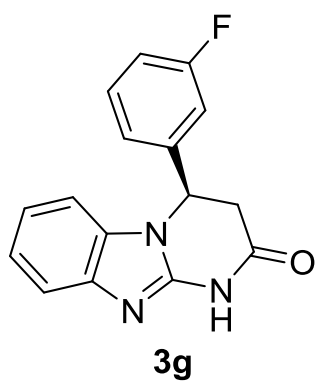

3g: white solid, $75 \%$ yield; ${ }^{1} \mathbf{H}$ NMR $\left(400 \mathrm{MHz}, \mathrm{CDCl}_{3}: \mathrm{CD}_{3} \mathrm{OD}=2: 1\right) \delta 7.57$ (d, $J=$ 8.0 Hz, 1H), 7.41-7.30 (m, 1H), 7.27-7.17 (m, 1H), $7.16-7.00(\mathrm{~m}, 2 \mathrm{H}), 6.98-6.89$ (m, 2H), 6.87-6.78 (m, 1H), 5.75 (dd, $J=7.3,3.8 \mathrm{~Hz}, 1 \mathrm{H}), 3.44(\mathrm{dd}, J=16.7,7.3 \mathrm{~Hz}$, $1 \mathrm{H}), 3.05(\mathrm{dd}, J=16.7,3.8 \mathrm{~Hz}, 1 \mathrm{H}) ;{ }^{13} \mathrm{C} \mathrm{NMR}\left(100 \mathrm{MHz}, \mathrm{CDCl}_{3}: \mathrm{CD}_{3} \mathrm{OD}=2: 1\right) \delta$ $168.1,163.7(\mathrm{~d}, J=248.0 \mathrm{~Hz}), 148.3,141.2,141.1,132.4,131.7(\mathrm{~d}, J=8.2 \mathrm{~Hz})$, 123.4, 122.7, 121.9 (d, $J=3.1 \mathrm{~Hz}), 118.0,116.3$ (d, $J=21.2 \mathrm{~Hz}), 113.4(\mathrm{~d}, J=22.7$ $\mathrm{Hz}), 110.0,53.3(\mathrm{~d}, J=1.9 \mathrm{~Hz}), 39.1 ;{ }^{19} \mathbf{F} \mathbf{N M R}\left(376 \mathrm{MHz}, \mathrm{CDCl}_{3}: \mathrm{CD}_{3} \mathrm{OD}=2: 1\right) \delta$ -111.5; HRMS (ESI): m/z: calculated for $\mathrm{C}_{16} \mathrm{H}_{13} \mathrm{FN}_{3} \mathrm{O}[\mathrm{M}+\mathrm{H}]^{+}:$282.1043, found: 282.1045; HPLC (Chiralpak AD-H, $i$-propanol/hexane $=20 / 80$, flow rate $1.0 \mathrm{~mL} / \mathrm{min}$, $\lambda=254 \mathrm{~nm}): t_{\mathrm{R}}($ major $)=15.8 \mathrm{~min}, t_{\mathrm{R}}($ minor $)=14.3 \mathrm{~min}, e e=92 \% ;[\alpha]^{24}{ }_{\mathrm{D}}=+223.6$ $(\mathrm{c}=0.28, \mathrm{DMSO})$.<smiles>O=C1C[C@H](c2ccccc2F)n2c(nc3ccccc32)N1</smiles>

3h: white solid, $76 \%$ yield; ${ }^{1} \mathbf{H}$ NMR $\left(400 \mathrm{MHz}, \mathrm{CDCl}_{3}: \mathrm{CD}_{3} \mathrm{OD}=2: 1\right) \delta 7.56(\mathrm{~d}, J=$ $8.0 \mathrm{~Hz}, 1 \mathrm{H}), 7.40-7.32(\mathrm{~m}, 1 \mathrm{H}), 7.25-7.03(\mathrm{~m}, 4 \mathrm{H}), 6.99(\mathrm{~d}, J=8.0 \mathrm{~Hz}, 1 \mathrm{H})$, 6.74-6.66 (m, 1H), 6.03 (dd, $J=7.7,3.1 \mathrm{~Hz}, 1 \mathrm{H}), 3.47(\mathrm{dd}, J=16.8,7.7 \mathrm{~Hz}, 1 \mathrm{H})$, $3.09(\mathrm{dd}, J=16.8,3.1 \mathrm{~Hz}, 1 \mathrm{H}) ;{ }^{13} \mathbf{C}$ NMR $\left(100 \mathrm{MHz}, \mathrm{CDCl}_{3}: \mathrm{CD}_{3} \mathrm{OD}=2: 1\right) \delta 168.11$, $160.25(\mathrm{~d}, J=247.0 \mathrm{~Hz}), 148.45,141.19,132.17,131.28(\mathrm{~d}, J=8.4 \mathrm{~Hz}), 127.1$ (d, $J=$ $3.3 \mathrm{~Hz}), 125.6,125.5(\mathrm{~d}, J=3.7 \mathrm{~Hz}), 123.4,122.8,118.0,116.7(\mathrm{~d}, J=21.2 \mathrm{~Hz})$, 109.7, $48.3(\mathrm{~d}, J=3.5 \mathrm{~Hz}), 37.5 ;{ }^{19} \mathbf{F}$ NMR $\left(376 \mathrm{MHz}, \mathrm{CDCl}_{3}: \mathrm{CD}_{3} \mathrm{OD}=2: 1\right) \delta$-118.6; HRMS (ESI): $\mathrm{m} / \mathrm{z}$ : calculated for $\mathrm{C}_{16} \mathrm{H}_{13} \mathrm{FN}_{3} \mathrm{O}[\mathrm{M}+\mathrm{H}]^{+}$: 282.1043, found: 282.1038; HPLC (Chiralpak IC, $i$-propanol/hexane $=20 / 80$, flow rate $1.0 \mathrm{~mL} / \mathrm{min}, 30{ }^{\circ} \mathrm{C}, \lambda=$ $254 \mathrm{~nm}): t_{\mathrm{R}}($ major $)=18.2 \min , t_{\mathrm{R}}($ minor $)=22.2 \min , e e=90 \% ;[\alpha]^{23}{ }_{\mathrm{D}}=+126(\mathrm{c}=$ $0.2, \mathrm{DMSO})$. 


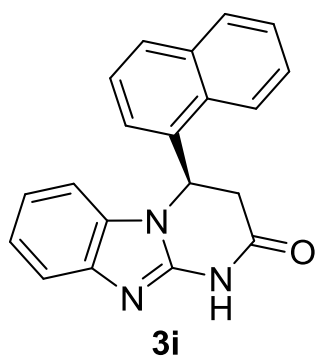

3i: white solid, $62 \%$ yield; ${ }^{1} \mathbf{H}$ NMR $\left(400 \mathrm{MHz}, \mathrm{CDCl}_{3}: \mathrm{CD}_{3} \mathrm{OD}=2: 1\right) \delta 8.10(\mathrm{~d}, J=$ $8.5 \mathrm{~Hz}, 1 \mathrm{H}), 7.97(\mathrm{~d}, J=8.0 \mathrm{~Hz}, 1 \mathrm{H}), 7.84(\mathrm{~d}, J=8.2 \mathrm{~Hz}, 1 \mathrm{H}), 7.74-7.65(\mathrm{~m}, 1 \mathrm{H})$, $7.64-7.55(\mathrm{~m}, 2 \mathrm{H}), 7.28(\mathrm{dd}, J=8.2,7.2 \mathrm{~Hz}, 1 \mathrm{H}), 7.25-7.15(\mathrm{~m}, 1 \mathrm{H}), 7.08-7.00(\mathrm{~m}$, $1 \mathrm{H}), 6.87(\mathrm{~d}, J=8.0 \mathrm{~Hz}, 1 \mathrm{H}), 6.60(\mathrm{~d}, J=7.2 \mathrm{~Hz}, 1 \mathrm{H}), 6.55(\mathrm{dd}, J=7.8,2.9 \mathrm{~Hz}, 1 \mathrm{H})$, $3.62(\mathrm{dd}, J=16.6,7.8 \mathrm{~Hz}, 1 \mathrm{H}), 3.24(\mathrm{dd}, J=16.6,2.9 \mathrm{~Hz}, 1 \mathrm{H}) ;{ }^{13} \mathrm{C}$ NMR $(100 \mathrm{MHz}$, $\left.\mathrm{CDCl}_{3}: \mathrm{CD}_{3} \mathrm{OD}=2: 1\right) \delta 168.1,148.8,141.3,134.7,133.2,132.3,130.0,129.9,129.9$, $127.7,126.7,125.7,123.3,122.7,122.7,122.2,117.9,109.9,50.6,38.1$; HRMS (ESI): m/z: calculated for $\mathrm{C}_{20} \mathrm{H}_{16} \mathrm{~N}_{3} \mathrm{O}[\mathrm{M}+\mathrm{H}]^{+}: 314.1293$, found: 314.1290 ; HPLC (Chiralpak IC, $i$-propanol $/$ hexane $=20 / 80$, flow rate $1.0 \mathrm{~mL} / \mathrm{min}, 30{ }^{\circ} \mathrm{C}, \lambda=254 \mathrm{~nm}$ ): $t_{\mathrm{R}}($ major $)=21.3 \mathrm{~min}, t_{\mathrm{R}}($ minor $)=32.3 \mathrm{~min}, e e=86 \% ;[\alpha]^{23} \mathrm{D}=+72.5(\mathrm{c}=0.16$, DMSO).

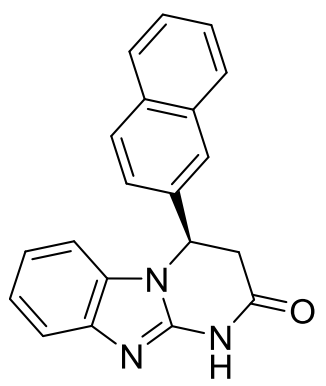

3j

3j: light orange solid, 86\% yield; ${ }^{\mathbf{1}} \mathbf{H}$ NMR (400 MHz, $\left.\mathrm{CDCl}_{3}: \mathrm{CD}_{3} \mathrm{OD}=2: 1\right) \delta 7.88$ $(\mathrm{d}, J=8.6 \mathrm{~Hz}, 1 \mathrm{H}), 7.88-7.81(\mathrm{~m}, 1 \mathrm{H}), 7.80-7.72(\mathrm{~m}, 1 \mathrm{H}), 7.57(\mathrm{~d}, J=8.0 \mathrm{~Hz}, 1 \mathrm{H})$, $7.54-7.47$ (m, 3H), $7.32(\mathrm{dd}, J=8.6,2.0 \mathrm{~Hz}, 1 \mathrm{H}), 7.19(\mathrm{td}, J=7.8,1.1 \mathrm{~Hz}, 1 \mathrm{H}), 7.03$ $(\mathrm{td}, J=7.8,1.1 \mathrm{~Hz}, 1 \mathrm{H}), 6.85(\mathrm{~d}, J=8.0 \mathrm{~Hz}, 1 \mathrm{H}), 5.87(\mathrm{dd}, J=7.1,4.5 \mathrm{~Hz}, 1 \mathrm{H}), 3.46$ $(\mathrm{dd}, J=16.7,7.1 \mathrm{~Hz}, 1 \mathrm{H}), 3.17(\mathrm{dd}, J=16.7,4.5 \mathrm{~Hz}, 1 \mathrm{H}) ;{ }^{13} \mathbf{C}$ NMR $(100 \mathrm{MHz}$, $\left.\mathrm{CDCl}_{3}: \mathrm{CD}_{3} \mathrm{OD}=2: 1\right) \delta 168.5,148.5,141.2,135.7,133.8,133.7,132.6,130.1,128.5$, $128.2,127.3,127.2,125.5,123.5,123.2,122.6,117.9,110.3,54.3,39.3$; HRMS (ESI): $\mathrm{m} / \mathrm{z}$ : calculated for $\mathrm{C}_{20} \mathrm{H}_{16} \mathrm{~N}_{3} \mathrm{O}[\mathrm{M}+\mathrm{H}]^{+}$: 314.1293, found: 314.1293; HPLC (Chiralpak AD-H, $i$-propanol $/$ hexane $=10 / 90$, flow rate $1.0 \mathrm{~mL} / \mathrm{min}, 30{ }^{\circ} \mathrm{C}, \lambda=254$ $\mathrm{nm}): t_{\mathrm{R}}($ major $)=42.2 \mathrm{~min}, t_{\mathrm{R}}($ minor $)=51.5 \mathrm{~min}, e e=93 \% ;[\alpha]^{23} \mathrm{D}=+173.9(\mathrm{c}=$ 0.23, DMSO). 


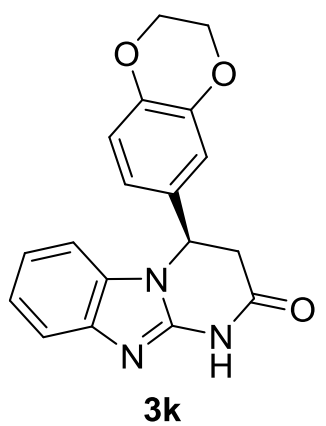

3k: light yellow solid, 84\% yield; ${ }^{1} \mathbf{H}$ NMR (400 MHz, $\left.\mathrm{CDCl}_{3}: \mathrm{CD}_{3} \mathrm{OD}=2: 1\right) \delta 7.56$ $(\mathrm{d}, J=7.9 \mathrm{~Hz}, 1 \mathrm{H}), 7.19(\mathrm{td}, J=7.7,1.2 \mathrm{~Hz}, 1 \mathrm{H}), 7.08(\mathrm{td}, J=7.7,1.2 \mathrm{~Hz}, 1 \mathrm{H}), 6.88$ $(\mathrm{d}, J=7.9 \mathrm{~Hz}, 1 \mathrm{H}), 6.86-6.74(\mathrm{~m}, 1 \mathrm{H}), 6.72-6.48(\mathrm{~m}, 2 \mathrm{H}), 5.56(\mathrm{dd}, J=7.0,4.4$ $\mathrm{Hz}, 1 \mathrm{H}), 4.22$ (s, 4H), $3.38-3.27(\mathrm{~m}, 1 \mathrm{H}), 3.02(\mathrm{dd}, J=16.6,4.4 \mathrm{~Hz}, 1 \mathrm{H}) ;{ }^{13} \mathbf{C}$ NMR $\left(100 \mathrm{MHz}, \mathrm{CDCl}_{3}: \mathrm{CD}_{3} \mathrm{OD}=2: 1\right) \delta 168.4,148.2,144.5,144.5,141.2,132.4,131.5$, 123.1, 122.5, 119.2, 118.5, 117.9, 115.2, 110.2, 64.7, 53.5, 39.4; HRMS (ESI): m/z: calculated for $\mathrm{C}_{18} \mathrm{H}_{16} \mathrm{~N}_{3} \mathrm{O}_{3}[\mathrm{M}+\mathrm{H}]^{+}$: 322.1192, found: 322.1192; HPLC (Chiralpak AD-H, $i$-propanol/hexane $=20 / 80$, flow rate $\left.1.0 \mathrm{~mL} / \mathrm{min}, 30{ }^{\circ} \mathrm{C}, \lambda=254 \mathrm{~nm}\right): t_{\mathrm{R}}$ $($ major $)=43.1 \mathrm{~min}, t_{\mathrm{R}}($ minor $)=35.0 \mathrm{~min}, e e=97 \% ;[\alpha]_{\mathrm{D}}^{24}=+181.3(\mathrm{c}=0.32$, DMSO).<smiles>O=C1C[C@H](c2ccco2)n2c(nc3ccccc32)N1</smiles>

31: yellow solid, 50\% yield; ${ }^{1} \mathbf{H}$ NMR (400 $\left.\mathrm{MHz}, \mathrm{CDCl}_{3}: \mathrm{CD}_{3} \mathrm{OD}=2: 1\right) \delta 7.57-7.50$ (m, 1H), $7.42-7.31(\mathrm{~m}, 1 \mathrm{H}), 7.28-7.13(\mathrm{~m}, 3 \mathrm{H}), 6.34(\mathrm{dd}, J=3.3,1.9 \mathrm{~Hz}, 1 \mathrm{H}), 6.29$ $(\mathrm{d}, J=3.3 \mathrm{~Hz}, 1 \mathrm{H}), 5.78(\mathrm{dd}, J=7.1,3.4 \mathrm{~Hz}, 1 \mathrm{H}), 3.43-3.28(\mathrm{~m}, 1 \mathrm{H}), 3.20(\mathrm{dd}, J=$ 16.6, 3.4 Hz, 1H); $\left.{ }^{13} \mathbf{C ~ N M R ~ ( 1 0 0 ~ M H z , ~} \mathrm{CDCl}_{3}: \mathrm{CD}_{3} \mathrm{OD}=2: 1\right) \delta 168.2,150.2,147.6$, 144.0, 140.9, 132.2, 123.1, 122.6, 117.8, 110.9, 109.6, 108.6, 47.5, 35.7; HRMS (ESI): $\mathrm{m} / \mathrm{z}$ : calculated for $\mathrm{C}_{14} \mathrm{H}_{12} \mathrm{~N}_{3} \mathrm{O}_{2}[\mathrm{M}+\mathrm{H}]^{+}$: 254.0930, found: 254.0928; HPLC (Chiralpak OD-H, $i$-propanol/hexane $=20 / 80$, flow rate $1.0 \mathrm{~mL} / \mathrm{min}, 30{ }^{\circ} \mathrm{C}, \lambda=254$ $\mathrm{nm}): t_{\mathrm{R}}($ major $)=21.8 \mathrm{~min}, t_{\mathrm{R}}($ minor $)=12.8 \mathrm{~min}, e e=95 \% ;[\alpha]^{25} \mathrm{D}=+267.6(\mathrm{c}=$ 0.21 , DMSO). 


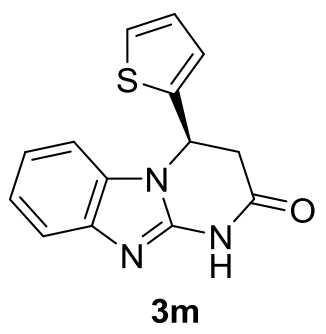

3m: light yellow solid, 70\% yield; ${ }^{1} \mathbf{H}$ NMR $\left(400 \mathrm{MHz}, \mathrm{CDCl}_{3}: \mathrm{CD}_{3} \mathrm{OD}=2: 1\right) \delta 7.54$ $(\mathrm{d}, J=7.6 \mathrm{~Hz}, 1 \mathrm{H}), 7.30(\mathrm{dd}, J=4.6,1.7 \mathrm{~Hz}, 1 \mathrm{H}), 7.26-7.07(\mathrm{~m}, 3 \mathrm{H}), 6.99-6.84$ $(\mathrm{m}, 2 \mathrm{H}), 6.01(\mathrm{dd}, J=6.8,3.4 \mathrm{~Hz}, 1 \mathrm{H}), 3.44(\mathrm{dd}, J=16.6,6.8 \mathrm{~Hz}, 1 \mathrm{H}), 3.18(\mathrm{dd}, J=$ 16.6, $3.4 \mathrm{~Hz}, 1 \mathrm{H}) ;{ }^{13} \mathrm{C}$ NMR $\left(100 \mathrm{MHz}, \mathrm{CDCl}_{3}: \mathrm{CD}_{3} \mathrm{OD}=2: 1\right) \delta 168.2,147.6,141.2$, 141.1 132.1, 127.6, 126.7, 126.0, 123.3, 122.7, 117.9, 109.8, 49.7, 39.3; HRMS (ESI): $\mathrm{m} / \mathrm{z}$ : calculated for $\mathrm{C}_{14} \mathrm{H}_{12} \mathrm{~N}_{3} \mathrm{OS}[\mathrm{M}+\mathrm{H}]^{+}:$270.0701, found: 270.0701; HPLC (Chiralpak IC, $i$-propanol $/$ hexane $=20 / 80$, flow rate $1.0 \mathrm{~mL} / \mathrm{min}, 30{ }^{\circ} \mathrm{C}, \lambda=254 \mathrm{~nm}$ ): $t_{\mathrm{R}}($ major $)=23.1 \mathrm{~min}, t_{\mathrm{R}}($ minor $)=26.5 \mathrm{~min}, e e>99 \% ;[\alpha]_{\mathrm{D}}^{25}=+217.8(\mathrm{c}=0.27$, DMSO).

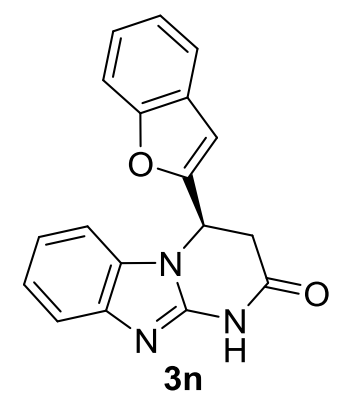

3n: white solid, $43 \%$ yield; ${ }^{1} \mathbf{H}$ NMR (400 MHz, $\left.\mathrm{CDCl}_{3}: \mathrm{CD}_{3} \mathrm{OD}=2: 1\right) \delta 7.54(\mathrm{~d}, J=$ $7.2 \mathrm{~Hz}, 1 \mathrm{H}), 7.50(\mathrm{~d}, J=7.4 \mathrm{~Hz}, 1 \mathrm{H}), 7.40$ (d, $J=8.2 \mathrm{~Hz}, 1 \mathrm{H}), 7.34-7.16(\mathrm{~m}, 5 \mathrm{H})$, 6.58 (s, 1H), 5.97 (dd, $J=7.4,2.5 \mathrm{~Hz}, 1 \mathrm{H}), 3.47$ (dd, $J=16.7,7.4 \mathrm{~Hz}, 1 \mathrm{H}), 3.31$ (dd, $J=16.7,2.5 \mathrm{~Hz}, 1 \mathrm{H}) ;{ }^{13} \mathbf{C}$ NMR $\left(100 \mathrm{MHz}, \mathrm{CDCl}_{3}: \mathrm{CD}_{3} \mathrm{OD}=2: 1\right) \delta 168.1,155.7$, 152.9, 147.9, 141.1, 132.3, 127.8, 125.6, 123.8, 123.4, 122.8, 121.8, 118.0, 111.8, 109.7, 105.3, 47.9, 35.5; HRMS (ESI): m/z: calculated for $\mathrm{C}_{18} \mathrm{H}_{14} \mathrm{~N}_{3} \mathrm{O}_{2}[\mathrm{M}+\mathrm{H}]^{+}$: 304.1086, found: 304.1086; HPLC (Chiralpak AD-H, $i$-propanol/hexane $=20 / 80$, flow rate $\left.1.0 \mathrm{~mL} / \mathrm{min}, 30{ }^{\circ} \mathrm{C}, \lambda=254 \mathrm{~nm}\right): t_{\mathrm{R}}($ major $)=16.8 \mathrm{~min}, t_{\mathrm{R}}($ minor $)=21.8$ $\min , e e=91 \% ;[\alpha]^{24}=+330.4(\mathrm{c}=0.23$, DMSO).<smiles>CCOC[C@@H]1CC(=O)Nc2nc3ccccc3n21</smiles> 
3o: light red solid, 73\% yield; ${ }^{1}$ H NMR (400 MHz, DMSO- $\left.d_{6}\right) \delta 11.63(\mathrm{~s}, 1 \mathrm{H}), 7.52-$ $7.31(\mathrm{~m}, 2 \mathrm{H}), 7.20-7.07(\mathrm{~m}, 2 \mathrm{H}), 5.62(\mathrm{dd}, J=8.2,1.5 \mathrm{~Hz}, 1 \mathrm{H}), 4.21-4.00(\mathrm{~m}, 2 \mathrm{H})$, $3.46(\mathrm{dd}, J=16.8,8.2 \mathrm{~Hz}, 1 \mathrm{H}), 2.92(\mathrm{dd}, J=16.8,1.6 \mathrm{~Hz}, 1 \mathrm{H}), 1.12(\mathrm{t}, J=7.1 \mathrm{~Hz}$, $3 \mathrm{H}) ;{ }^{13} \mathrm{C}$ NMR $\left(100 \mathrm{MHz}, \mathrm{DMSO}-d_{6}\right) \delta$ 169.03, 166.32, 147.64, 141.70, 132.64, 121.79, 121.05, 117.39, 109.23, 61.89, 50.51, 32.83, 13.83; HRMS (ESI): m/z: calculated for $\mathrm{C}_{13} \mathrm{H}_{14} \mathrm{~N}_{3} \mathrm{O}_{3}[\mathrm{M}+\mathrm{H}]^{+}:$260.1035, found: 260.1034; HPLC (Chiralpak ID, $i$-propanol $/$ hexane $=20 / 80$, flow rate $\left.1.0 \mathrm{~mL} / \mathrm{min}, 30{ }^{\circ} \mathrm{C}, \lambda=254 \mathrm{~nm}\right): t_{\mathrm{R}}($ major $)=$ $36.7 \mathrm{~min}, t_{\mathrm{R}}($ minor $)=44.2 \mathrm{~min}, e e=93 \% ;[\alpha]_{\mathrm{D}}^{22}=+81.2(\mathrm{c}=1, \mathrm{DMSO})$.

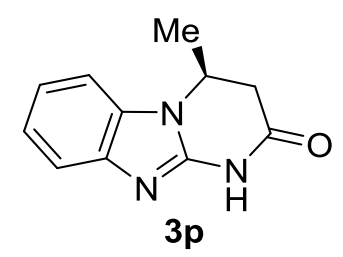

3p: light yellow solid, 54\% yield; ${ }^{1} \mathbf{H}$ NMR (400 MHz, $\left.\mathrm{CDCl}_{3}: \mathrm{CD}_{3} \mathrm{OD}=2: 1\right) \delta 7.55-$ 7.50 (m, 1H), $7.35-7.29$ (m, 1H), $7.27-7.20$ (m, 2H), $4.90-4.73(\mathrm{~m}, 1 \mathrm{H}), 3.20$ (dd, $J=16.6,7.1 \mathrm{~Hz}, 1 \mathrm{H}), 2.75(\mathrm{dd}, J=16.6,1.8 \mathrm{~Hz}, 1 \mathrm{H}), 1.47(\mathrm{~d}, J=6.7 \mathrm{~Hz}, 3 \mathrm{H}) ;{ }^{13} \mathrm{C}$ NMR $\left(100 \mathrm{MHz}, \mathrm{CDCl}_{3}: \mathrm{CD}_{3} \mathrm{OD}=2: 1\right) \delta 168.9,147.3,141.2,131.9,123.0,122.5$, 117.9, 109.0, 46.0, 37.6, 20.0; HRMS (ESI): m/z: calculated for $\mathrm{C}_{11} \mathrm{H}_{12} \mathrm{~N}_{3} \mathrm{O}[\mathrm{M}+\mathrm{H}]^{+}$: 202.0980, found: 202.0981; HPLC (Chiralpak IC, $i$-propanol/hexane $=10 / 90$, flow rate $\left.1.0 \mathrm{~mL} / \mathrm{min}, 30{ }^{\circ} \mathrm{C}, \lambda=254 \mathrm{~nm}\right): t_{\mathrm{R}}($ major $)=43.5 \mathrm{~min}, t_{\mathrm{R}}($ minor $)=55.6 \mathrm{~min}, e e$ $=49 \% ;[\alpha]^{25}=+54.3(\mathrm{c}=0.21$, DMSO $)$.

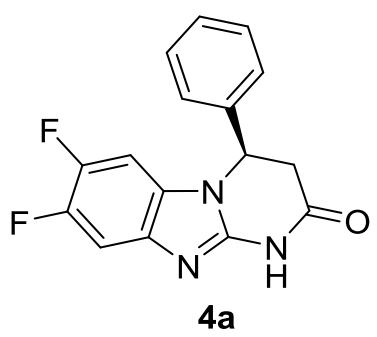

4a: white solid, $73 \%$ yield; ${ }^{1} \mathbf{H}$ NMR $\left(400 \mathrm{MHz}\right.$, DMSO- $\left.d_{6}\right) \delta 11.81(\mathrm{~s}, 1 \mathrm{H}), 7.53$ (dd, $J=11.0,7.5 \mathrm{~Hz}, 1 \mathrm{H}), 7.42-7.28(\mathrm{~m}, 3 \mathrm{H}), 7.22(\mathrm{dd}, J=10.5,7.5 \mathrm{~Hz}, 1 \mathrm{H}), 7.12-$ $7.00(\mathrm{~m}, 2 \mathrm{H}), 5.93(\mathrm{dd}, J=6.9,3.2 \mathrm{~Hz}, 1 \mathrm{H}), 3.52(\mathrm{dd}, J=16.5,7.0 \mathrm{~Hz}, 1 \mathrm{H}), 2.96(\mathrm{dd}$, $J=16.5,3.3 \mathrm{~Hz}, 1 \mathrm{H}) ;{ }^{13} \mathbf{C}$ NMR $\left(100 \mathrm{MHz}, \mathrm{DMSO}-d_{6}\right) \delta 167.2,149.5,146.3(\mathrm{dd}, J=$ 237.9, $17.3 \mathrm{~Hz}), 145.6(\mathrm{dd}, J=237.7,17.3 \mathrm{~Hz}), 138.7,137.6(\mathrm{dd}, J=10.6,1.5 \mathrm{~Hz})$, 129.2, 128.4, $128.0(\mathrm{~d}, J=11.4 \mathrm{~Hz}), 125.8,105.5$ (d, $J=19.6 \mathrm{~Hz}), 98.4$ (d, $J=21.9$ $\mathrm{Hz}), 52.3,38.2 ;{ }^{19}$ F NMR $\left(376 \mathrm{MHz}, \mathrm{DMSO}-d_{6}\right) \delta-145.7(\mathrm{~d}, J=22.2 \mathrm{~Hz}),-145.9$ (d, $J=22.2 \mathrm{~Hz}$ ); HRMS (ESI): m/z: calcd for $\mathrm{C}_{16} \mathrm{H}_{12} \mathrm{~F}_{2} \mathrm{~N}_{3} \mathrm{O}[\mathrm{M}+\mathrm{H}]^{+}: 300.0948$, found 300.0947; HPLC (Chiralpak AD-H, $i$-propanol/hexane = 20/80, flow rate $1.0 \mathrm{~mL} / \mathrm{min}$, 
$\left.30^{\circ} \mathrm{C}, \lambda=254 \mathrm{~nm}\right): t_{\mathrm{R}}($ minor $)=13.2 \mathrm{~min}, t_{\mathrm{R}}($ major $)=22.4 \min , e e=92 \% .[\alpha]^{23}{ }_{\mathrm{D}}=$ $+127.0\left(\mathrm{c}=0.4, \mathrm{CHCl}_{3} / \mathrm{MeOH}=2: 1\right)$.<smiles></smiles>

4b: white solid, 78\% yield; ${ }^{1}$ H NMR (400 MHz, DMSO- $d_{6}$ ) $\delta 11.90$ (s, 1H), 7.85 (s, $1 \mathrm{H}), 7.51(\mathrm{~s}, 1 \mathrm{H}), 7.44-7.25(\mathrm{~m}, 3 \mathrm{H}), 7.14-6.97$ (m, 2H), 5.99 (dd, $J=8.0,3.5 \mathrm{~Hz}$, 1H), $3.52(\mathrm{dd}, J=16.4,8.0 \mathrm{~Hz}, 1 \mathrm{H}), 2.96(\mathrm{dd}, J=16.4,3.5 \mathrm{~Hz}, 1 \mathrm{H}) ;{ }^{13} \mathbf{C}$ NMR (100 MHz, DMSO- $\left.d_{6}\right) \delta 167.2,149.9,142.9,138.6,133.0,129.2,128.4,125.7,121.8$, 115.9, 114.6, 114.2, 52.3, 38.2; HRMS (ESI): m/z: calcd for $\mathrm{C}_{16} \mathrm{H}_{12} \mathrm{Br}_{2} \mathrm{~N}_{3} \mathrm{O}[\mathrm{M}+\mathrm{H}]^{+}$: 419.9347, found 419.9348; HPLC (Chiralpak AD-H, $i$-propanol/hexane = 20/80, flow rate $\left.1.0 \mathrm{~mL} / \mathrm{min}, 30^{\circ} \mathrm{C}, \lambda=254 \mathrm{~nm}\right): t_{\mathrm{R}}($ minor $)=13.3 \mathrm{~min}, t_{\mathrm{R}}($ major $)=20.5 \mathrm{~min}, e e$ $=93 \% .[\alpha]^{23}{ }_{\mathrm{D}}=+151.0\left(\mathrm{c}=0.2, \mathrm{CHCl}_{3} / \mathrm{MeOH}=2: 1\right)$.

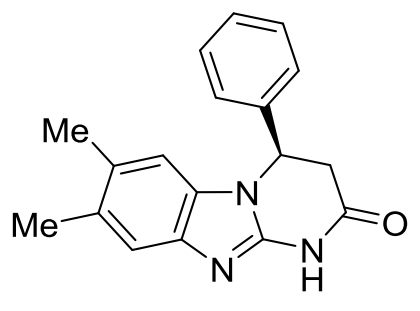

4c

4c: yellow solid, 62\% yield; ${ }^{1} \mathbf{H}$ NMR $\left(400 \mathrm{MHz}, \mathrm{CDCl}_{3}: \mathrm{CD}_{3} \mathrm{OD}=2: 1\right) \delta 7.40-7.29$ (m, 4H), $7.14-7.05$ (m, 2H), 6.63 (s, 1H), 5.65 (dd, J= 7.1, 4.0 Hz, 1H), $3.44-3.30$ (m, 1H), $3.04(\mathrm{dd}, J=16.6,4.0 \mathrm{~Hz}, 1 \mathrm{H}), 2.31$ (s, 3H), $2.22(\mathrm{~s}, 3 \mathrm{H}) ;{ }^{13} \mathbf{C}$ NMR (100 $\left.\mathrm{MHz}, \mathrm{CDCl}_{3}: \mathrm{CD}_{3} \mathrm{OD}=2: 1\right) \delta 168.5,147.8,139.1,138.5,131.9,131.5,130.7,129.7$, 129.2, 126.1, 118.1, 110.5, 53.8, 39.3, 20.4, 20.3; HRMS (ESI): m/z: calculated for $\mathrm{C}_{18} \mathrm{H}_{18} \mathrm{~N}_{3} \mathrm{O} \quad[\mathrm{M}+\mathrm{H}]^{+}:$292.1450, found: 292.1447; HPLC (Chiralpak AD-H, $i$-propanol $/$ hexane $=20 / 80$, flow rate $\left.1.0 \mathrm{~mL} / \mathrm{min}, 30{ }^{\circ} \mathrm{C}, \lambda=254 \mathrm{~nm}\right): t_{\mathrm{R}}($ major $)=$ $15.0 \mathrm{~min}, t_{\mathrm{R}}($ minor $)=12.0 \mathrm{~min}, e e=88 \% ;[\alpha]_{\mathrm{D}}^{25}=+239(\mathrm{c}=0.21, \mathrm{DMSO})$.<smiles>O=C1C[C@H](c2ccccc2)n2c(nc3c(Br)cccc32)N1</smiles> 
4d: white solid, $88 \%$ yield; ${ }^{1} \mathbf{H}$ NMR (400 MHz, $\left.\mathrm{CDCl}_{3}: \mathrm{CD}_{3} \mathrm{OD}=2: 1\right) \delta 7.43-7.28$ (m, 4H), $7.18-7.04(\mathrm{~m}, 2 \mathrm{H}), 6.93(\mathrm{t}, J=8.0 \mathrm{~Hz}, 1 \mathrm{H}), 6.79$ (dd, $J=8.0,0.9 \mathrm{~Hz}, 1 \mathrm{H})$, $5.70(\mathrm{dd}, J=7.1,4.3 \mathrm{~Hz}, 1 \mathrm{H}), 3.43(\mathrm{dd}, J=16.7,7.1 \mathrm{~Hz}, 1 \mathrm{H}), 3.08(\mathrm{dd}, J=16.7,4.3$ $\mathrm{Hz}, 1 \mathrm{H}) ;{ }^{13} \mathrm{C}$ NMR $\left(100 \mathrm{MHz}, \mathrm{CDCl}_{3}: \mathrm{CD}_{3} \mathrm{OD}=2: 1\right) \delta 167.7,148.5,140.5,137.9$, 133.1, 129.8, 129.4, 126.1, 126.1, 123.4, 111.2, 109.4, 54.2, 39.1; HRMS (ESI): m/z: calculated for $\mathrm{C}_{16} \mathrm{H}_{13} \mathrm{BrN}_{3} \mathrm{O}[\mathrm{M}+\mathrm{H}]^{+}:$342.0242, found: 342.0239; HPLC (Chiralpak AD-H, $i$-propanol/hexane $=20 / 80$, flow rate $\left.1.0 \mathrm{~mL} / \mathrm{min}, 30{ }^{\circ} \mathrm{C}, \lambda=254 \mathrm{~nm}\right): t_{\mathrm{R}}$ $($ major $)=11.4 \mathrm{~min}, t_{\mathrm{R}}(\operatorname{minor})=9.4 \mathrm{~min}, e e=92 \%$;

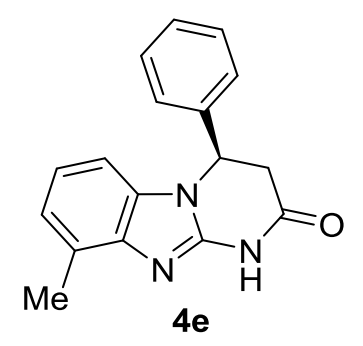

4e: white wax, $79 \%$ yield; ${ }^{1} \mathbf{H}$ NMR $\left(400 \mathrm{MHz}, \mathrm{CDCl}_{3}\right) \delta 7.40-7.30(\mathrm{~m}, 3 \mathrm{H}), 7.21-$ $7.10(\mathrm{~m}, 2 \mathrm{H}), 7.08-6.90(\mathrm{~m}, 2 \mathrm{H}), 6.66(\mathrm{~d}, J=7.7 \mathrm{~Hz}, 1 \mathrm{H}), 5.59(\mathrm{dd}, J=7.0,4.2 \mathrm{~Hz}$, 1H), $3.36(\mathrm{dd}, J=16.4,7.1 \mathrm{~Hz}, 1 \mathrm{H}), 3.08(\mathrm{dd}, J=16.5,4.2 \mathrm{~Hz}, 1 \mathrm{H}), 2.69(\mathrm{~s}, 3 \mathrm{H}) ;{ }^{13} \mathrm{C}$ NMR $\left(100 \mathrm{MHz}, \mathrm{CDCl}_{3}\right) \delta 166.7,147.7,140.7,138.0,131.8,129.5,129.0,128.9$, 126.0, 123.6, 122.1, 107.0, 53.7, 39.4, 17.0; HRMS (ESI): m/z: calcd for $\mathrm{C}_{17} \mathrm{H}_{16} \mathrm{~N}_{3} \mathrm{O}$ $[\mathrm{M}+\mathrm{H}]^{+}:$278.1293, found 278.1292; HPLC (Chiralpak IA, ${ }^{i}$ propanol/hexane $=20 / 80$, flow rate $\left.1.0 \mathrm{~mL} / \mathrm{min}, 30^{\circ} \mathrm{C}, \lambda=254 \mathrm{~nm}\right): t_{\mathrm{R}}($ minor $)=8.4 \mathrm{~min}, t_{\mathrm{R}}($ major $)=9.7 \mathrm{~min}$, $e e=93 \% ;[\alpha]^{23}=+164.8\left(\mathrm{c}=0.5, \mathrm{CHCl}_{3} / \mathrm{MeOH}=2: 1\right)$.

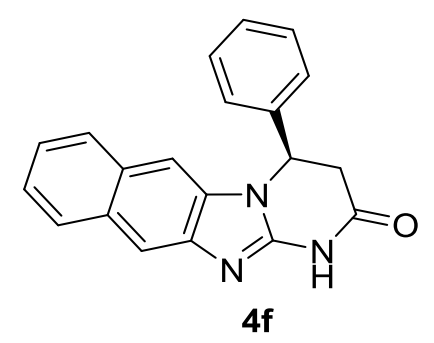

4f: brown solid, 83\% yield; ${ }^{1} \mathbf{H}$ NMR (400 MHz, $\left.\mathrm{CDCl}_{3}: \mathrm{CD}_{3} \mathrm{OD}=2: 1\right) \delta 7.99(\mathrm{~s}, 1 \mathrm{H})$, $7.92(\mathrm{~d}, J=8.1 \mathrm{~Hz}, 1 \mathrm{H}), 7.64(\mathrm{~d}, J=8.1 \mathrm{~Hz}, 1 \mathrm{H}), 7.45-7.26(\mathrm{~m}, 5 \mathrm{H}), 7.18-7.06(\mathrm{~m}$, 2H), 6.99 (s, 1H), $5.64(\mathrm{dd}, J=7.2,4.3 \mathrm{~Hz}, 1 \mathrm{H}), 3.47$ (dd, $J=16.6,7.2 \mathrm{~Hz}, 1 \mathrm{H}), 3.08$ $(\mathrm{dd}, J=16.6,4.3 \mathrm{~Hz}, 1 \mathrm{H}) ;{ }^{13} \mathbf{C} \mathbf{~ N M R}\left(100 \mathrm{MHz}, \mathrm{CDCl}_{3}: \mathrm{CD}_{3} \mathrm{OD}=2: 1\right) \delta 168.8,151.8$, 140.9 , 138.3, 133.0, 131.0, 130.3, 129.8, 129.3, 128.1, 127.9, 126.2, 124.6, 124.5, 114.0, 106.2, 54.0, 39.3; HRMS (ESI): m/z: calculated for $\mathrm{C}_{20} \mathrm{H}_{16} \mathrm{~N}_{3} \mathrm{O}[\mathrm{M}+\mathrm{H}]^{+}$: 314.1293, found: 314.1289; HPLC (Chiralpak IC, $i$-propanol/hexane $=20 / 80$, flow 
rate $\left.1.0 \mathrm{~mL} / \mathrm{min}, 30{ }^{\circ} \mathrm{C}, \lambda=254 \mathrm{~nm}\right): t_{\mathrm{R}}($ major $)=29.7 \mathrm{~min}, t_{\mathrm{R}}($ minor $)=49.5 \mathrm{~min}, e e$ $=92 \% ;[\alpha]^{24}=+268.8(\mathrm{c}=0.25$, DMSO $)$.

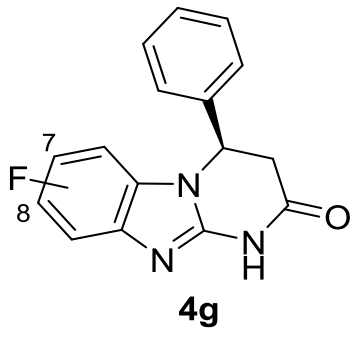

$(1: 1)$

4g: light yellow solid, $72 \%$ yield; ${ }^{1} \mathbf{H}$ NMR (400 MHz, $\left.\mathrm{CDCl}_{3}: \mathrm{CD}_{3} \mathrm{OD}=2: 1\right) \delta 7.48$ $(8.8 \mathrm{~Hz}, 4.7 \mathrm{~Hz}, 1 \mathrm{H}), 7.42-7.32(\mathrm{~m}, 6 \mathrm{H}), 7.25(\mathrm{dd}, J=9.2,2.4 \mathrm{~Hz}, 1 \mathrm{H}), 7.19-7.06(\mathrm{~m}$, $4 \mathrm{H}), 6.92(\mathrm{td}, J=9.3,2.5 \mathrm{~Hz}, 1 \mathrm{H}), 6.78(\mathrm{td}, J=9.1,2.5 \mathrm{~Hz}, 1 \mathrm{H}), 6.68(\mathrm{dd}, J=8.8,4.6$ $\mathrm{Hz}, 1 \mathrm{H}), 6.49(\mathrm{dd}, J=8.6,2.5 \mathrm{~Hz}, 1 \mathrm{H}), 5.66(\mathrm{td}, J=6.9,4.9 \mathrm{~Hz}, 2 \mathrm{H}), 3.45-3.36(\mathrm{~m}$, $2 \mathrm{H}), 3.08(\mathrm{dd}, J=16.7,4.9 \mathrm{~Hz}, 2 \mathrm{H}) ;{ }^{13} \mathrm{C} \mathbf{N M R}\left(100 \mathrm{MHz}, \mathrm{CDCl}_{3}: \mathrm{CD}_{3} \mathrm{OD}=2: 1\right) \delta$ $168.0,167.9,161.1,160.5,158.8,158.1,149.4,148.7,142.3,142.2,138.0,137.9$, $137.7,132.7,132.6,129.9,129.8,129.5,129.5,129.0,126.3,118.6,118.5,110.8$, $110.6,110.5,110.1,109.8,104.6,104.4,97.8,97.5,54.3,54.3,39.4,39.3 ;{ }^{19}$ F NMR (376 MHz, $\left.\mathrm{CDCl}_{3}: \mathrm{CD}_{3} \mathrm{OD}=2: 1\right) \delta-119.7,-120.6$; HRMS (ESI): $\mathrm{m} / \mathrm{z}$ : calculated for $\mathrm{C}_{16} \mathrm{H}_{13} \mathrm{FN}_{3} \mathrm{O}[\mathrm{M}+\mathrm{H}]^{+}:$282.1043, found: 282.1042; HPLC (Chiralpak AD-H, $i$-propanol/hexane $=10 / 90$, flow rate $\left.1.0 \mathrm{~mL} / \mathrm{min}, 30{ }^{\circ} \mathrm{C}, \lambda=254 \mathrm{~nm}\right): t_{\mathrm{R}}$ (major) $=$ $53.0 \mathrm{~min}, 37.9 \mathrm{~min} ; t_{\mathrm{R}}(\operatorname{minor})=27.7 \mathrm{~min}, 32.8 \mathrm{~min} ; e e=88 \%, 91 \%$.

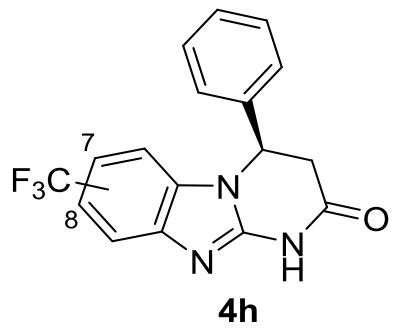

$(4: 5)$

4h: light yellow waxy solid, 68\% yield; ${ }^{1} \mathbf{H}$ NMR (400 MHz, $\left.\mathrm{CDCl}_{3}\right) \delta 14.06$ (s, 1H), $13.92(\mathrm{~s}, 1 \mathrm{H}), 7.86(\mathrm{~s}, 1 \mathrm{H}), 7.71(\mathrm{~d}, J=8.3 \mathrm{~Hz}, 1 \mathrm{H}), 7.40-7.34(\mathrm{~m}, 6 \mathrm{H}), 7.31(\mathrm{~d}, J=$ $8.4 \mathrm{~Hz}, 1 \mathrm{H}), 7.19-7.08(\mathrm{~m}, 4 \mathrm{H}), 6.96(\mathrm{~d}, J=8.4 \mathrm{~Hz}, 1 \mathrm{H}), 6.67(\mathrm{~s}, 1 \mathrm{H}), 6.26(\mathrm{~d}, J=$ $8.4 \mathrm{~Hz}, 1 \mathrm{H}), 5.67-5.56(\mathrm{~m}, 2 \mathrm{H}), 3.57(\mathrm{dd}, J=16.8,6.9 \mathrm{~Hz}, 2 \mathrm{H}), 3.16-3.03(\mathrm{~m}, 2 \mathrm{H})$; ${ }^{13}$ C NMR (100 MHz, $\left.\mathrm{CDCl}_{3}\right) \delta$ 167.4, 167.2, 150.5, 150.1, 143.4, 140.4, 137.5, 137.3, 133.7, 131.2, 129.7, 129.7, 129.4, 129.4, 126.2, 126.0, 124.8 (q, $J=31.9 \mathrm{~Hz}), 124.6$ $(\mathrm{q}, J=270.0 \mathrm{~Hz}), 124.5(\mathrm{q}, J=270.1 \mathrm{~Hz}), 124.0(\mathrm{q}, J=32.1 \mathrm{~Hz}), 119.9(\mathrm{q}, J=3.4$ $\mathrm{Hz}), 118.8$ (q, $J=3.8 \mathrm{~Hz}), 117.6,114.2$ (q, $J=4.2 \mathrm{~Hz}), 110.1,107.3$ (q, $J=4.1 \mathrm{~Hz})$, 54.8, 54.5, 39.3, 39.2; ${ }^{19}$ F NMR $\left(376 \mathrm{MHz} \mathrm{CDCl}_{3}\right) \delta-60.6,-60.8 ;$ HRMS (ESI): m/z: 
calculated for $\mathrm{C}_{17} \mathrm{H}_{13} \mathrm{~F}_{3} \mathrm{~N}_{3} \mathrm{O}[\mathrm{M}+\mathrm{H}]^{+}$: 332.0999, found: 332.1003; HPLC (Chiralpak AD-H, $i$-propanol/hexane $=10 / 90$, flow rate $\left.1.0 \mathrm{~mL} / \mathrm{min}, 30{ }^{\circ} \mathrm{C}, \lambda=254 \mathrm{~nm}\right): t_{\mathrm{R}}$ $($ major $)=30.7,34.1 \mathrm{~min}, t_{\mathrm{R}}($ minor $)=18.0,41.4 \mathrm{~min}$, ee $=96 \%, 94 \%$.

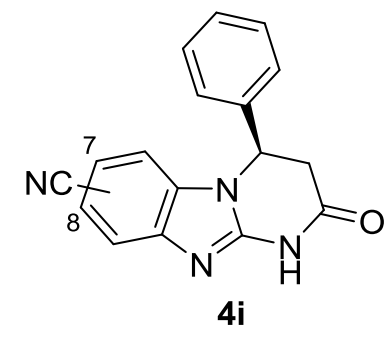

(1:1)

4i: white solid, $73 \%$ yield; ${ }^{1} \mathbf{H}$ NMR $\left(400 \mathrm{MHz} \mathrm{CDCl}_{3}\right) \delta 13.96(\mathrm{~s}, 2 \mathrm{H}), 7.73$ (d, $J=$ $1.0 \mathrm{~Hz}, 1 \mathrm{H}), 7.68(\mathrm{~d}, J=8.0 \mathrm{~Hz}, 1 \mathrm{H}), 7.46-7.37(\mathrm{~m}, 6 \mathrm{H}), 7.30(\mathrm{dd}, J=8.3,1.5 \mathrm{~Hz}$, $1 \mathrm{H}), 7.23-7.15(\mathrm{~m}, 4 \mathrm{H}), 7.05(\mathrm{dd}, J=8.3,1.5 \mathrm{~Hz}, 1 \mathrm{H}), 6.58(\mathrm{~d}, J=1.0 \mathrm{~Hz}, 1 \mathrm{H}), 6.36$ $(\mathrm{d}, J=8.4 \mathrm{~Hz}, 1 \mathrm{H}), 5.70-5.58(\mathrm{~m}, 2 \mathrm{H}), 3.59-3.42(\mathrm{~m}, 2 \mathrm{H}), 3.11(\mathrm{dd}, J=16.9,6.5 \mathrm{~Hz}$, $2 \mathrm{H}) ;{ }^{13} \mathbf{C}$ NMR $\left(100 \mathrm{MHz}, \mathrm{CDCl}_{3}\right) \delta 167.1,166.8,151.2,150.5,144.4,140.7,137.0$, 136.7 , 134.6, 131.6, 130.0, 129.9, 129.7, 127.0, 126.2, 126.2, 125.7, 121.4, 119.5, 119.5, 118.4, 114.2, 110.8, 106.0, 104.8, 55.1, 55.0, 39.3, 39.2; HRMS (ESI): m/z: calcd for $\mathrm{C}_{17} \mathrm{H}_{13} \mathrm{~N}_{4} \mathrm{O}[\mathrm{M}+\mathrm{H}]^{+}$: 289.1089, found 289.1087; HPLC (Chiralpak IA, ${ }^{i}$ propanol $/$ hexane $=15 / 85$, flow rate $\left.1.0 \mathrm{~mL} / \mathrm{min}, 30^{\circ} \mathrm{C}, \lambda=254 \mathrm{~nm}\right): t_{\mathrm{R}}($ minor $)=24.2$ $\min , 38.3 \mathrm{~min}, t_{\mathrm{R}}$ (major) $=45.8 \mathrm{~min}, 73.0 \mathrm{~min}$, $e e=93 \%, 93 \%$.

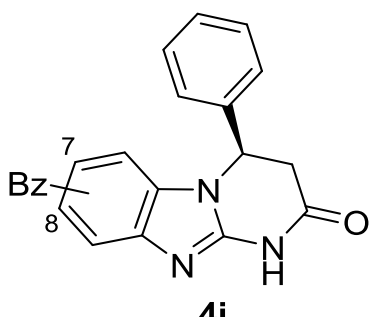

(1:1)

4j: light yellow solid, 71\% yield; ${ }^{1} \mathbf{H}$ NMR (400 MHz, $\left.\mathrm{CDCl}_{3}\right) \delta 13.94(\mathrm{~s}, 2 \mathrm{H}), 8.14$ $(\mathrm{d}, J=1.5 \mathrm{~Hz}, 1 \mathrm{H}), 7.78-7.68(\mathrm{~m}, 3 \mathrm{H}), 7.63(\mathrm{dd}, J=8.3,1.6 \mathrm{~Hz}, 1 \mathrm{H}), 7.59-7.49(\mathrm{~m}$, $4 \mathrm{H}), 7.45(\mathrm{t}, J=7.6 \mathrm{~Hz}, 2 \mathrm{H}), 7.39-7.28(\mathrm{~m}, 8 \mathrm{H}), 7.20-7.10(\mathrm{~m}, 5 \mathrm{H}), 6.94(\mathrm{~d}, J=1.5$ $\mathrm{Hz}, 1 \mathrm{H}), 6.35(\mathrm{~d}, J=8.4 \mathrm{~Hz}, 1 \mathrm{H}), 5.75-5.62(\mathrm{~m}, 2 \mathrm{H}), 3.71-3.49(\mathrm{~m}, 2 \mathrm{H}), 3.16-3.00$ (m, 2H); ${ }^{13} \mathrm{C}$ NMR $\left(100 \mathrm{MHz}, \mathrm{CDCl}_{3}\right) \delta 196.3,195.7,167.3,167.2,151.0,149.9,144.8$, 140.7, 138.1, 138.1, 137.9, 137.7, 134.8, 132.3, 132.3, 131.9, 131.5, 130.9, 130.1, $129.9,129.6,129.6,129.2,129.2,128.3,128.2,126.2,126.2,125.8,124.6,119.3$, 116.8, 112.5, 109.0, 54.4, 54.4, 39.1, 39.0; HRMS (ESI): m/z: calculated for $\mathrm{C}_{23} \mathrm{H}_{18} \mathrm{~N}_{3} \mathrm{O}_{2} \quad[\mathrm{M}+\mathrm{H}]^{+}:$368.1399, found: 368.1396; HPLC (Chiralpak IA, 
$i$-propanol $/$ hexane $=15 / 85$, flow rate $\left.1.0 \mathrm{~mL} / \mathrm{min}, 30{ }^{\circ} \mathrm{C}, \lambda=254 \mathrm{~nm}\right): t_{\mathrm{R}}($ major $)=$ $44.4 \mathrm{~min}, 60.7 \mathrm{~min}, t_{\mathrm{R}}$ (minor) $=27.9 \mathrm{~min}, 40.1 \mathrm{~min}, e e=90 \%, 92 \%$.

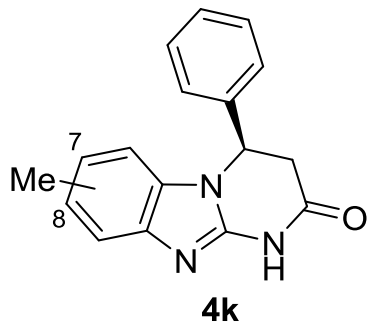

4k: light yellow solid, $82 \%$ yield; ${ }^{1} \mathbf{H}$ NMR $\left(400 \mathrm{MHz}, \mathrm{CDCl}_{3}\right) \delta 7.65(\mathrm{~d}, J=8.1 \mathrm{~Hz}$, 1H), 7.57 (s, 1H), 7.38 - $7.29(\mathrm{~m}, 6 \mathrm{H}), 7.19-7.07(\mathrm{~m}, 4 \mathrm{H}), 6.98-6.91(\mathrm{~m}, 1 \mathrm{H}), 6.79-$ $6.72(\mathrm{~m}, 1 \mathrm{H}), 6.48-6.38(\mathrm{~m}, 2 \mathrm{H}), 5.59-5.47(\mathrm{~m}, 2 \mathrm{H}), 3.51-3.35(\mathrm{~m}, 2 \mathrm{H}), 3.05(\mathrm{dd}, J$ $=16.6,4.9 \mathrm{~Hz}, 2 \mathrm{H}), 2.38(\mathrm{~s}, 3 \mathrm{H}), 2.28(\mathrm{~s}, 3 \mathrm{H}) ;{ }^{13} \mathbf{C ~ N M R}\left(100 \mathrm{MHz}, \mathrm{CDCl}_{3}\right) \delta 167.2$, $167.1,148.6,148.2$, 141.5, 139.1, 138.4, 138.3, 132.4, 132.0, 131.6, 129.9, 129.5, 129.5, 128.9, 128.9, 126.2, 126.0, 124.0, 122.9, 118.1, 117.5, 109.7, 109.2, 54.2, 53.9, 39.4, 39.3, 21.8, 21.6; HRMS (ESI): m/z: calcd for $\mathrm{C}_{17} \mathrm{H}_{16} \mathrm{~N}_{3} \mathrm{O}[\mathrm{M}+\mathrm{H}]^{+}:$: 278.1293, found 278.1292. HPLC (Chiralpak IA, ${ }^{i}$ propanol/hexane $=20 / 80$, flow rate 1.0 $\left.\mathrm{mL} / \mathrm{min}, 30^{\circ} \mathrm{C}, \lambda=254 \mathrm{~nm}\right): t_{\mathrm{R}}($ minor $)=10.1 \mathrm{~min}, 11.7 \mathrm{~min}, t_{\mathrm{R}}($ major $)=13.9 \mathrm{~min}$, $15.8 \min , e e=92 \%, 92 \%$.<smiles>O=C1CC(c2ccccc2)n2ccnc2N1</smiles>

4l: white solid, 57\% yield; ${ }^{1} \mathbf{H}$ NMR (400 $\left.\mathrm{MHz}, \mathrm{CDCl}_{3}\right) \delta 7.49-7.33(\mathrm{~m}, 3 \mathrm{H})$, 7.24-7.13 (m, 2H), $6.90(\mathrm{~d}, J=1.6 \mathrm{~Hz}, 1 \mathrm{H}), 6.41$ (d, $J=1.6 \mathrm{~Hz}, 1 \mathrm{H}), 5.26$ (dd, $J=8.4$, $5.6 \mathrm{~Hz}, 1 \mathrm{H}), 3.12(\mathrm{dd}, J=16.5,5.6 \mathrm{~Hz}, 1 \mathrm{H}), 2.98(\mathrm{dd}, J=16.5,8.4 \mathrm{~Hz}, 1 \mathrm{H}) ;{ }^{13} \mathrm{C}$ NMR $\left(100 \mathrm{MHz}, \mathrm{CDCl}_{3}\right) \delta 166.7,143.3,137.9,129.5,129.2,126.6,125.9,114.5$, 55.7, 39.6; HRMS (ESI): m/z: calcd for $\mathrm{C}_{12} \mathrm{H}_{12} \mathrm{~N}_{3} \mathrm{O}[\mathrm{M}+\mathrm{H}]^{+}:$214.0980, found 214.0981. HPLC (Chiralpak IA, ${ }^{i}$ propanol/hexane $=20 / 80$, flow rate $1.0 \mathrm{~mL} / \mathrm{min}$, $\left.30^{\circ} \mathrm{C}, \lambda=254 \mathrm{~nm}\right): t_{\mathrm{R}}($ major $)=16.6 \mathrm{~min}, t_{\mathrm{R}}($ minor $)=13.4 \mathrm{~min}, e e=64 \% .[\alpha]^{23}{ }_{\mathrm{D}}=$ $+38.0\left(\mathrm{c}=0.4, \mathrm{CHCl}_{3} / \mathrm{MeOH}=2: 1\right)$. 


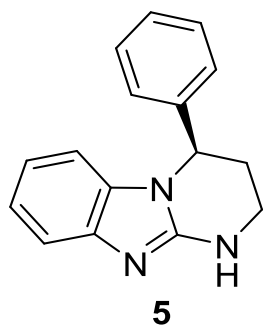

5: light yellow solid, 73\% yield; ${ }^{1} \mathbf{H}$ NMR $\left(400 \mathrm{MHz}, \mathrm{CDCl}_{3}\right) \delta 7.39-7.27(\mathrm{~m}, 4 \mathrm{H})$, $7.17-7.10(\mathrm{~m}, 2 \mathrm{H}), 7.06(\mathrm{td}, J=7.6,1.0 \mathrm{~Hz}, 1 \mathrm{H}), 6.83(\mathrm{td}, J=7.6,0.9 \mathrm{~Hz}, 1 \mathrm{H}), 6.62$ $(\mathrm{d}, J=7.7 \mathrm{~Hz}, 1 \mathrm{H}), 5.46(\mathrm{dd}, J=5.6,3.8 \mathrm{~Hz}, 1 \mathrm{H}), 3.53-3.34(\mathrm{~m}, 2 \mathrm{H}), 2.61-2.48$ $(\mathrm{m}, 1 \mathrm{H}), 2.29-2.16(\mathrm{~m}, 1 \mathrm{H}) ;{ }^{13} \mathbf{C}$ NMR $\left(100 \mathrm{MHz}, \mathrm{CDCl}_{3}\right) \delta 153.4,142.5,140.5$, 133.3, 129.0, 128.0, 126.1, 121.6, 118.9, 115.5, 108.3, 54.9, 35.9, 30.8; HRMS (ESI): $\mathrm{m} / \mathrm{z}$ : calcd for $\mathrm{C}_{16} \mathrm{H}_{16} \mathrm{~N}_{3}[\mathrm{M}+\mathrm{H}]^{+}:$250.1344, found 250.1344. HPLC (Chiralpak ID, ${ }^{i}$ propanol $/$ hexane $=20 / 80$, flow rate $\left.1.0 \mathrm{~mL} / \mathrm{min}, \lambda=254 \mathrm{~nm}\right): t_{\mathrm{R}}($ major $)=17.2 \mathrm{~min}$, $t_{\mathrm{R}}($ minor $)=13.2 \min , e e=92 \% ;[\alpha]_{\mathrm{D}}^{22}=+107.2(\mathrm{c}=0.25$, DMSO $)$.

\section{References}

1. (a) Rao, C.; Mai, S.; Song, Q. Org. Lett. 2017, 19, 4726-4729; (b) Rao, D. N.; Rasheed, S.; Kumar, K. A.; Reddy, A. S.; Das, P. Adv. Synth. Catal. 2016, 358, 2126-2133. (c) Ueda, S.; Buchwald, S. L. Angew. Chem. Int. Ed. 2012, 51, 10364-10367.

2. (a) Lang, M.; Wang, J. Eur. J. Org. Chem. 2018, 2958-2962; (b) Sakakura, A.; Yamada, H.; Ishihara, K. Org. Lett. 2012, 14, 2972-2975.

3. Sun, F. G.; Sun, L.H.; Ye, S. Adv. Synth. Catal. 2011, 353, 3134-3138. 
NMR Spectra

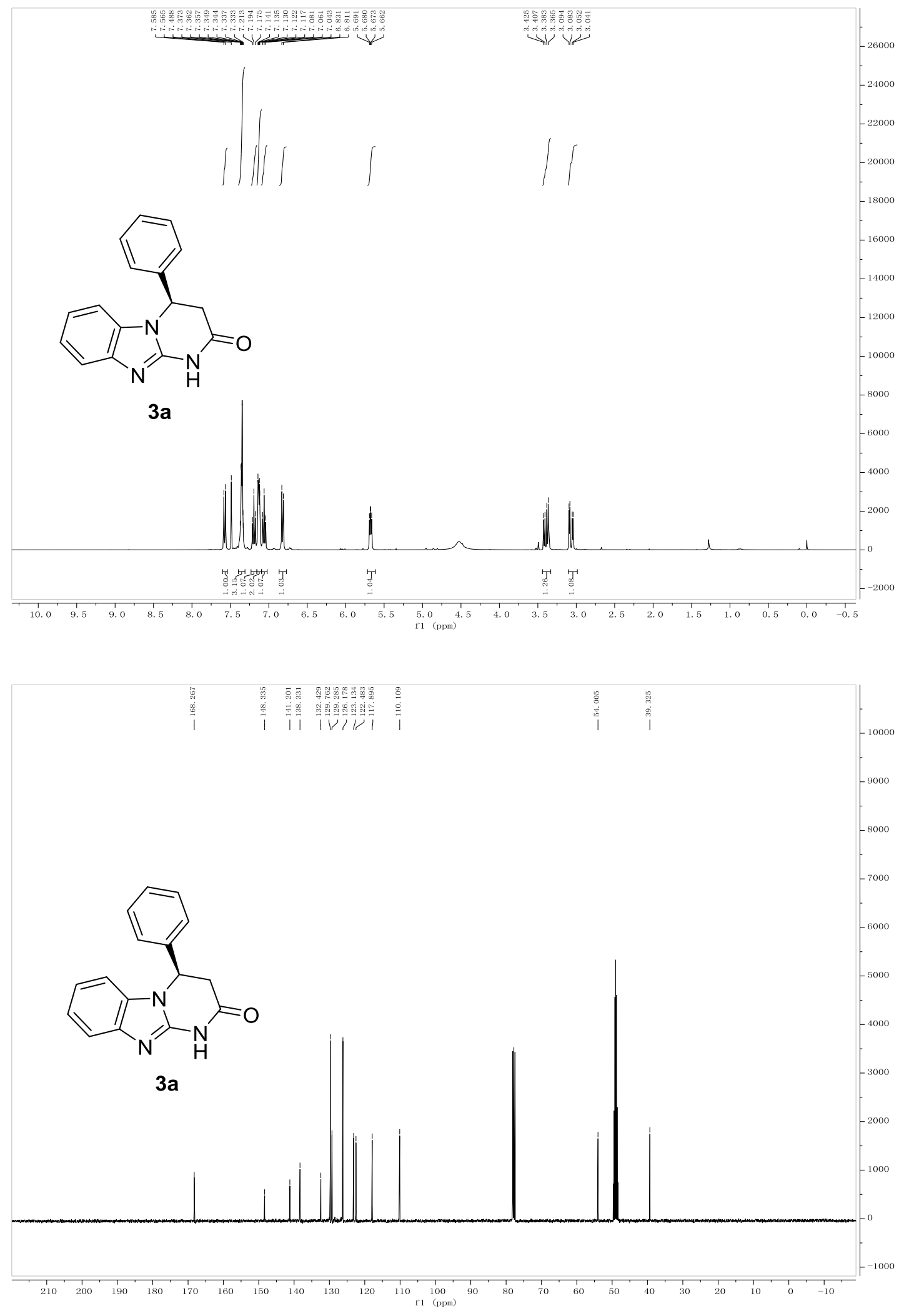




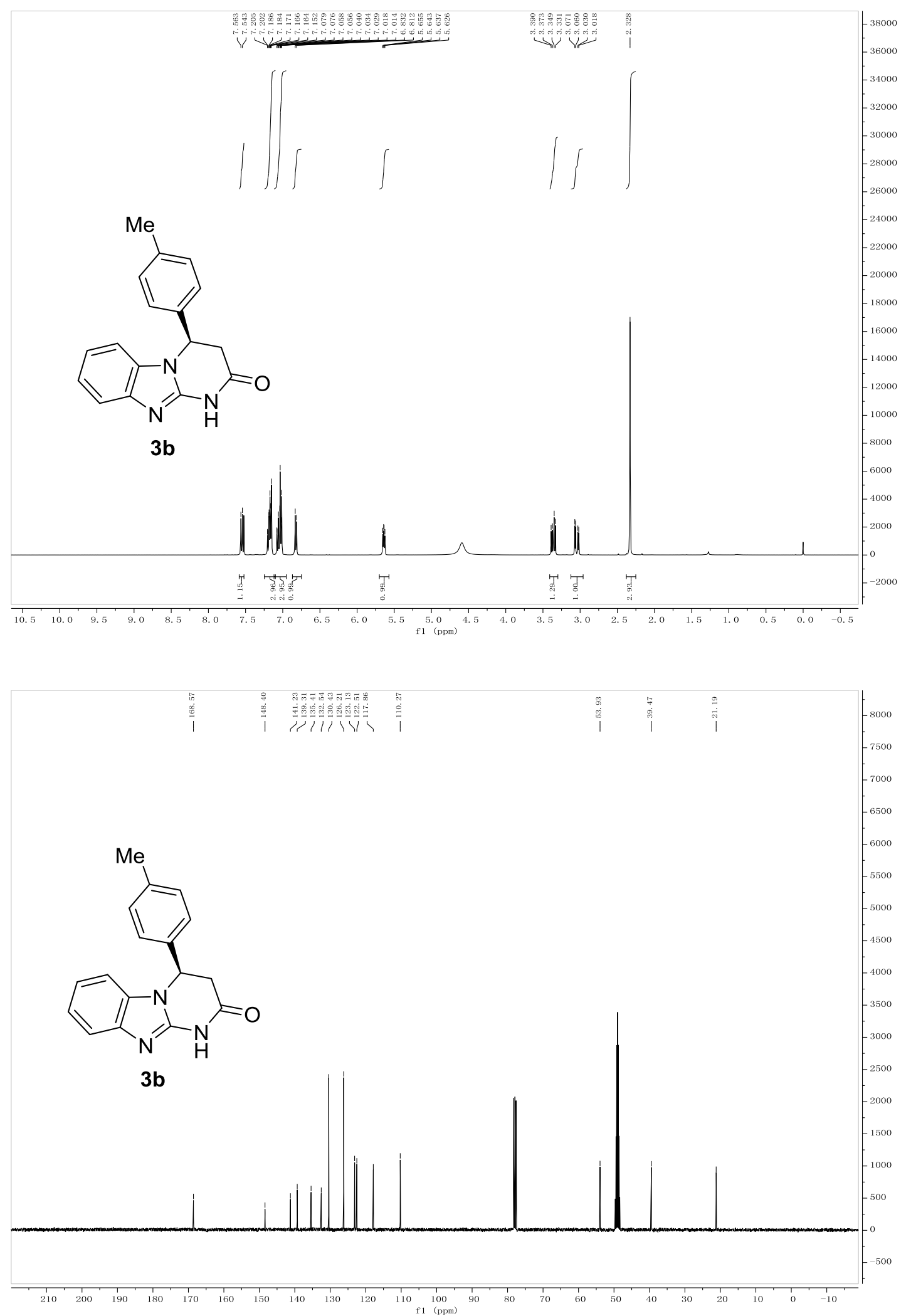




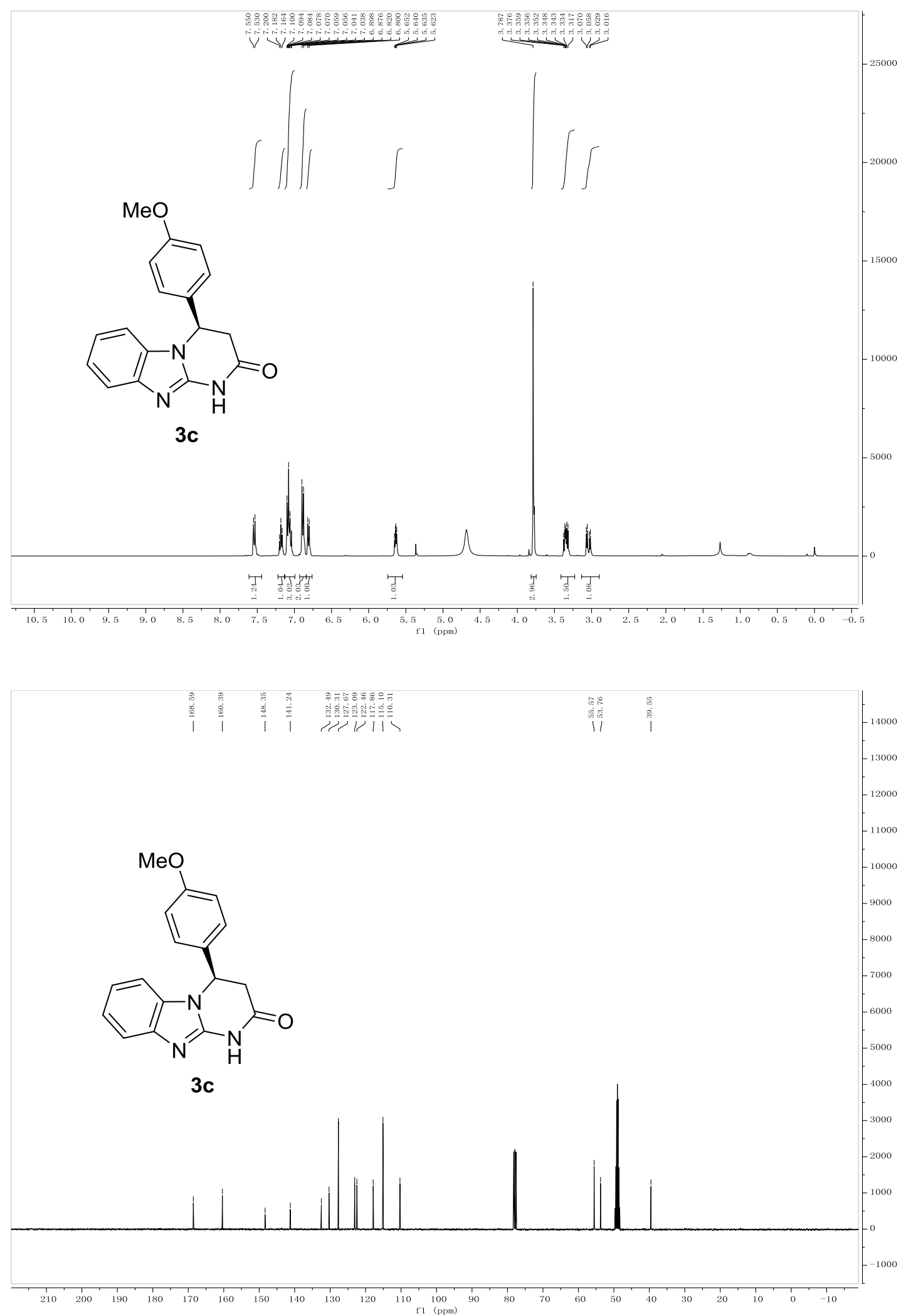




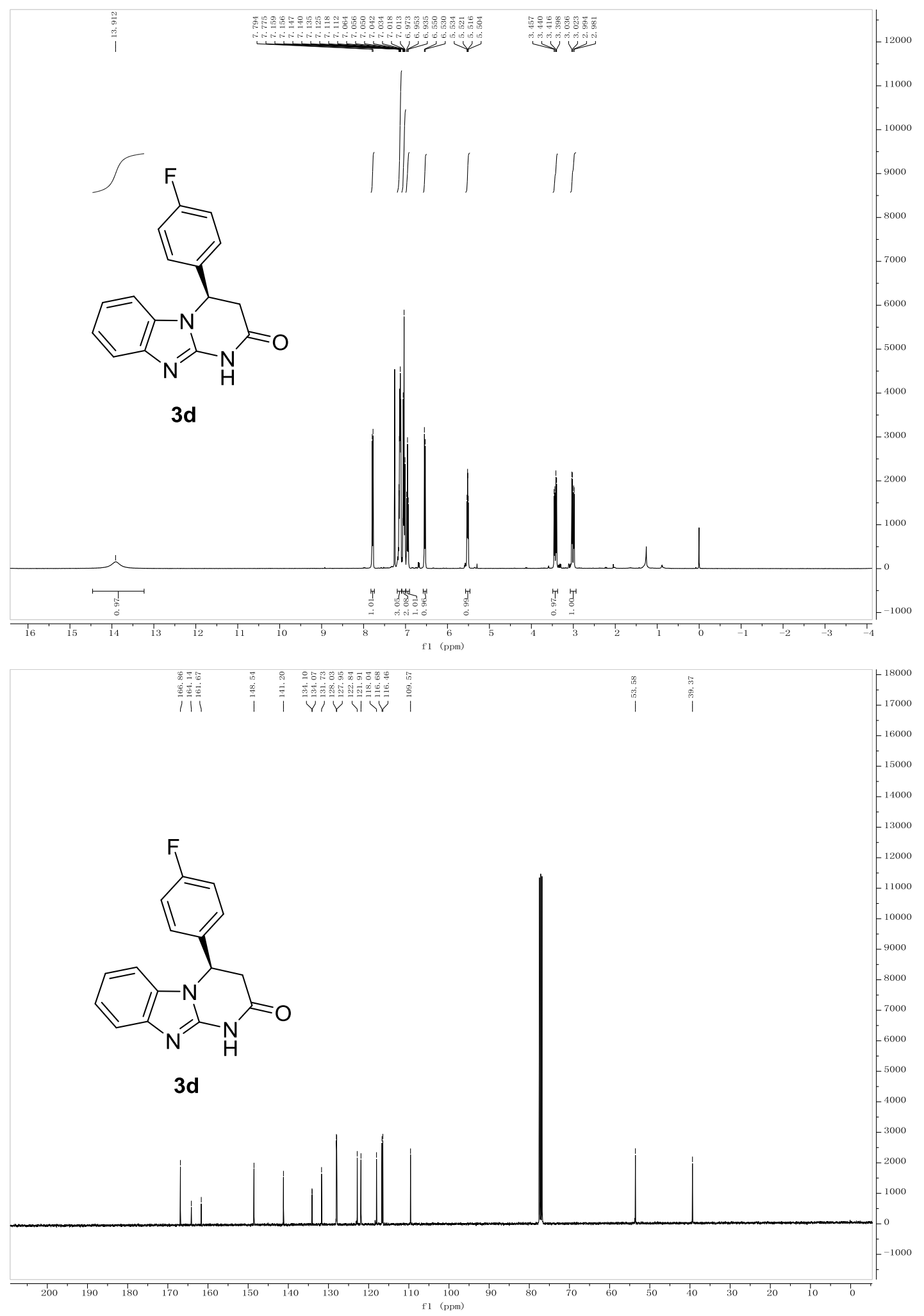




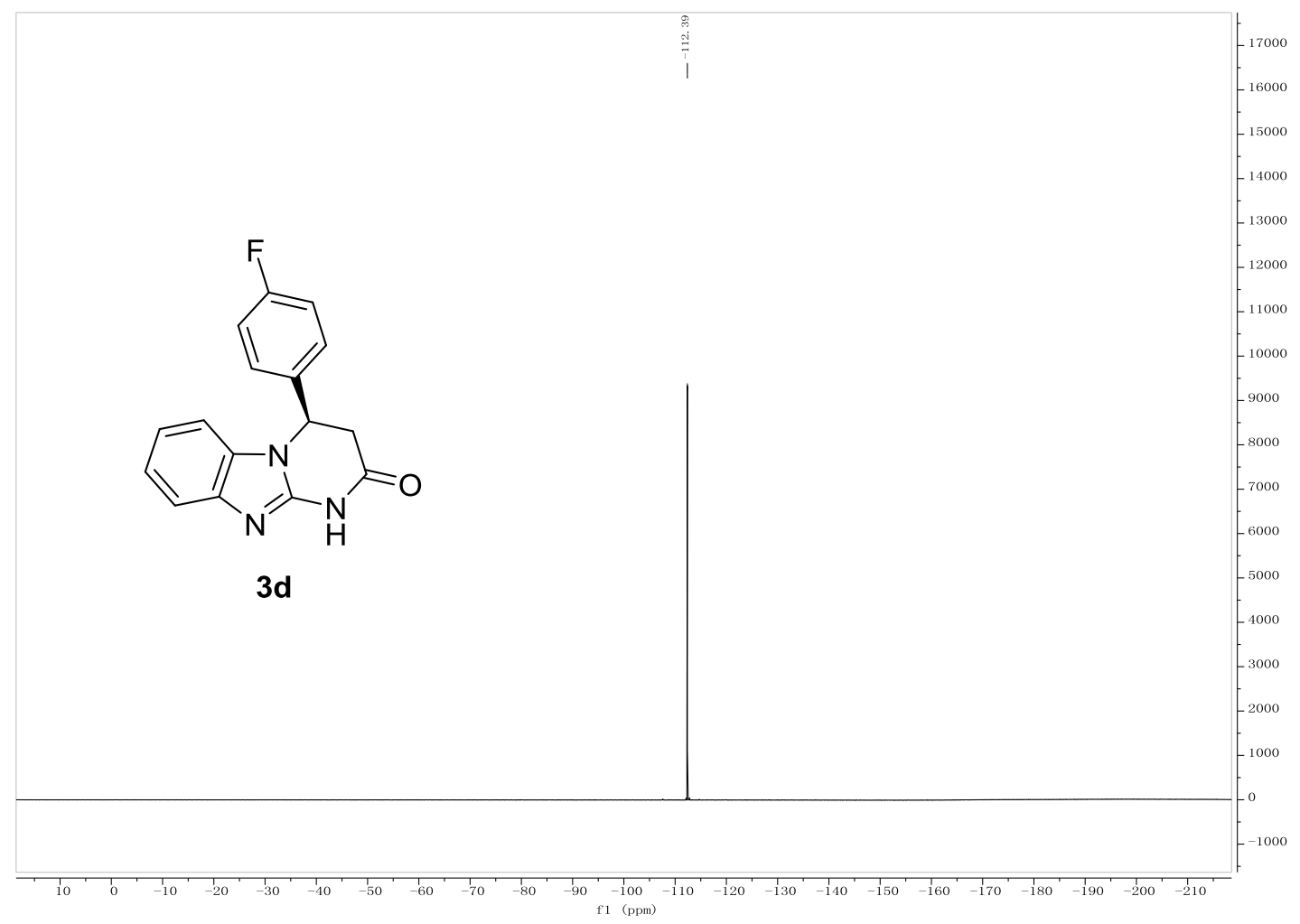



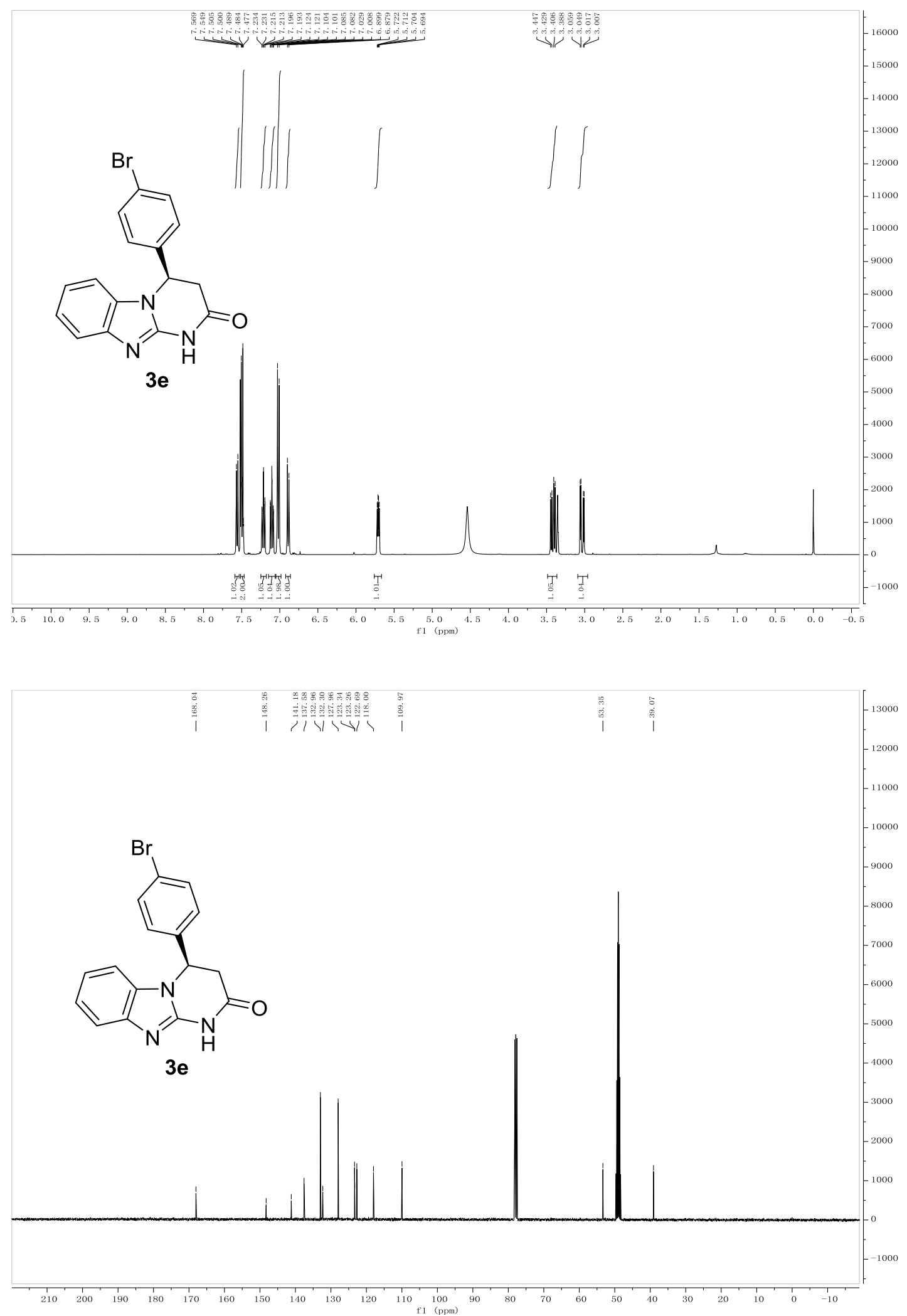


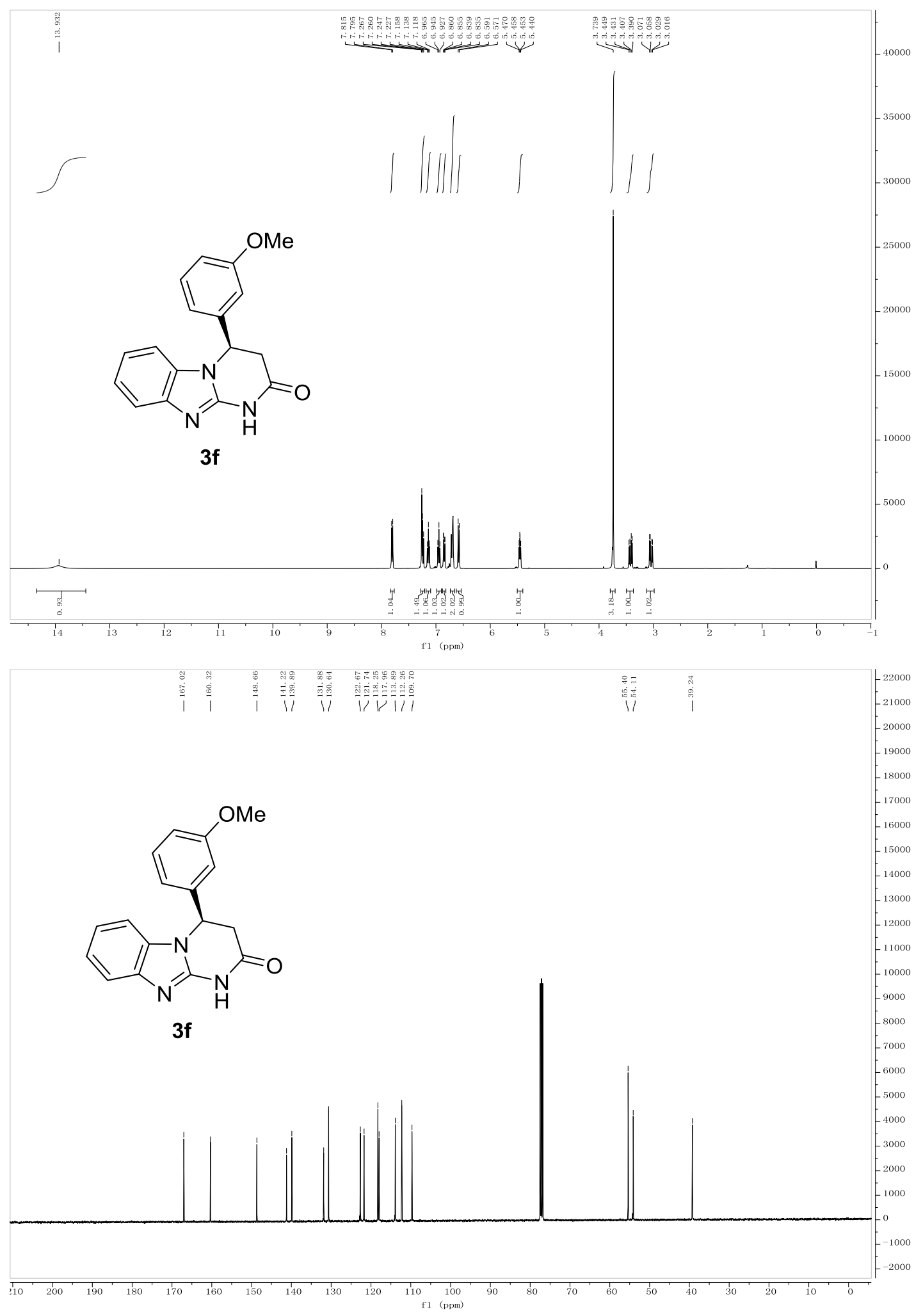




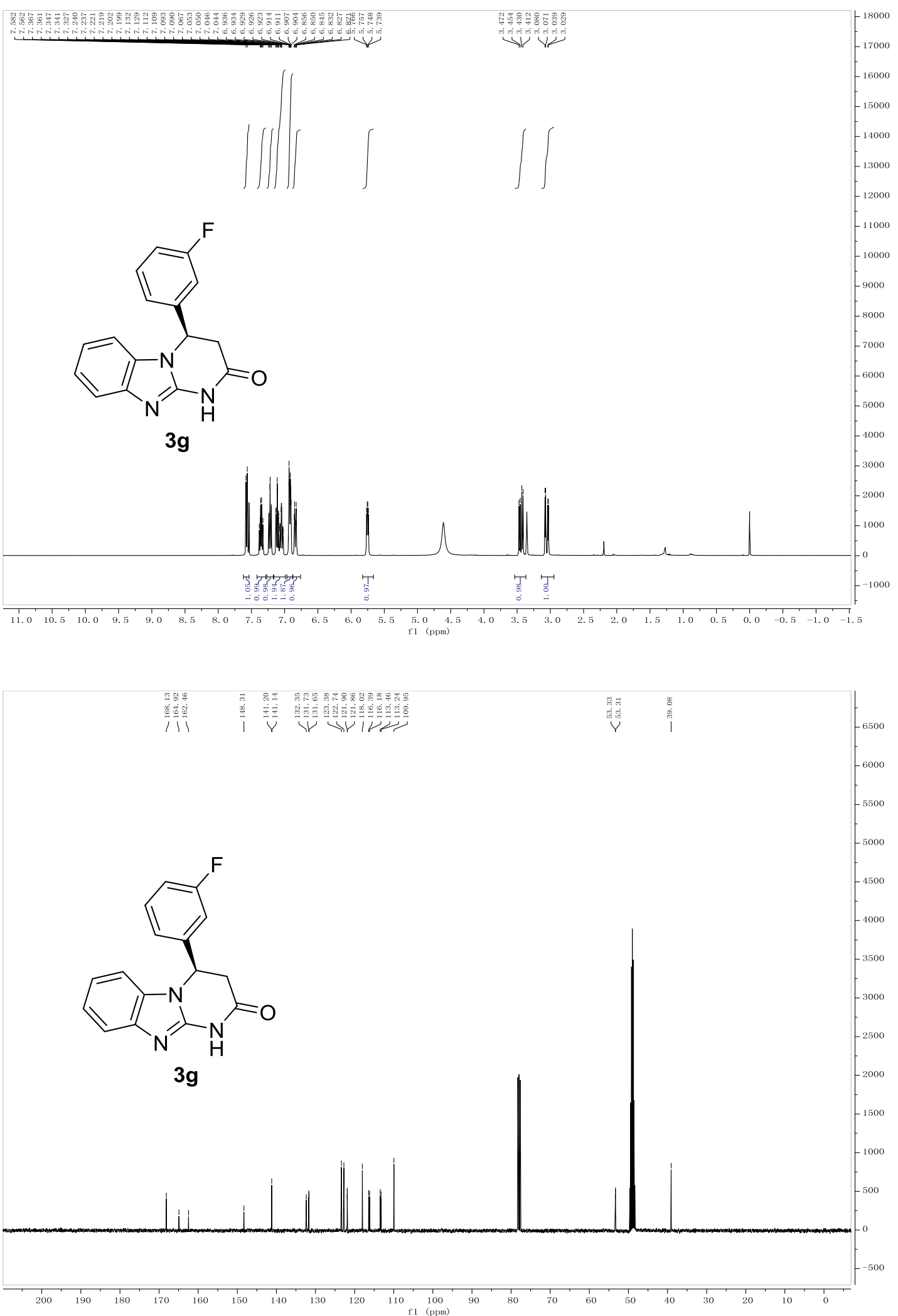




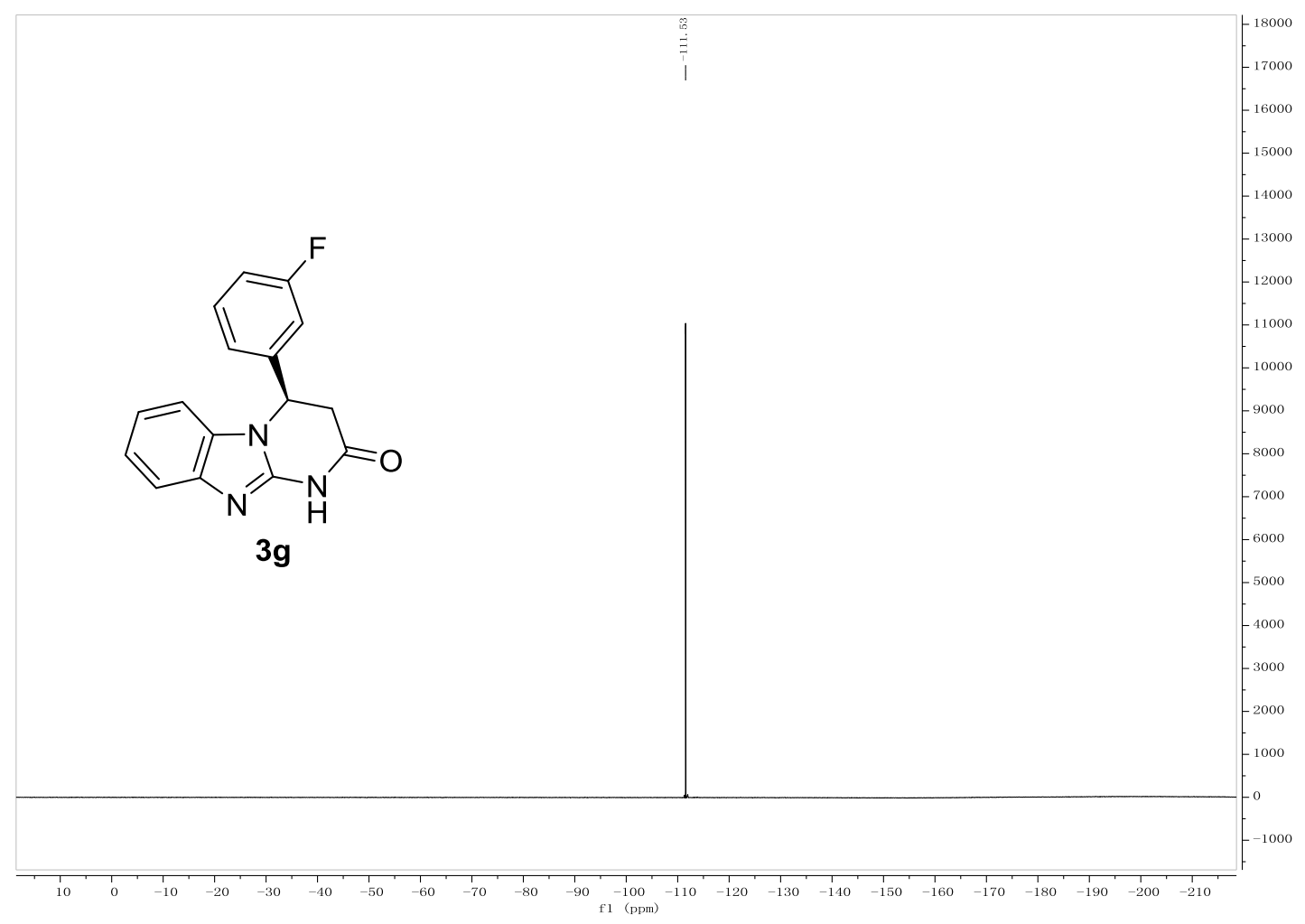




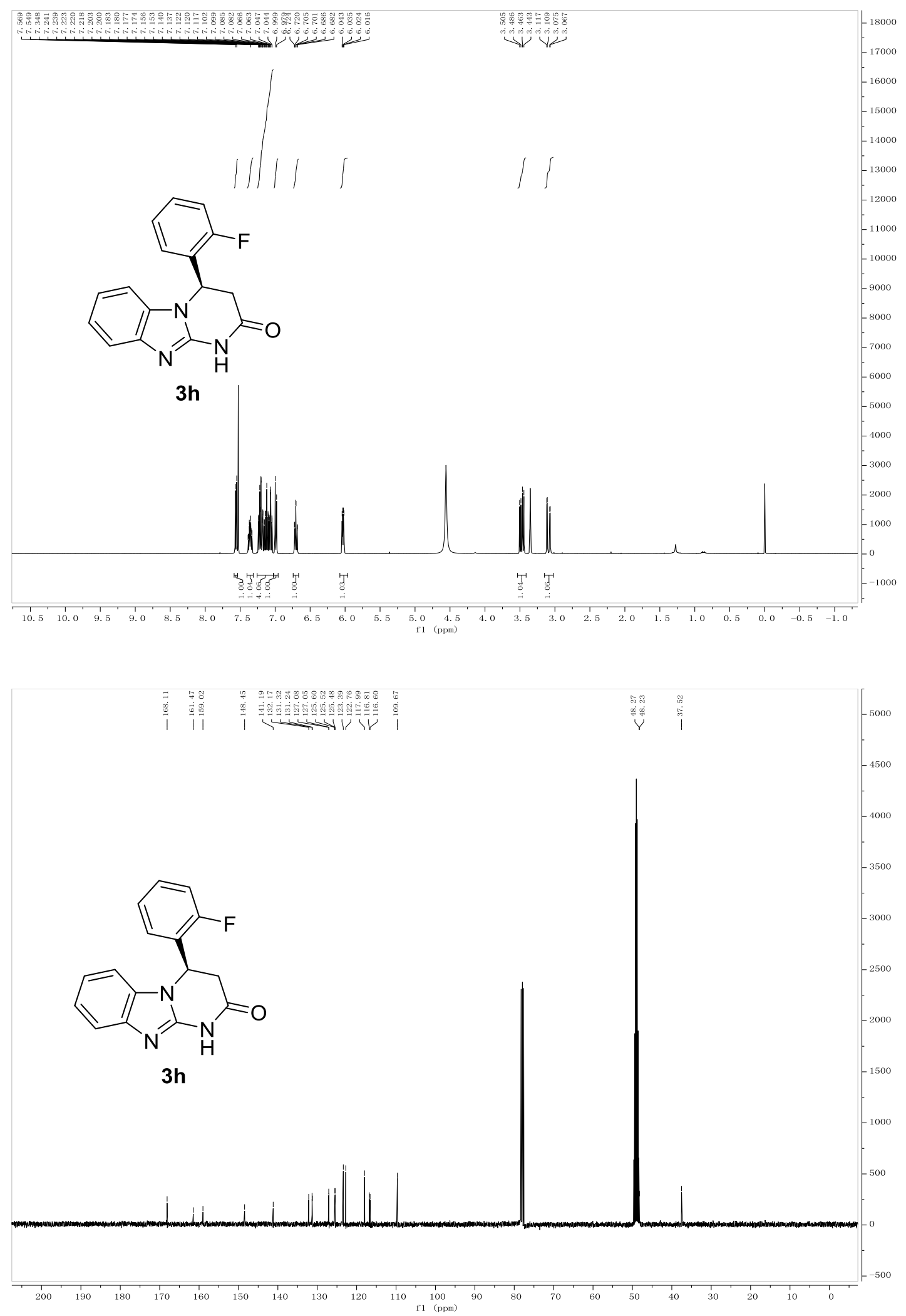




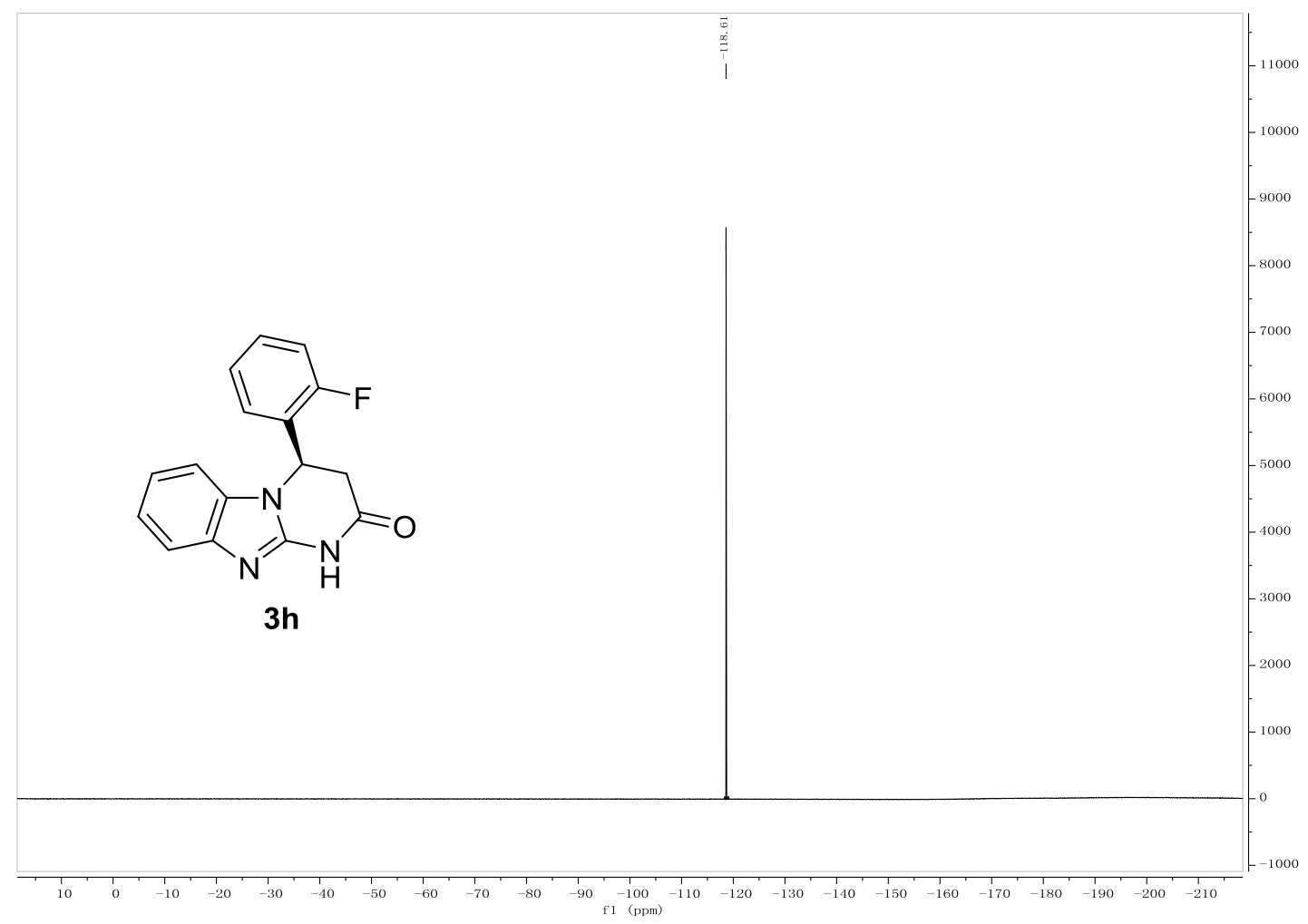



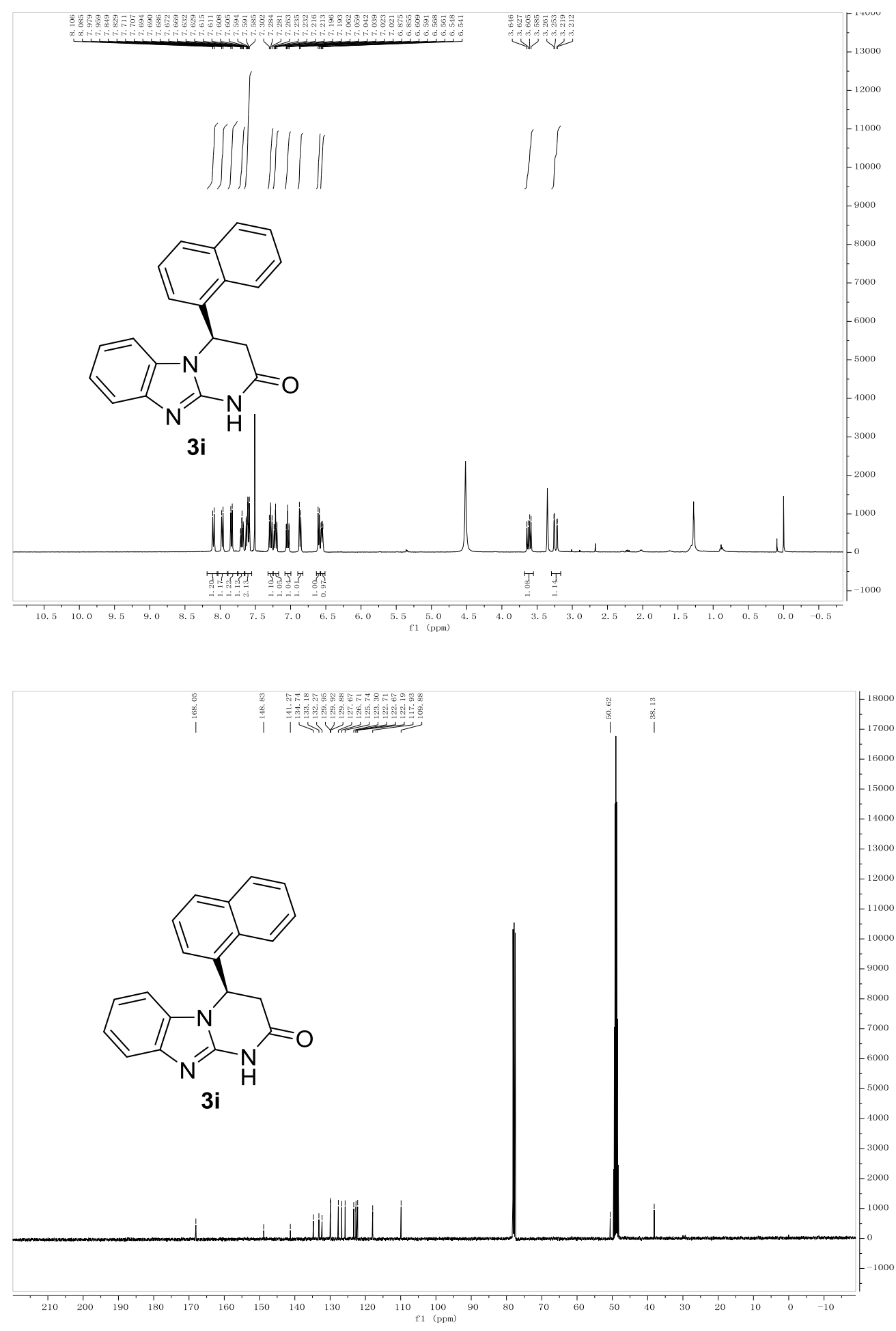


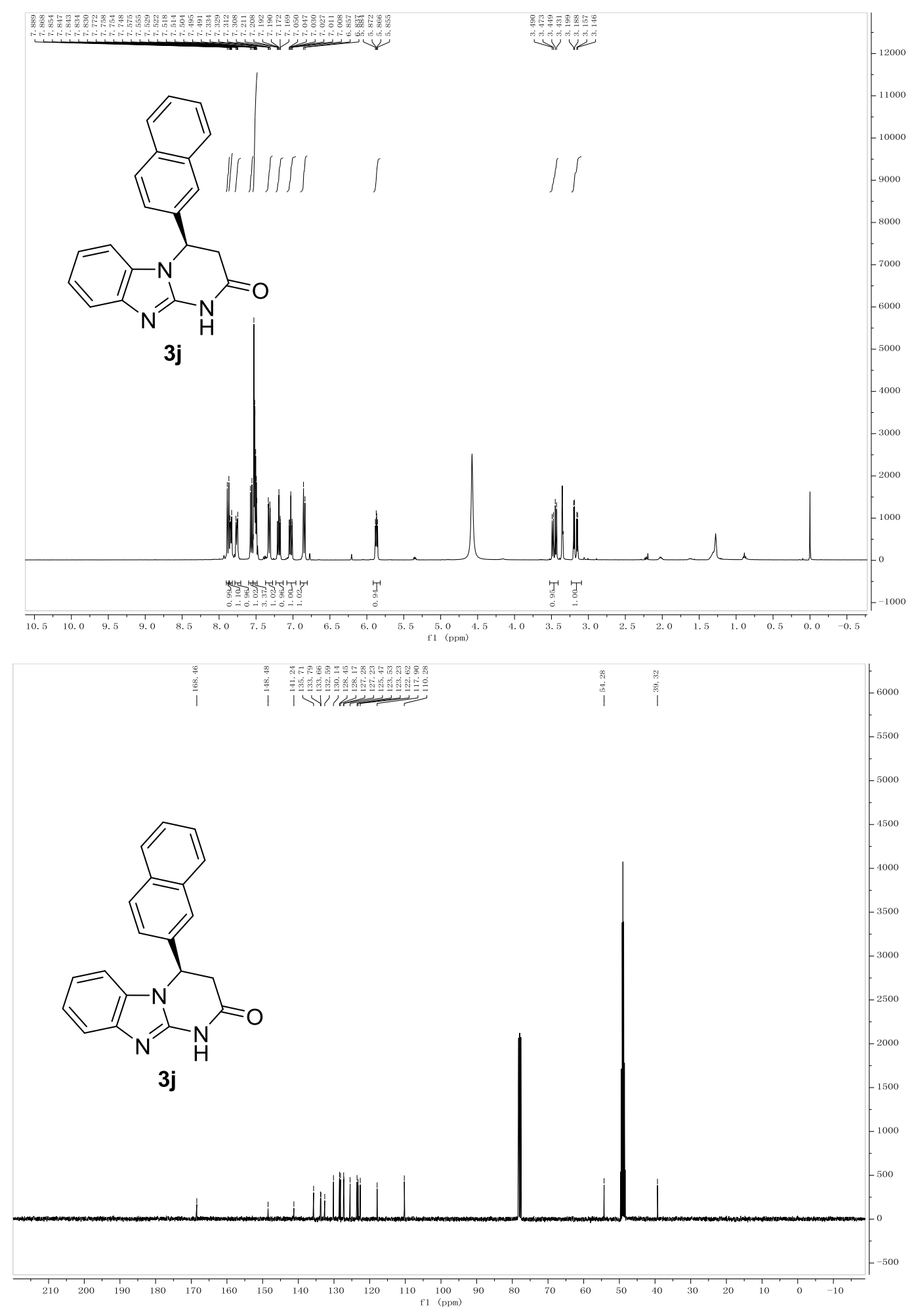




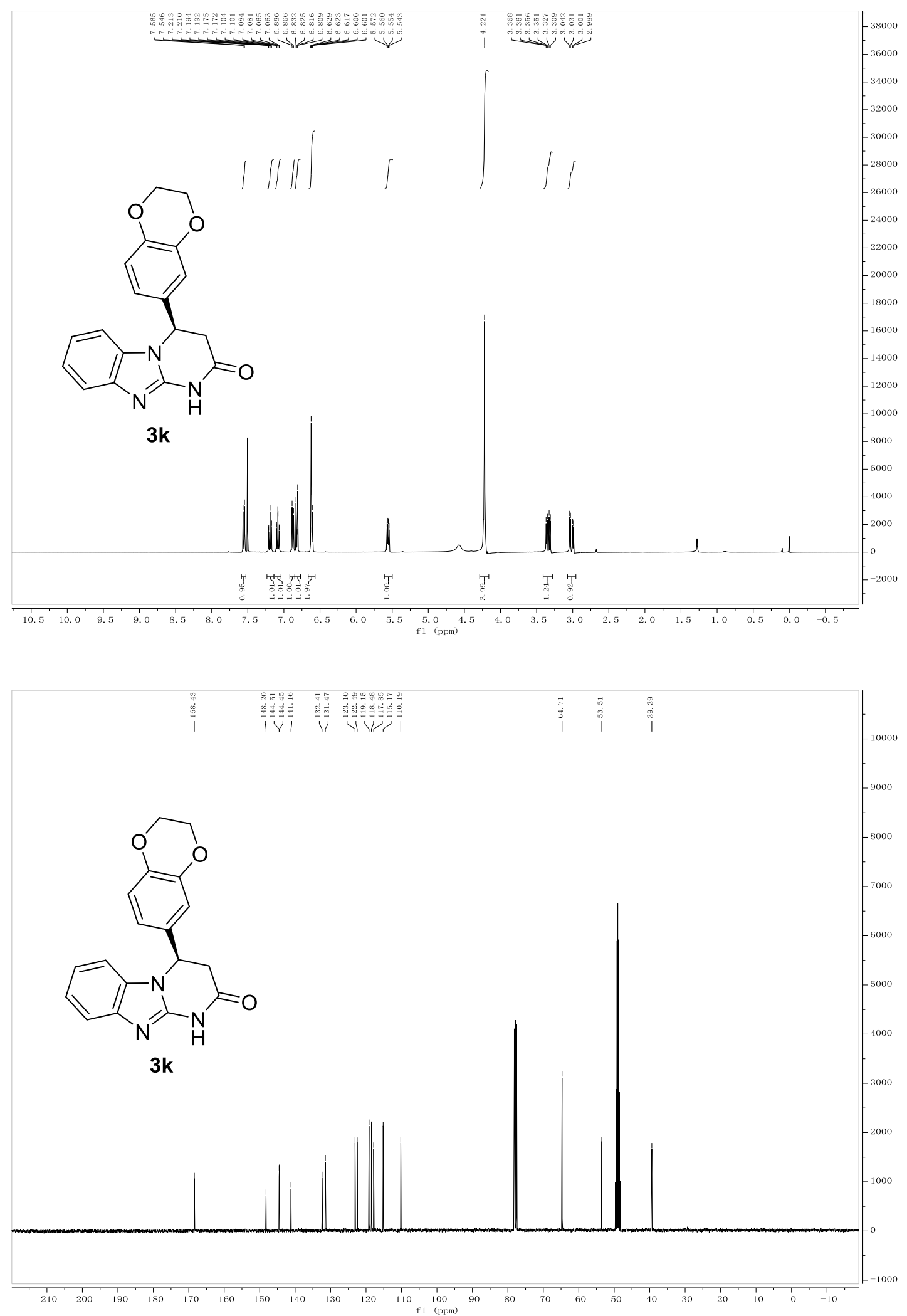




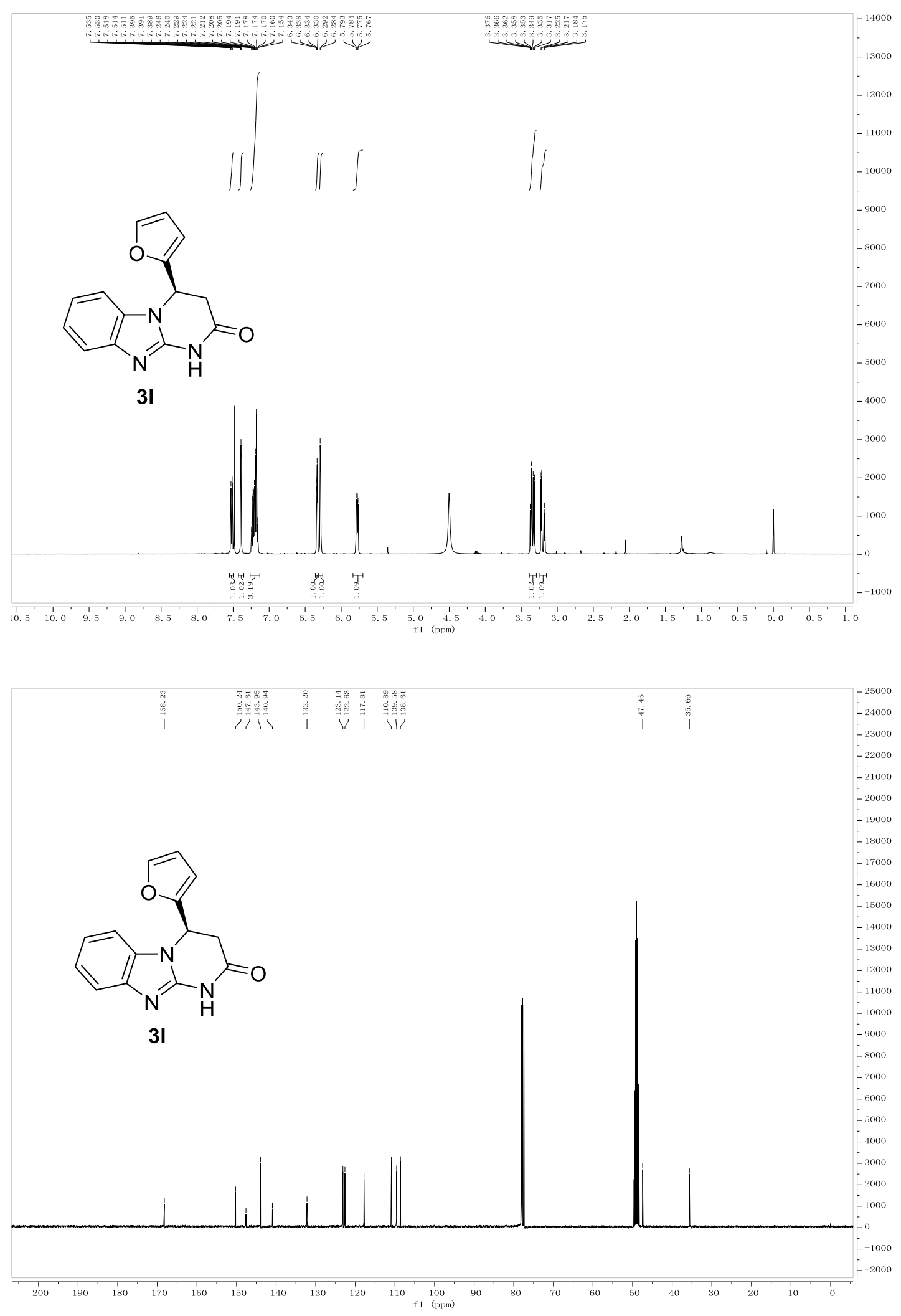




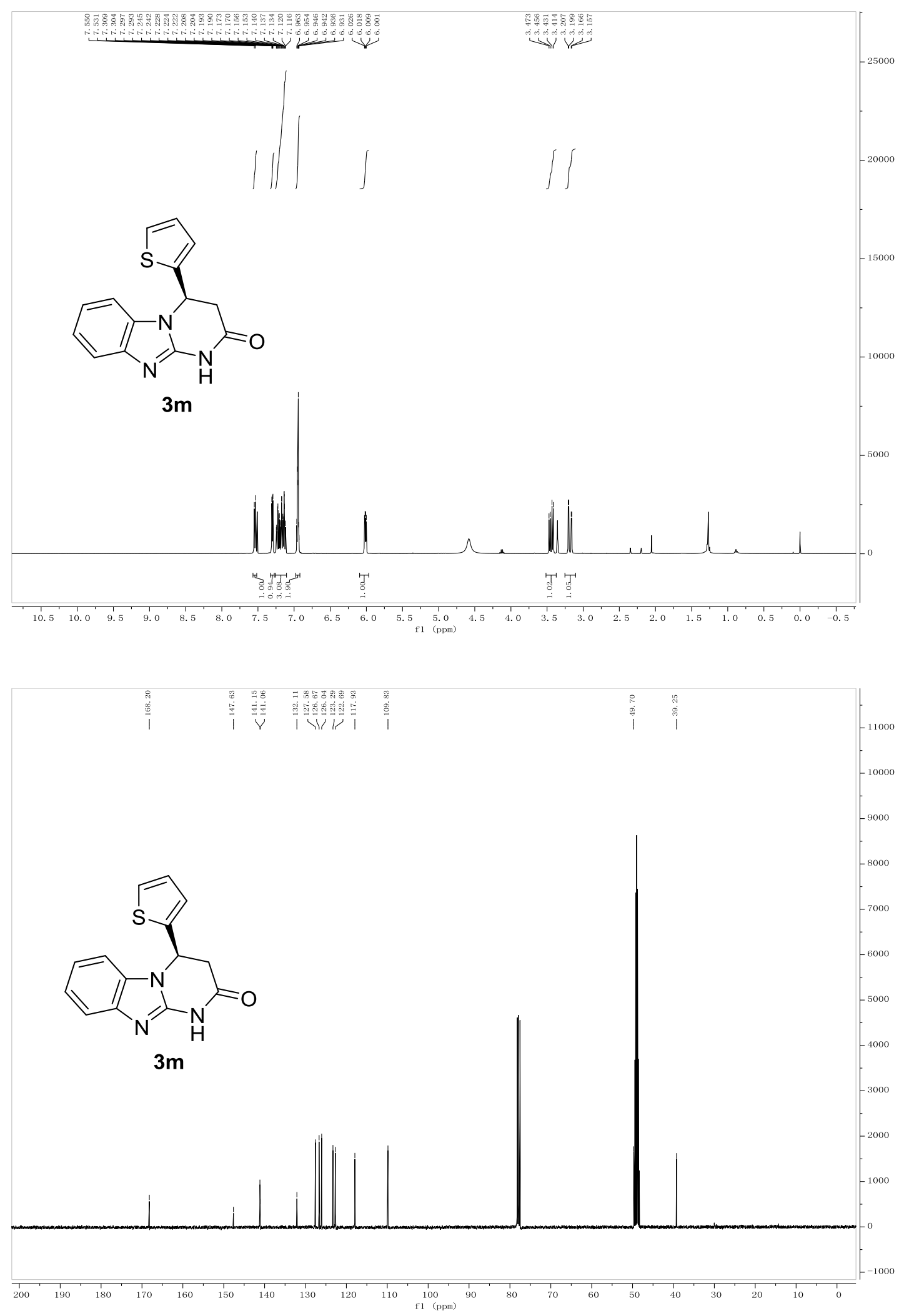




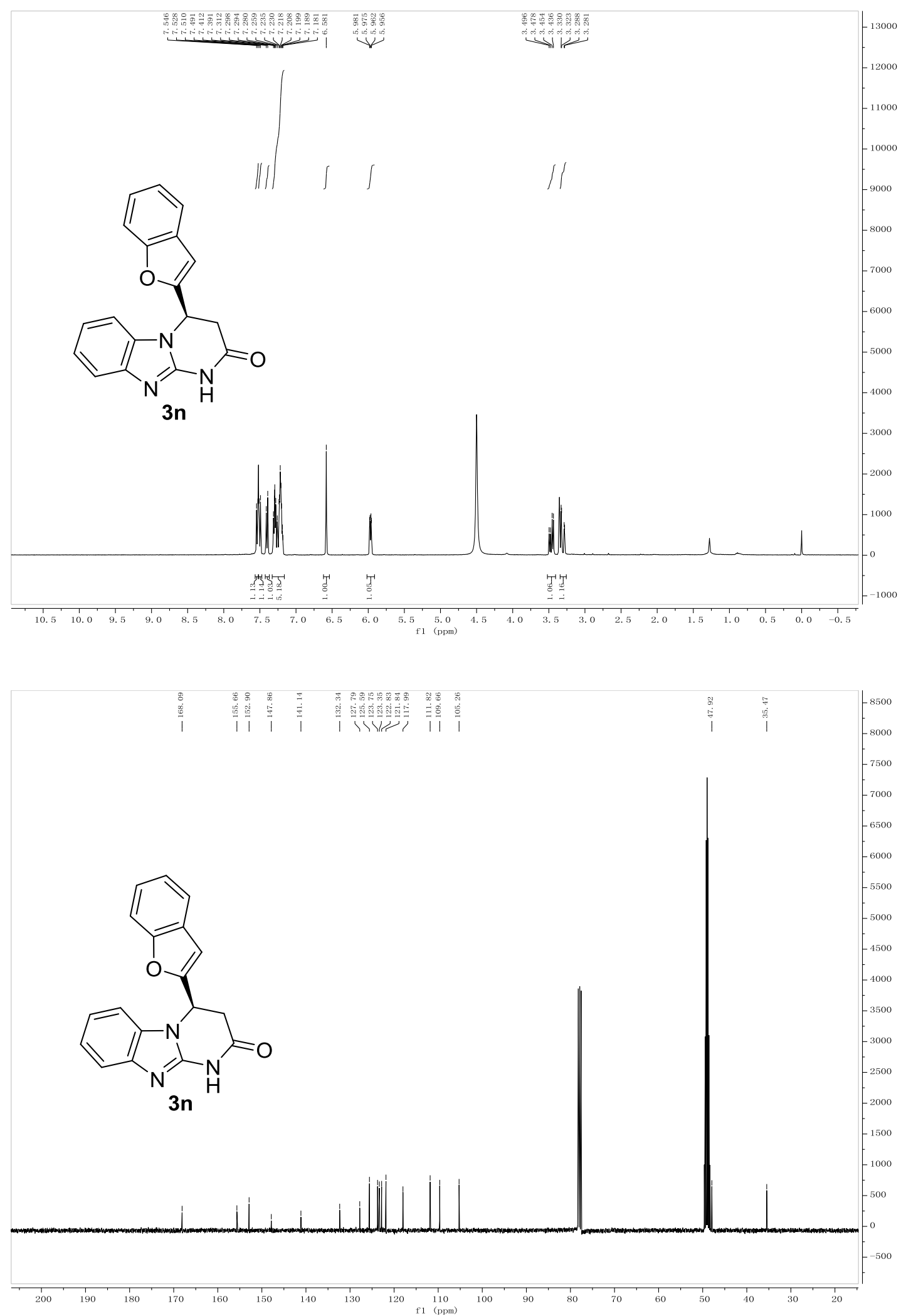



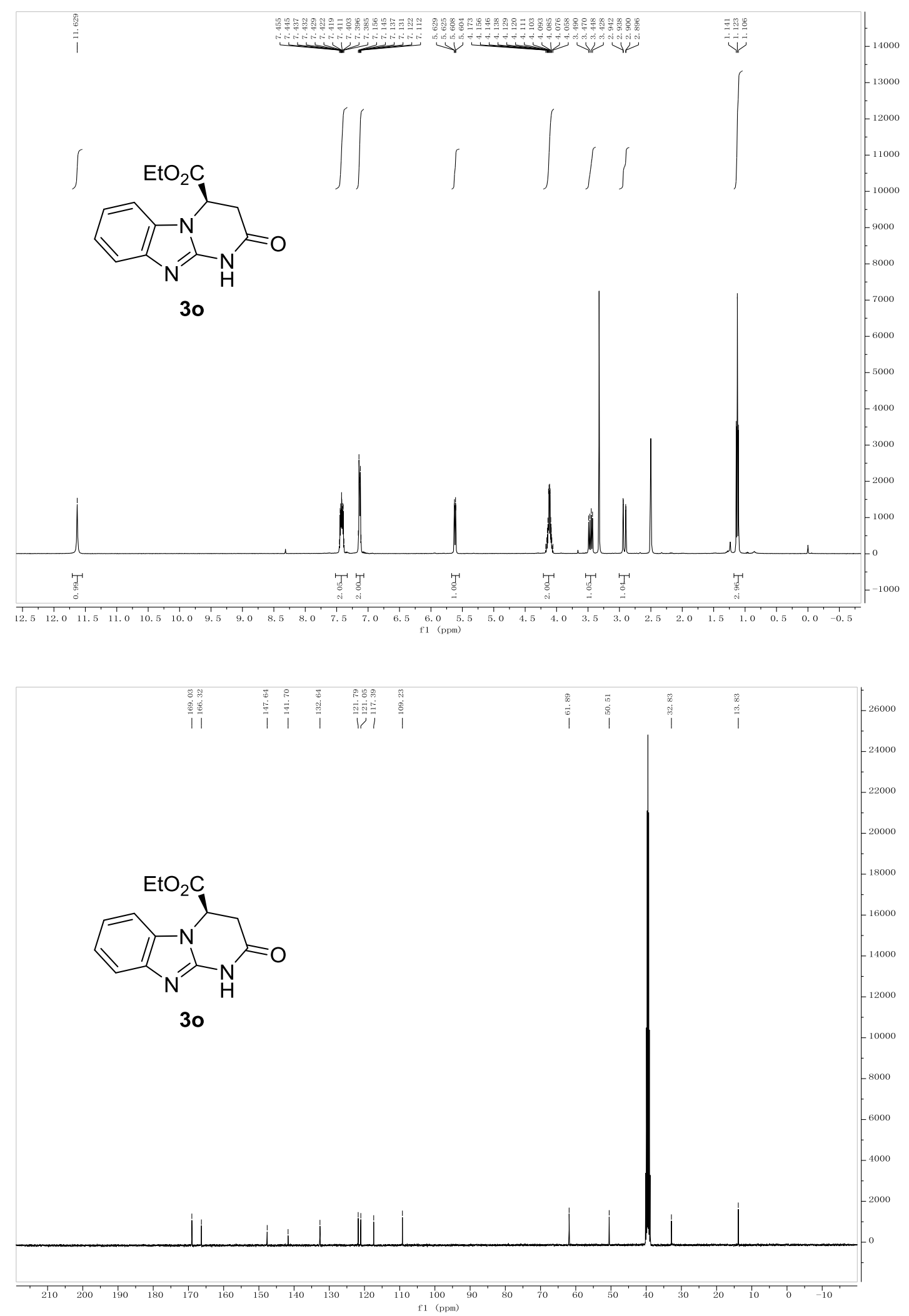


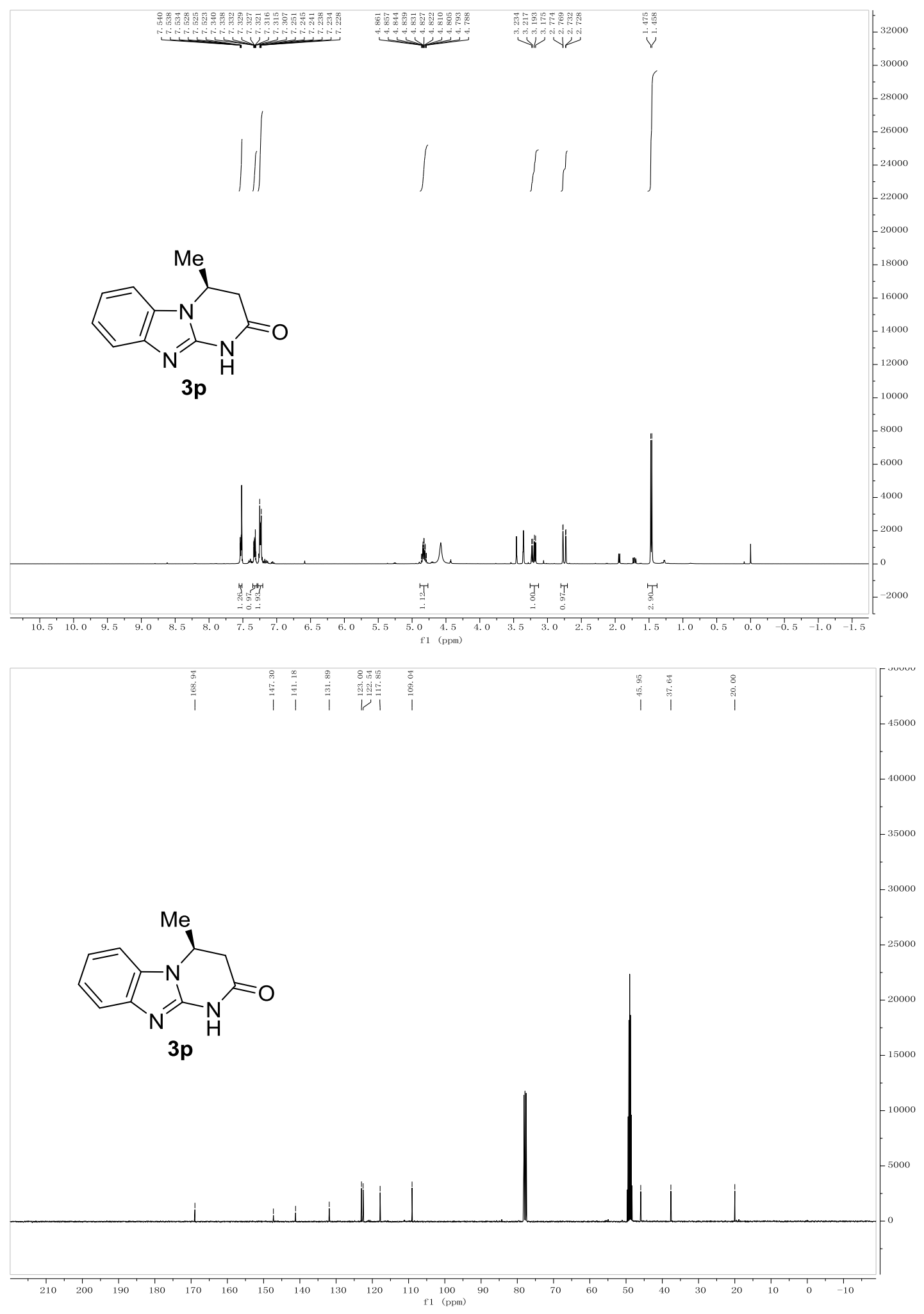




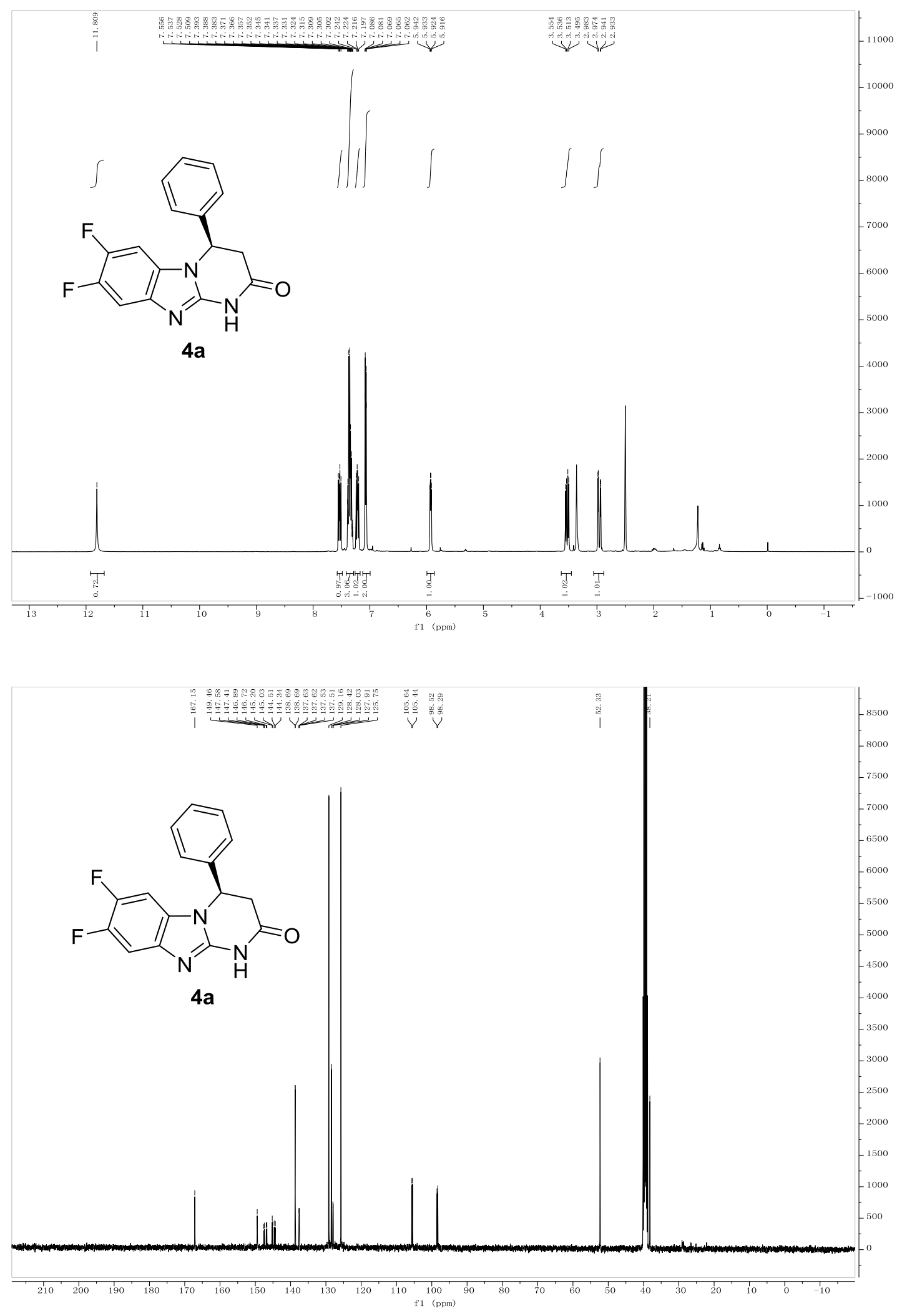




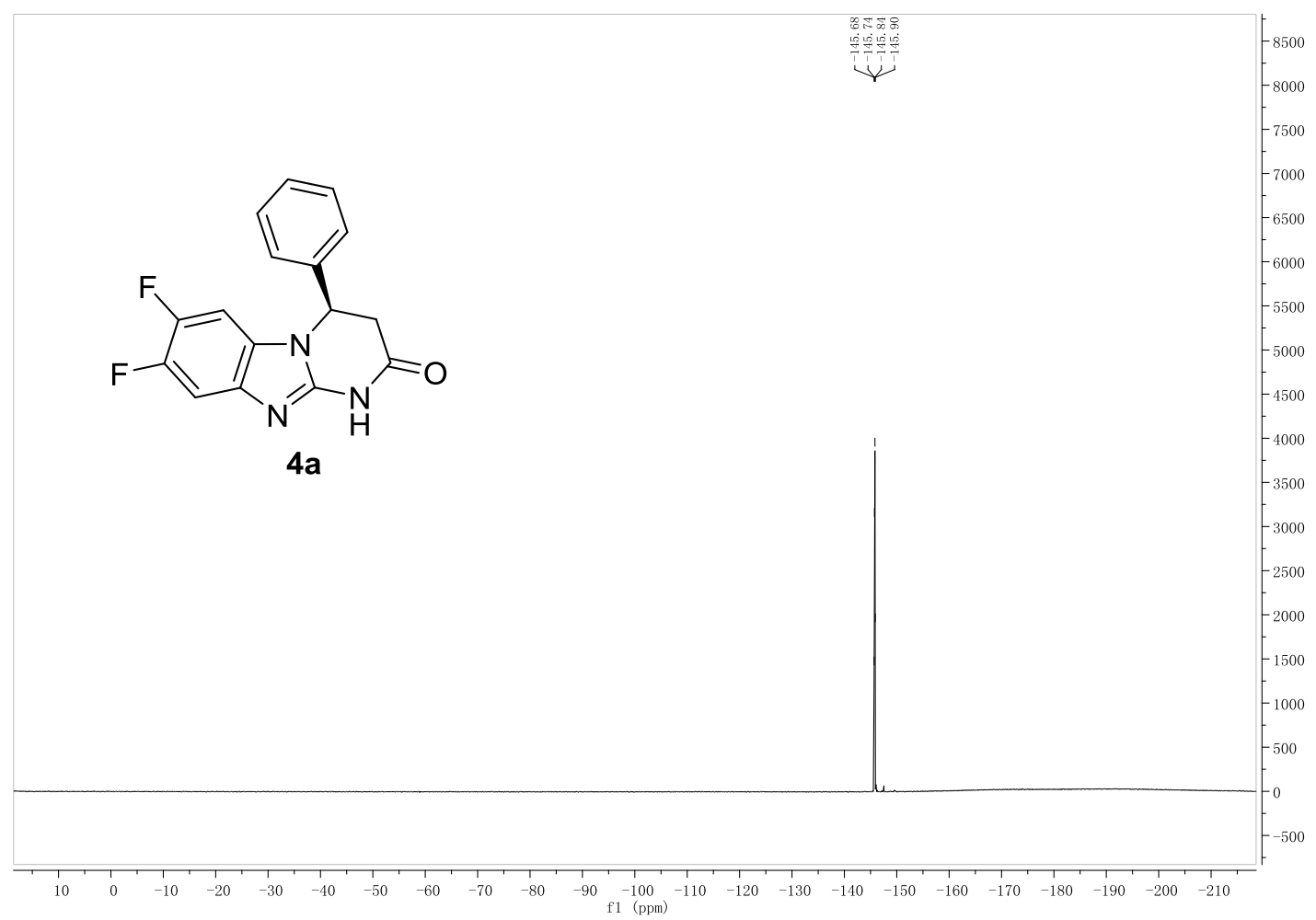



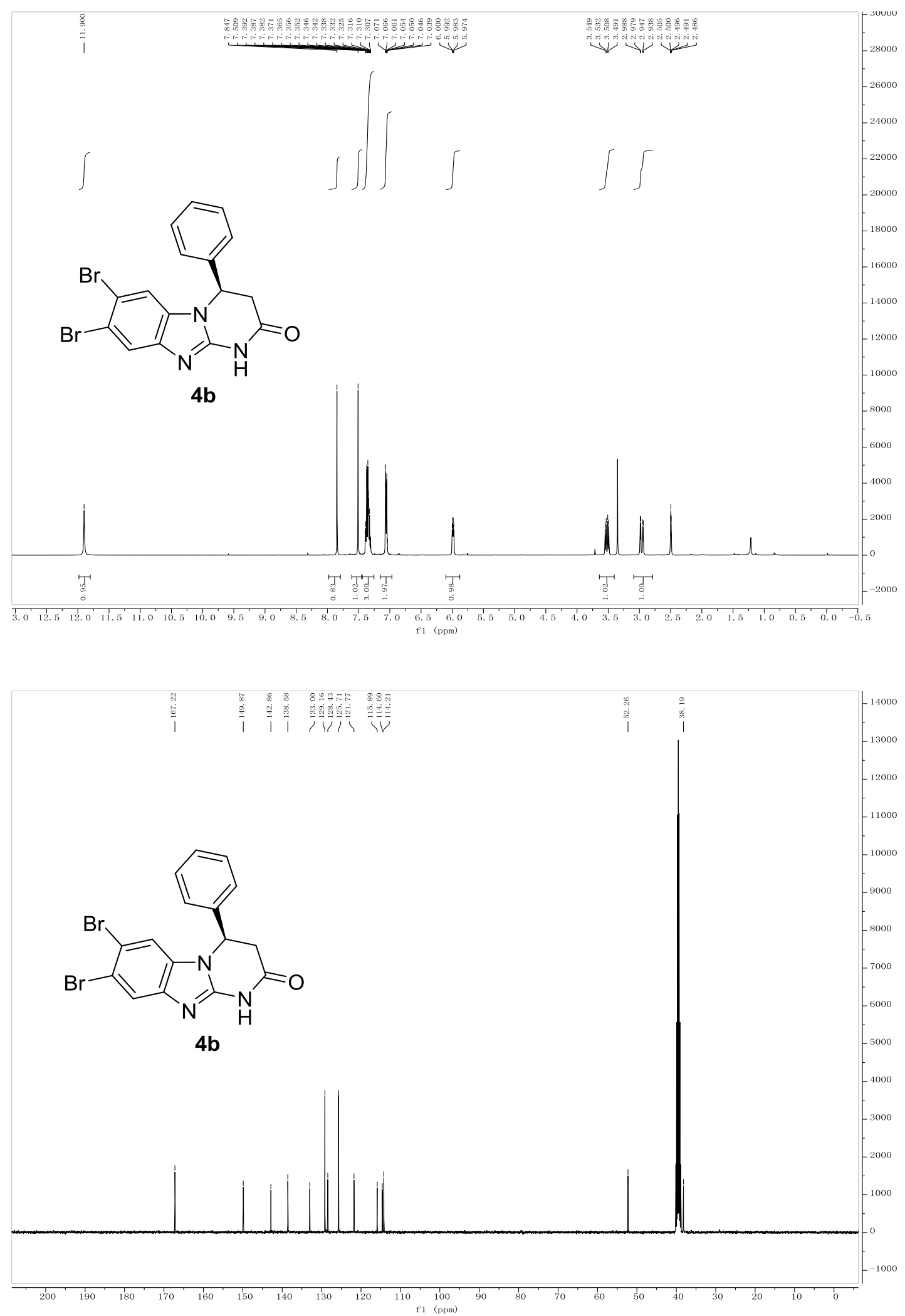

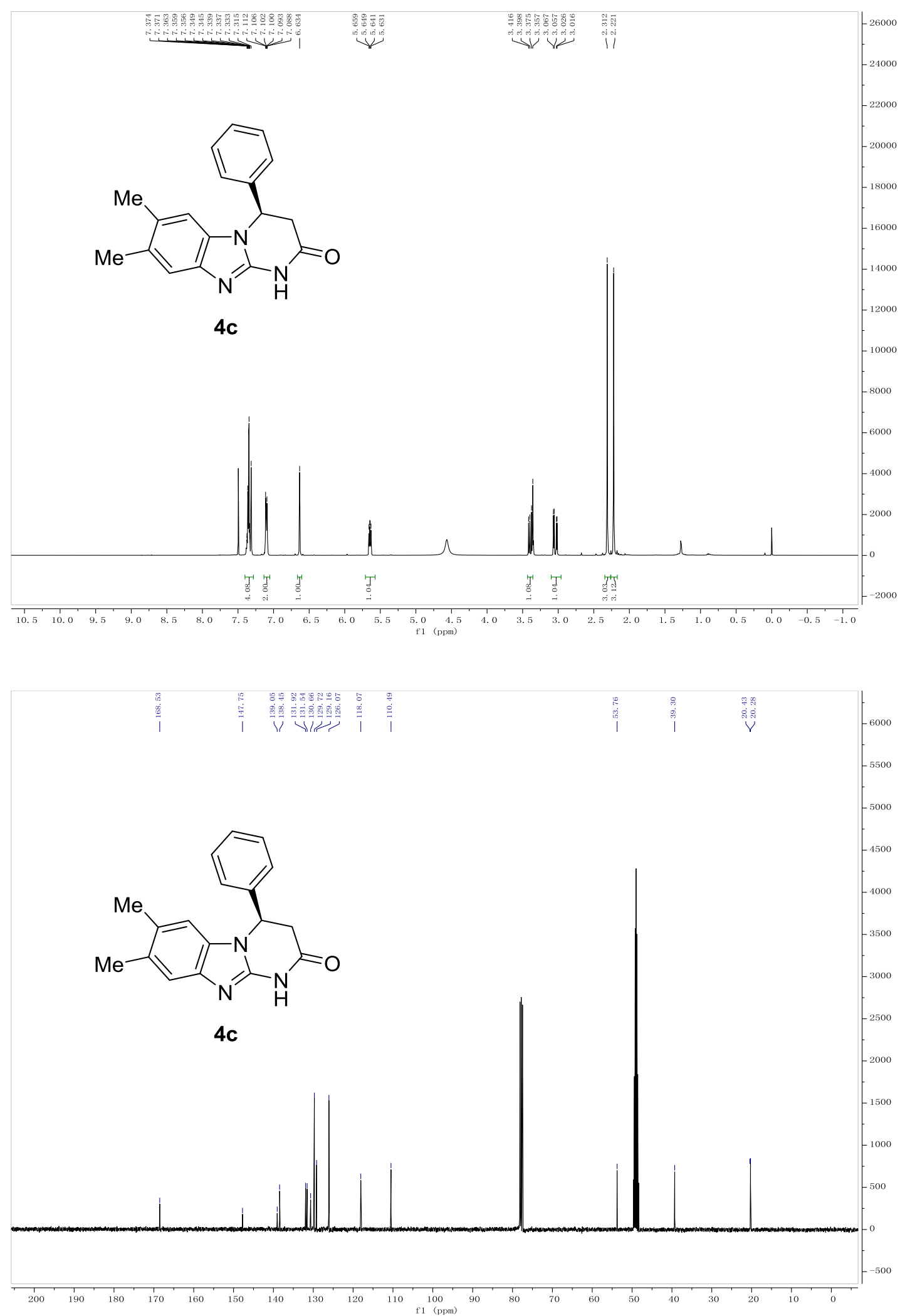

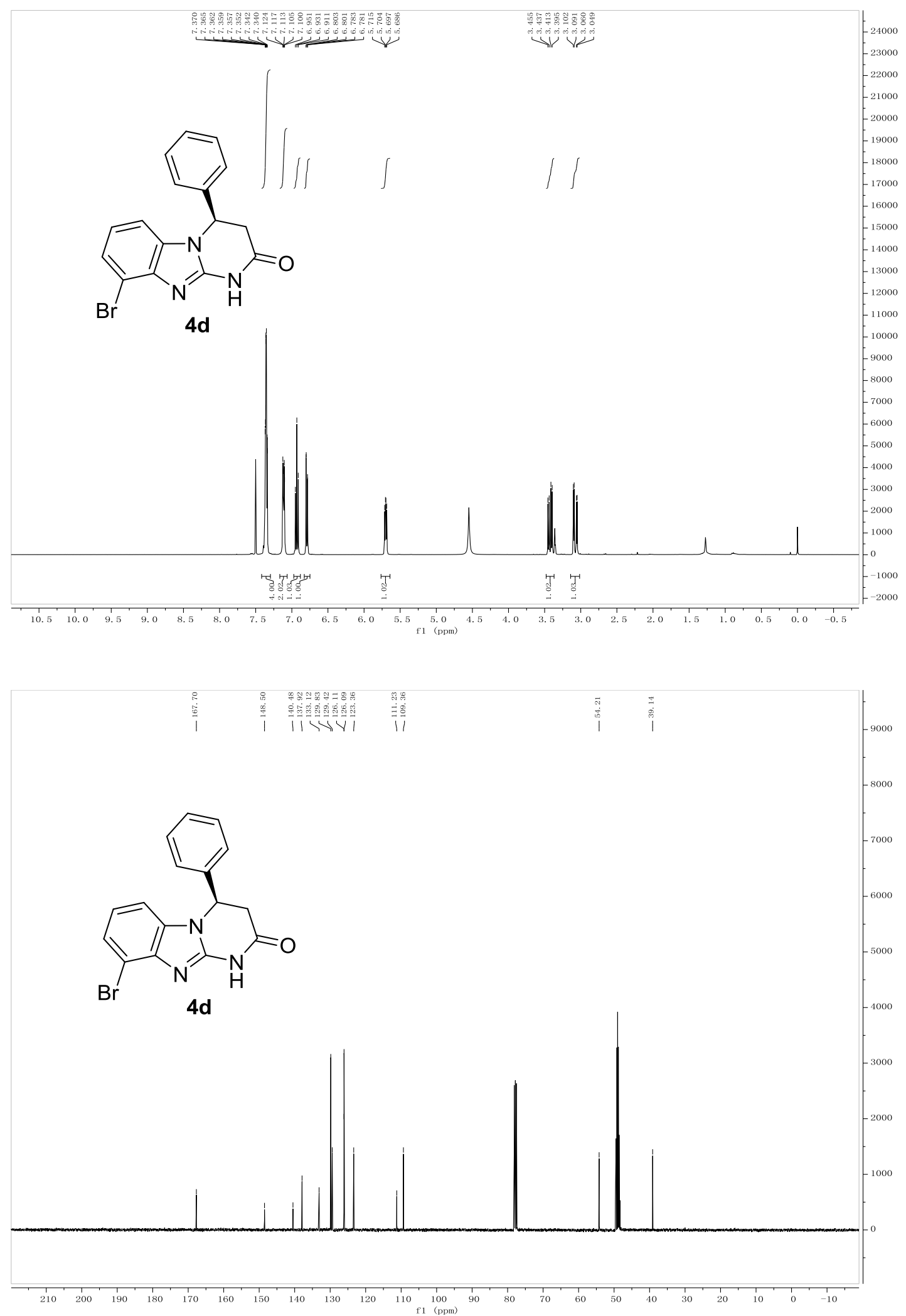

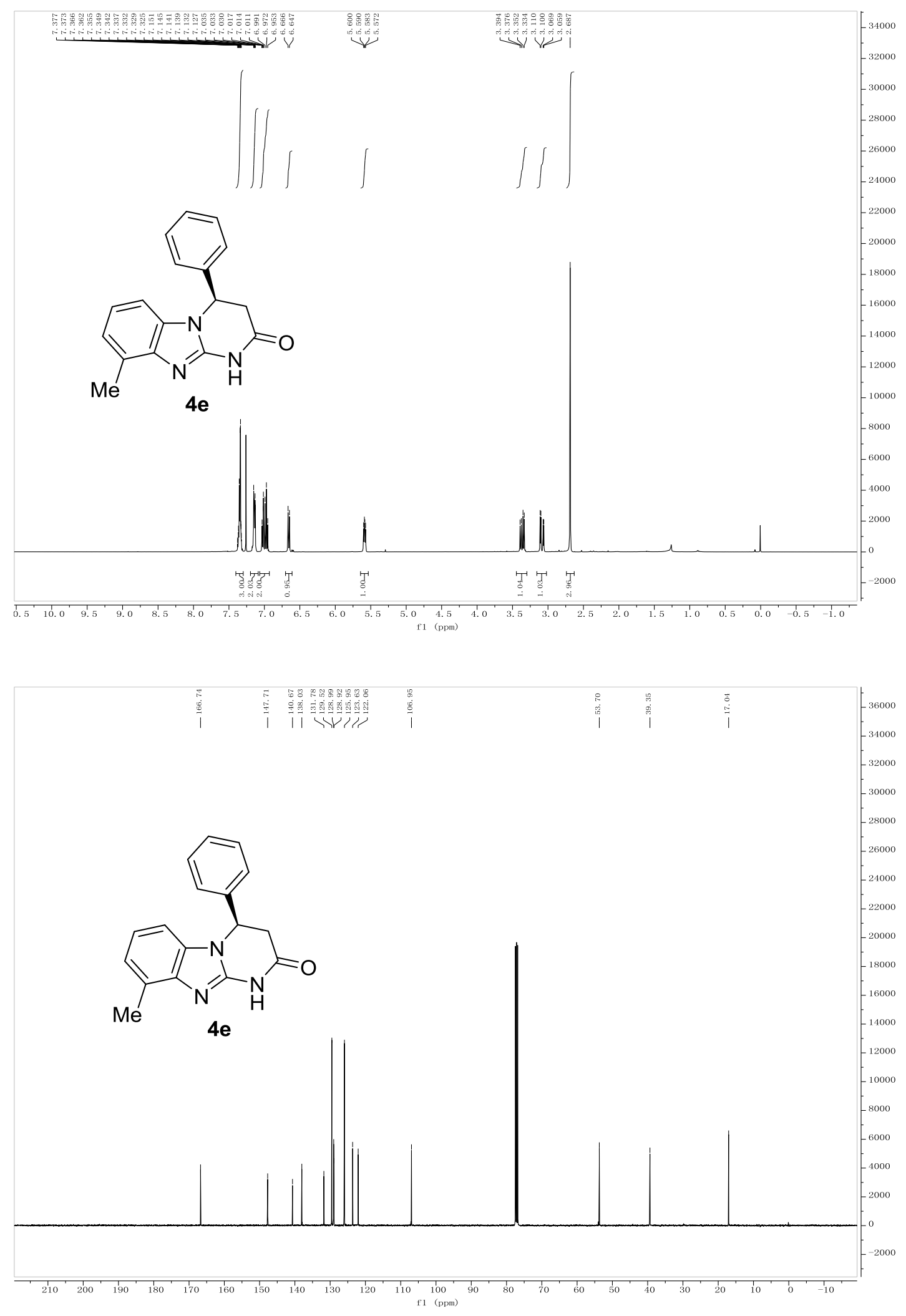

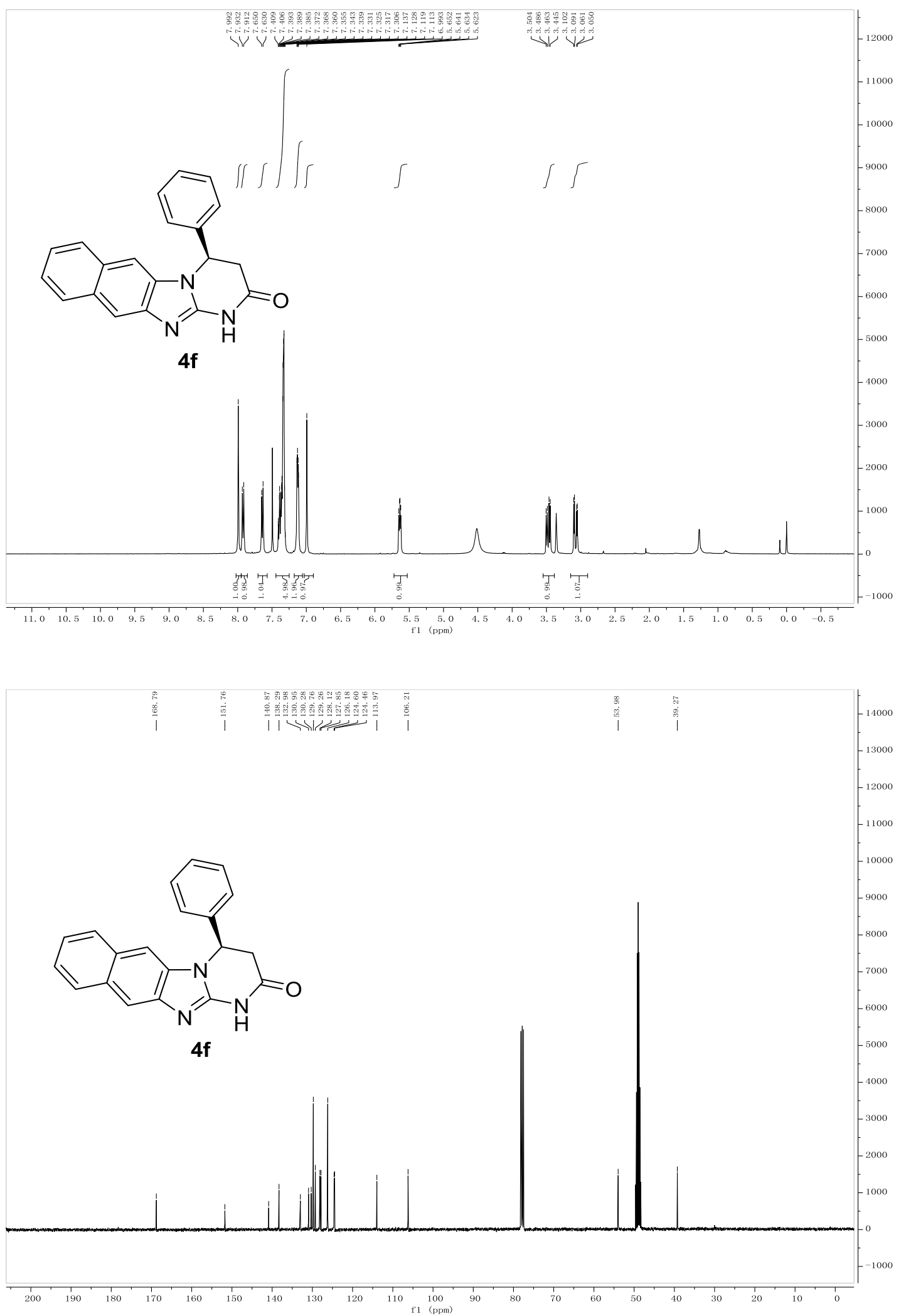

49 

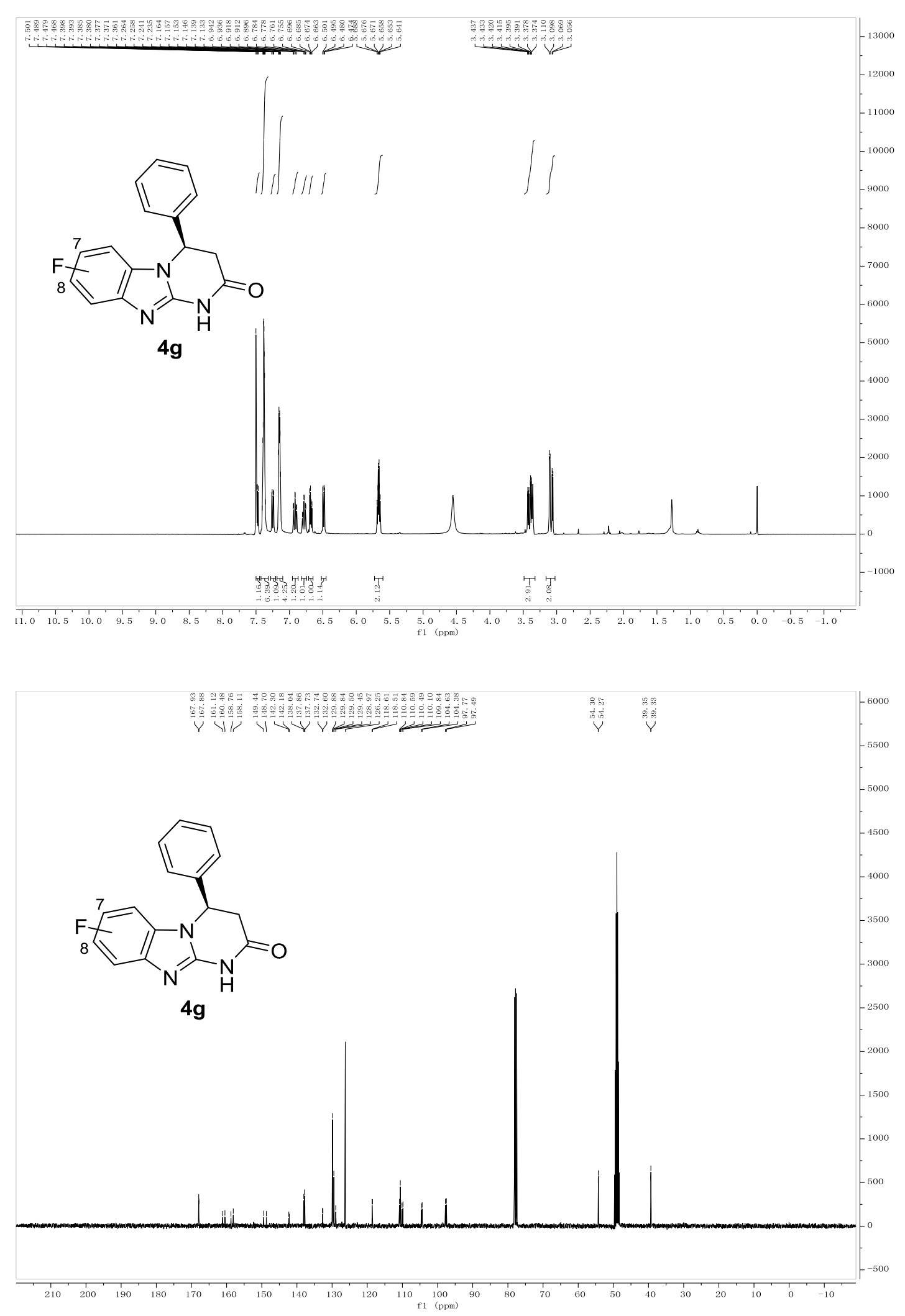


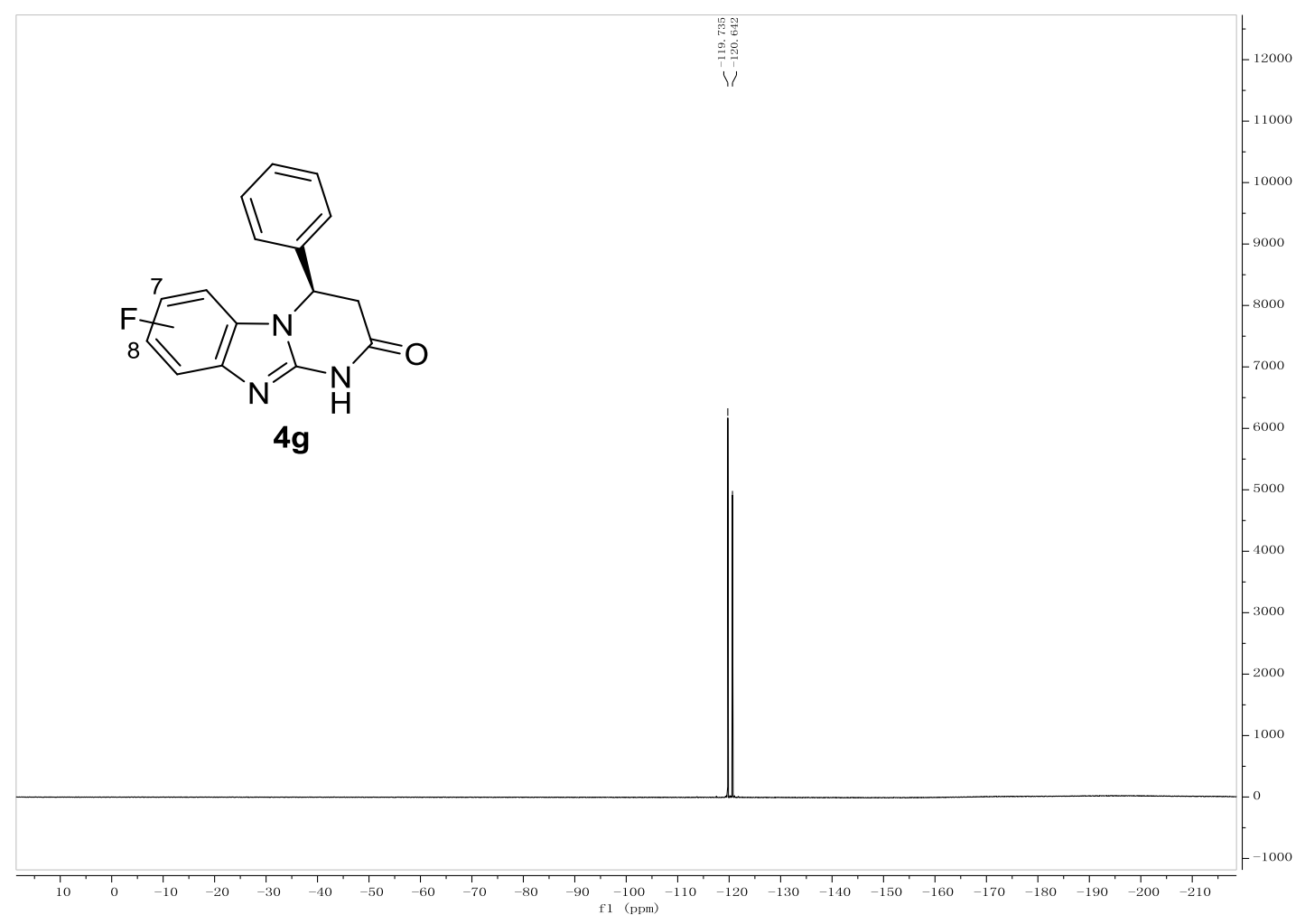



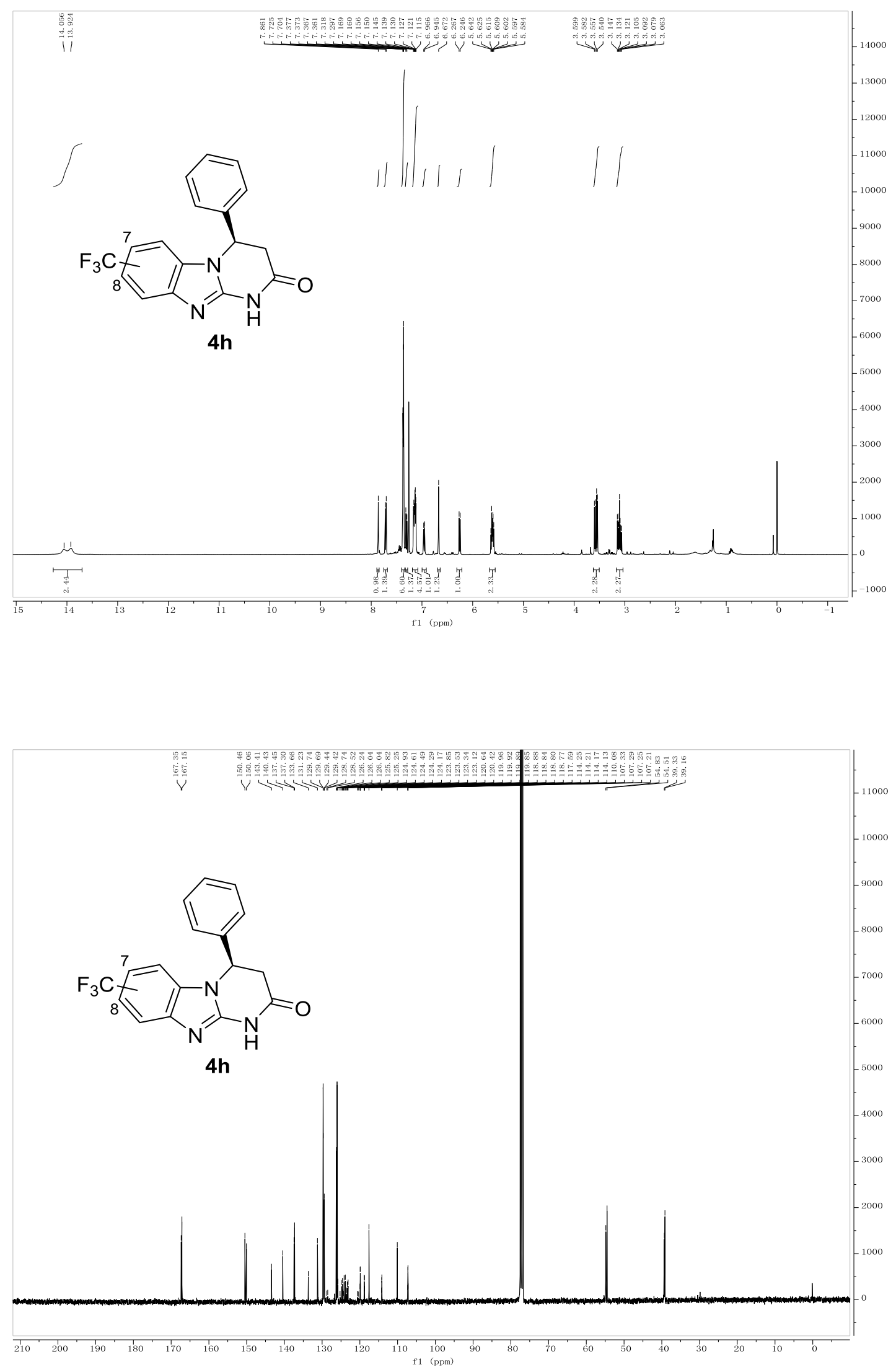


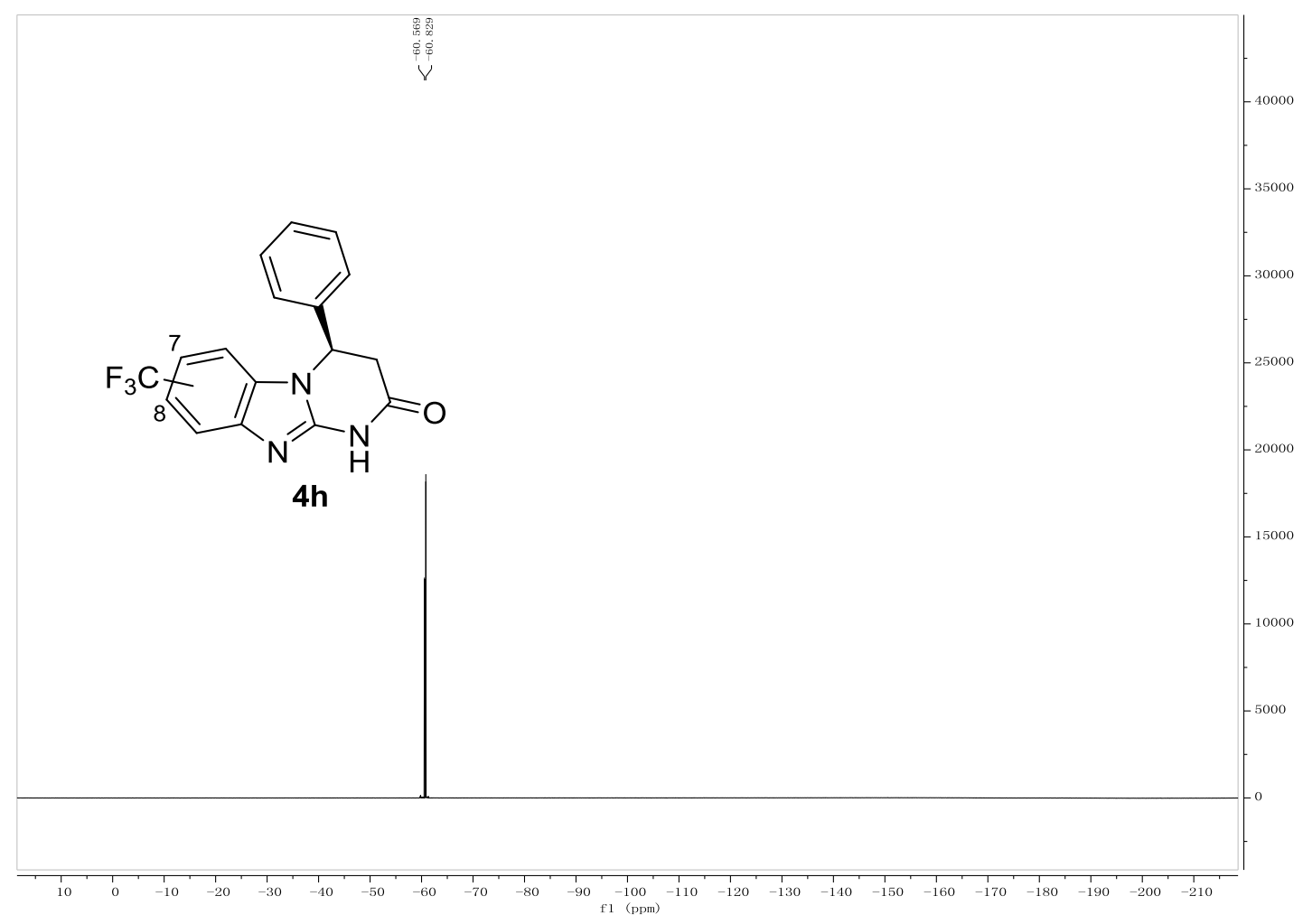




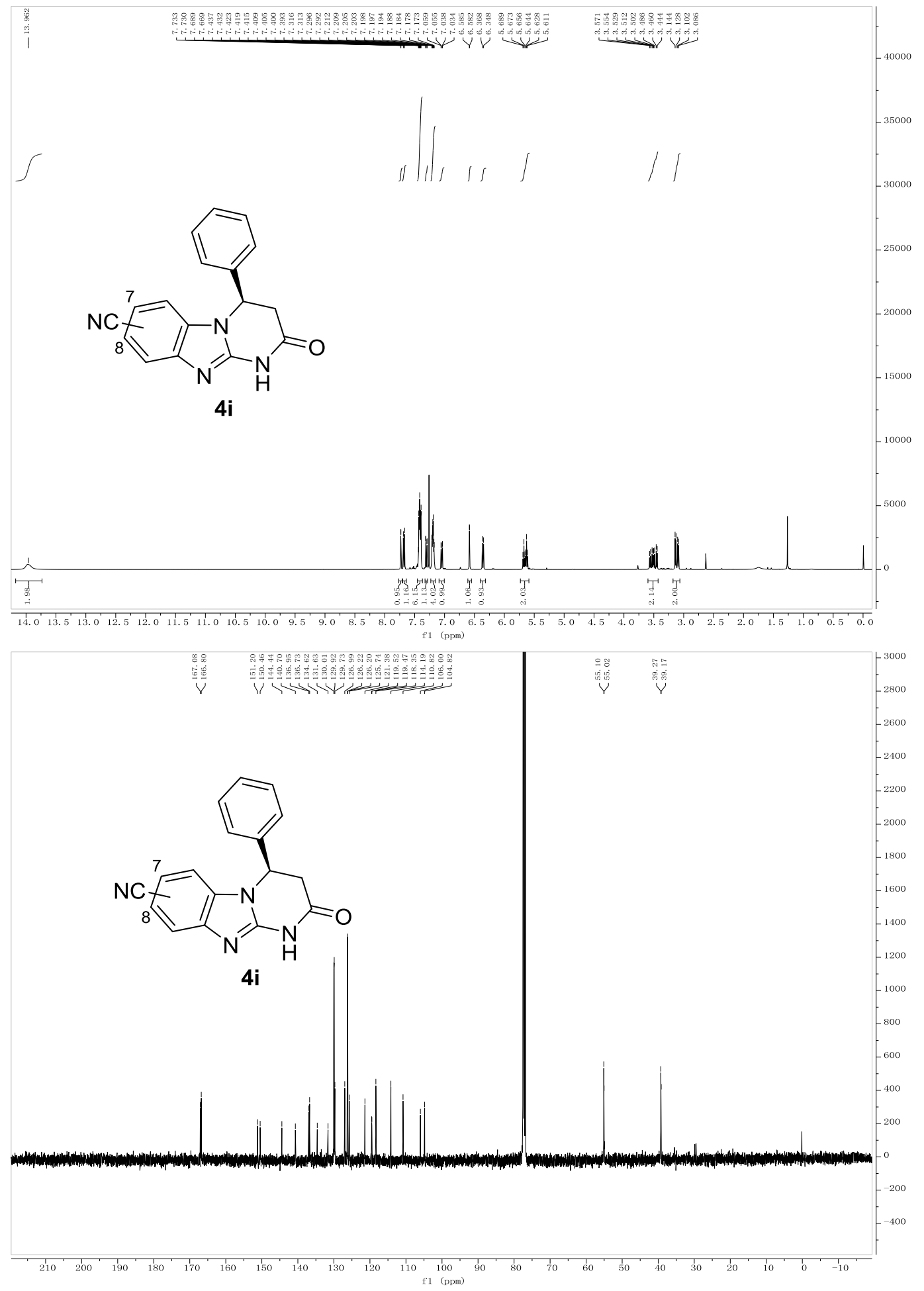




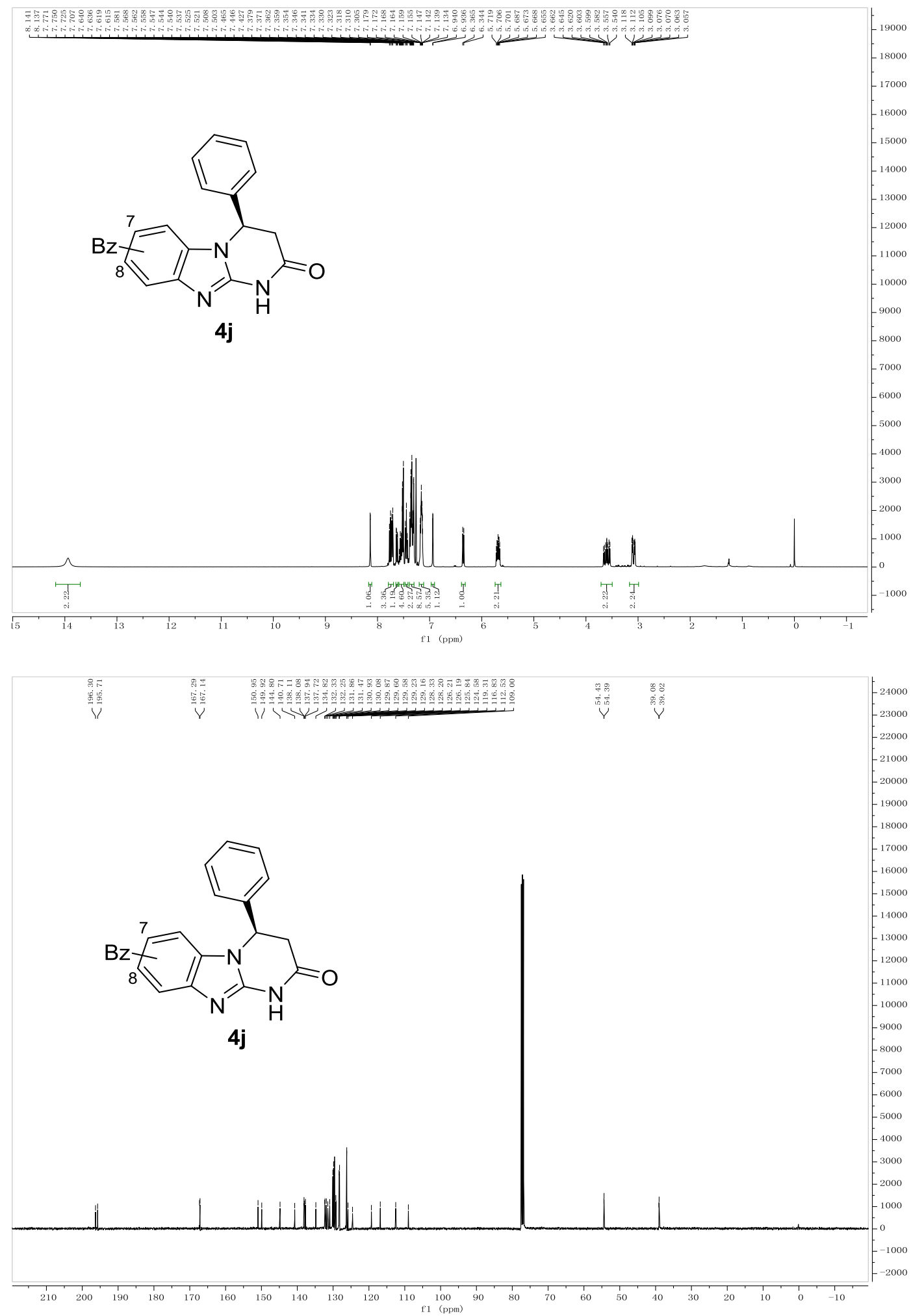




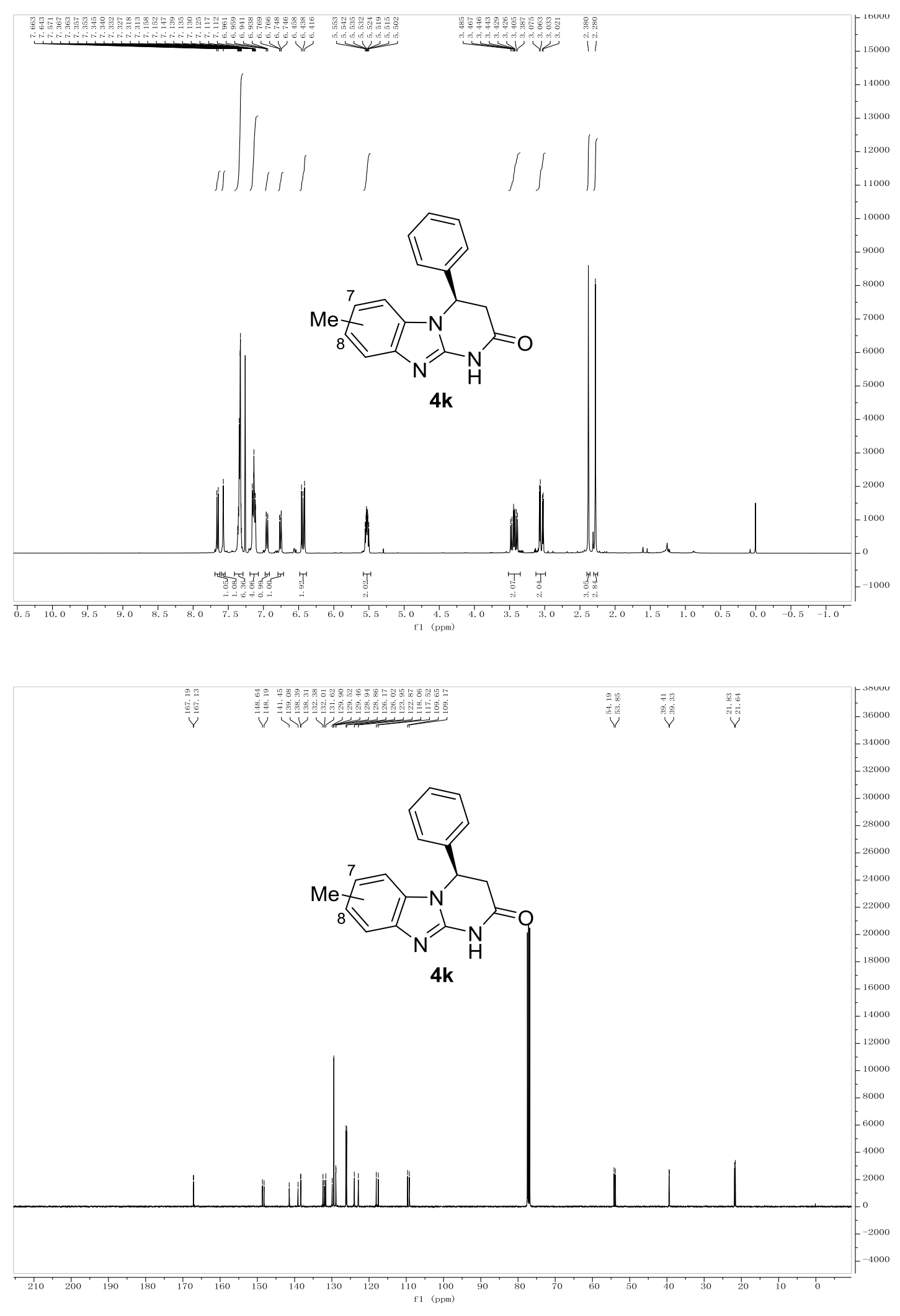



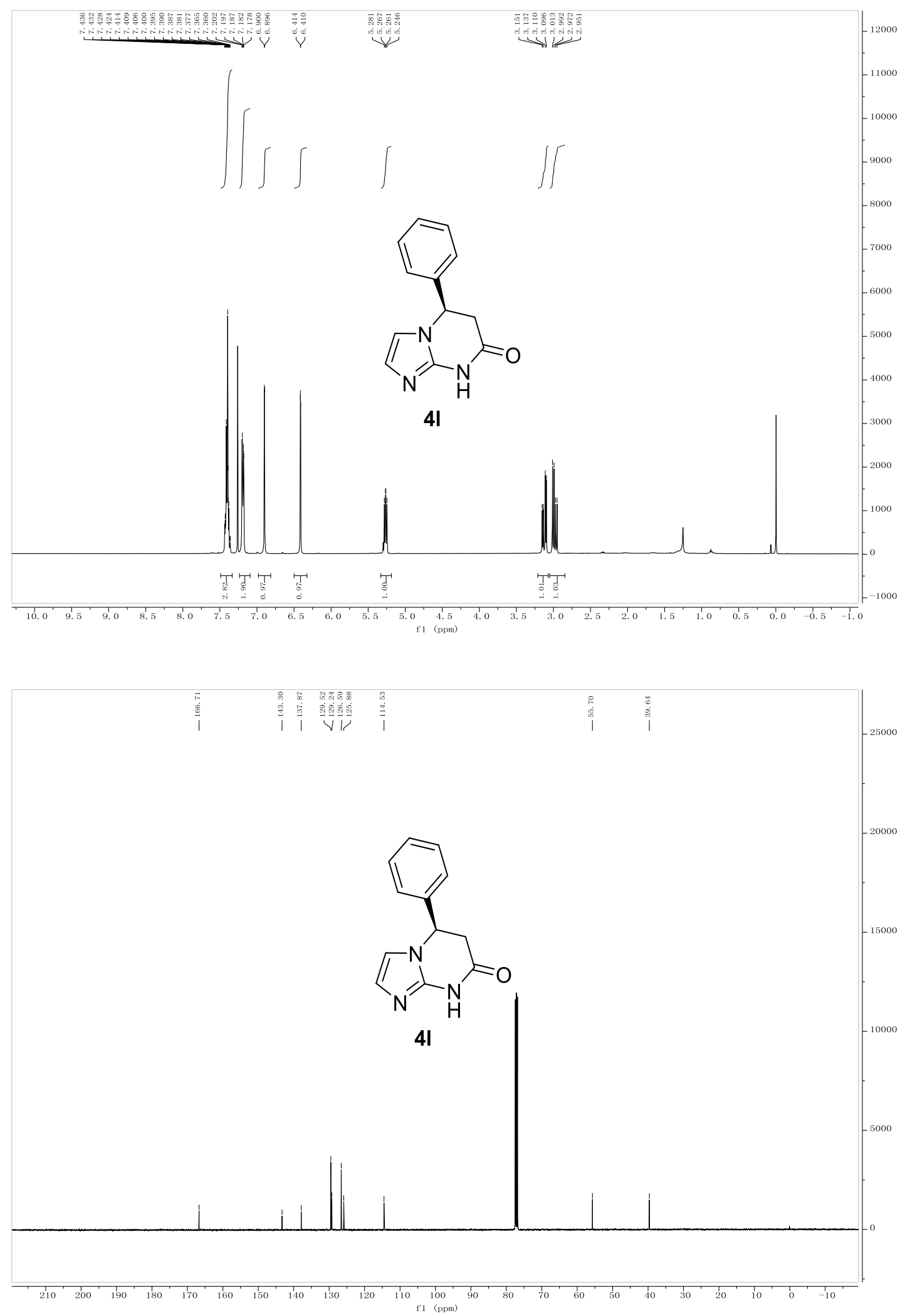


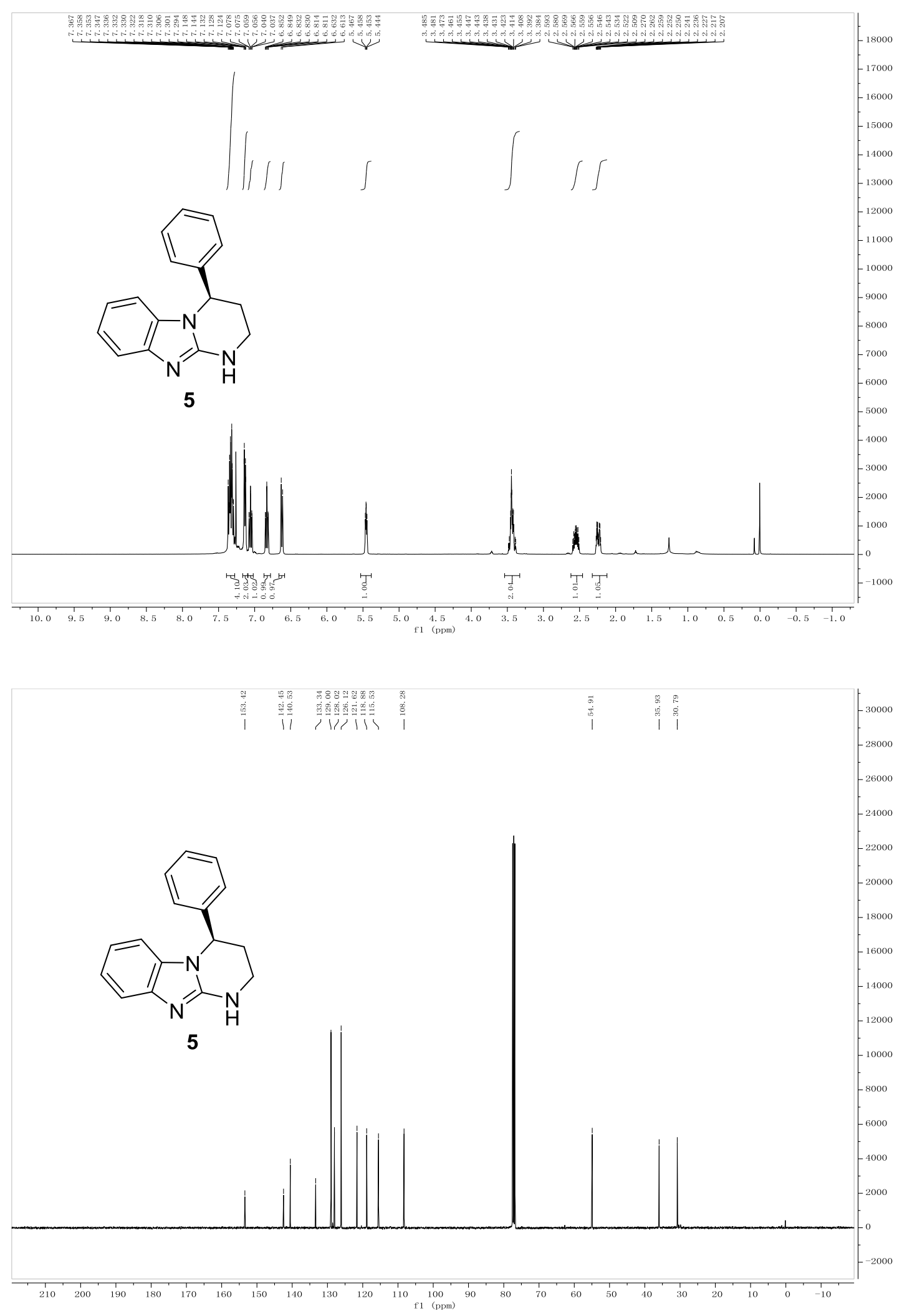




\section{HPLC Spectra}

\section{Compound 3a}

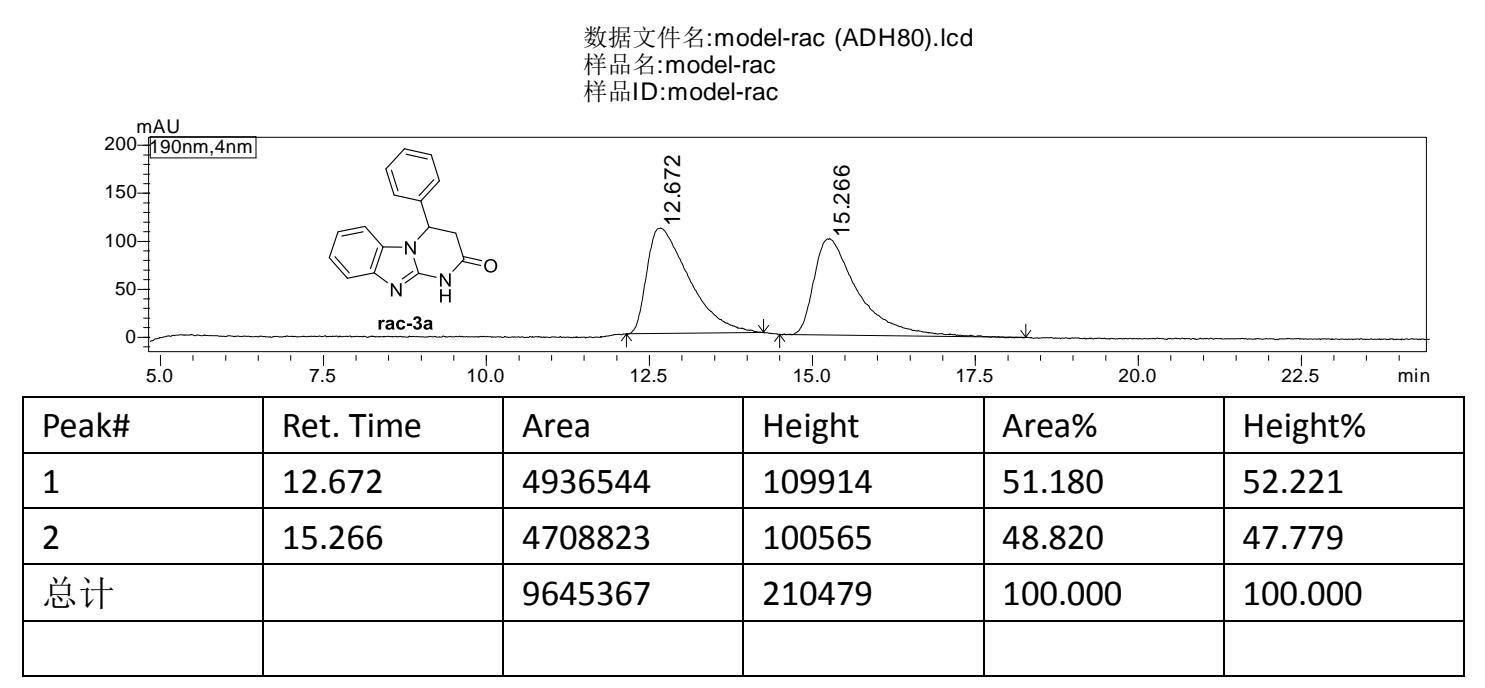

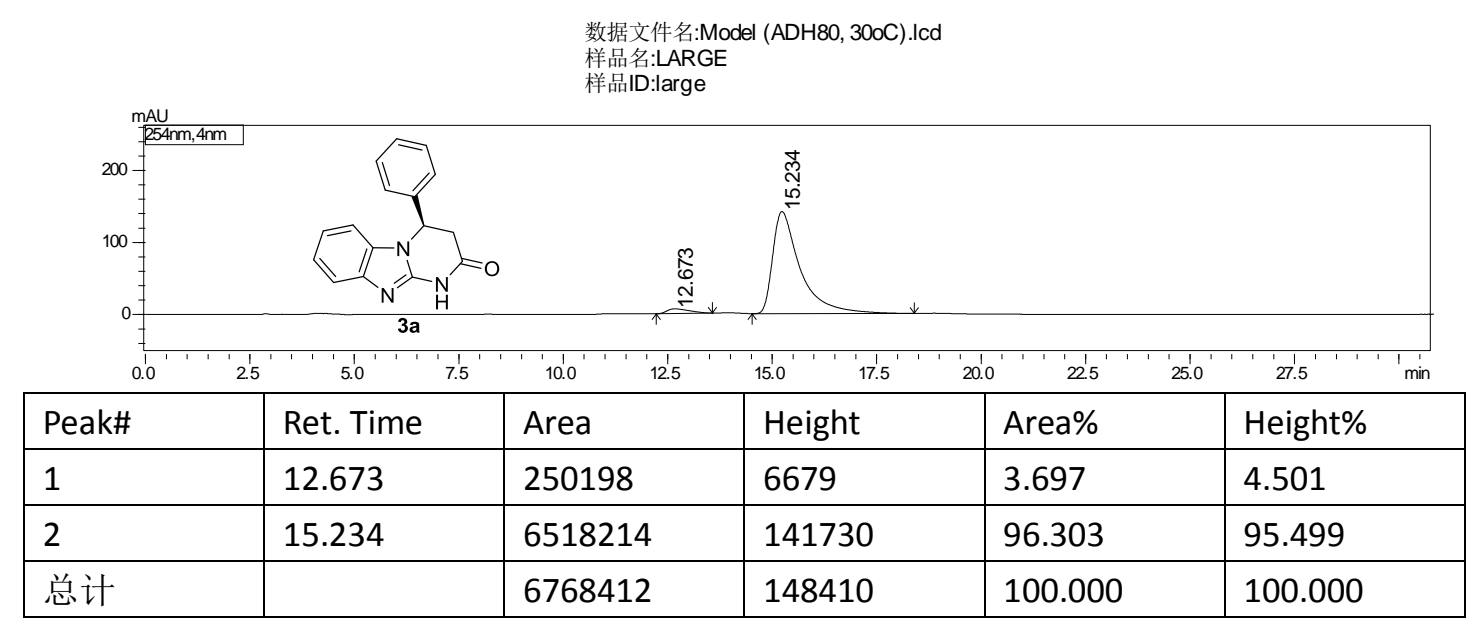




\section{Compound 3b}

数据文件名:XYX-7-88-4-Me-rac(IA80)30oC.Icd

样品名:XYX-7-88-4-Me-rac(IA80)300C

样品ID:XYX-7-88-4-Me-rac(IA80)30oC

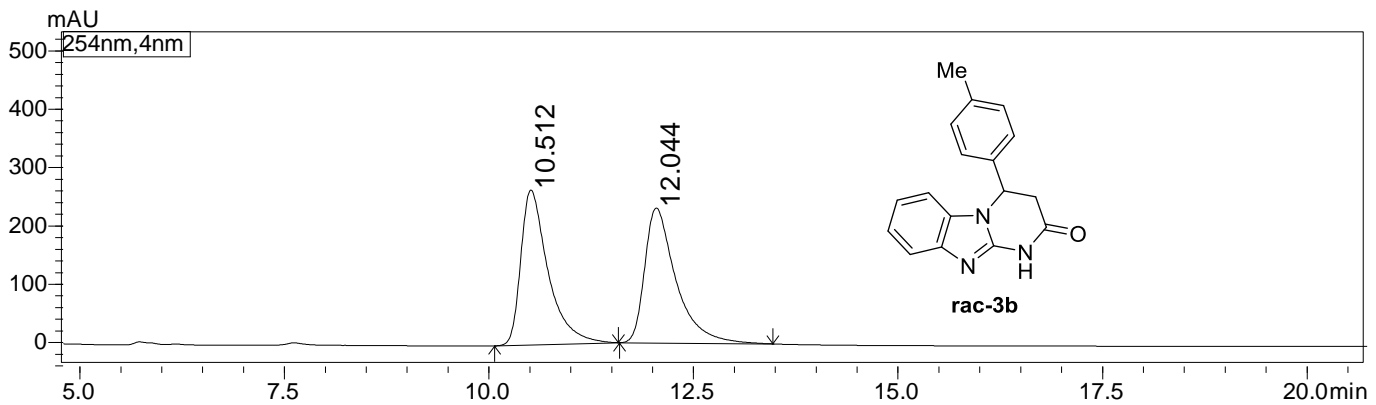

\begin{tabular}{|l|l|l|l|l|l|}
\hline Peak\# & Ret. Time & Area & Height & Area\% & Height\% \\
\hline 1 & 10.512 & 6169739 & 265632 & 49.999 & 53.432 \\
\hline 2 & 12.044 & 6169947 & 231507 & 50.001 & 46.568 \\
\hline Total & & 12339687 & 497139 & 100.000 & 100.000 \\
\hline
\end{tabular}

数据文件名:7-88-4-Me(IA80)30oC-1.Icd

样品名:XYX-7-88-4-Me(IA80)30oC

样品ID:XYX-7-88-4-Me(IA80)300C

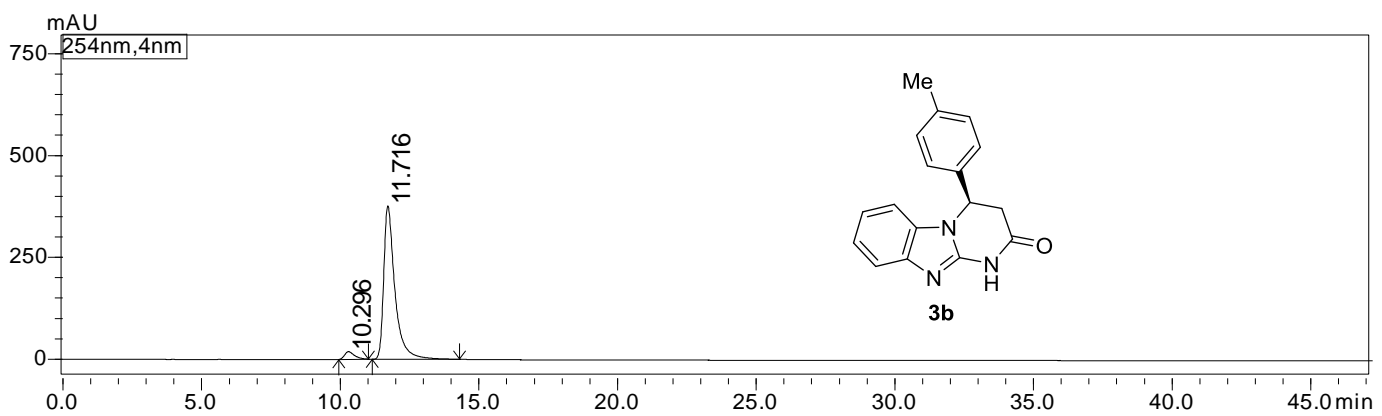

\begin{tabular}{|l|l|l|l|l|l|}
\hline Peak\# & Ret. Time & Area & Height & Area\% & Height\% \\
\hline 1 & 10.296 & 474461 & 18903 & 4.293 & 4.775 \\
\hline 2 & 11.716 & 10577261 & 376981 & 95.707 & 95.225 \\
\hline Total & & 11051721 & 395884 & 100.000 & 100.000 \\
\hline
\end{tabular}




\section{Compound 3c}

数据文件名:7-86-4-OMe-rac(IA80).Icd

样品名:7-86-4-OMe-rac(IA80)

样品ID:7-86-4-OMe-rac(IA80)

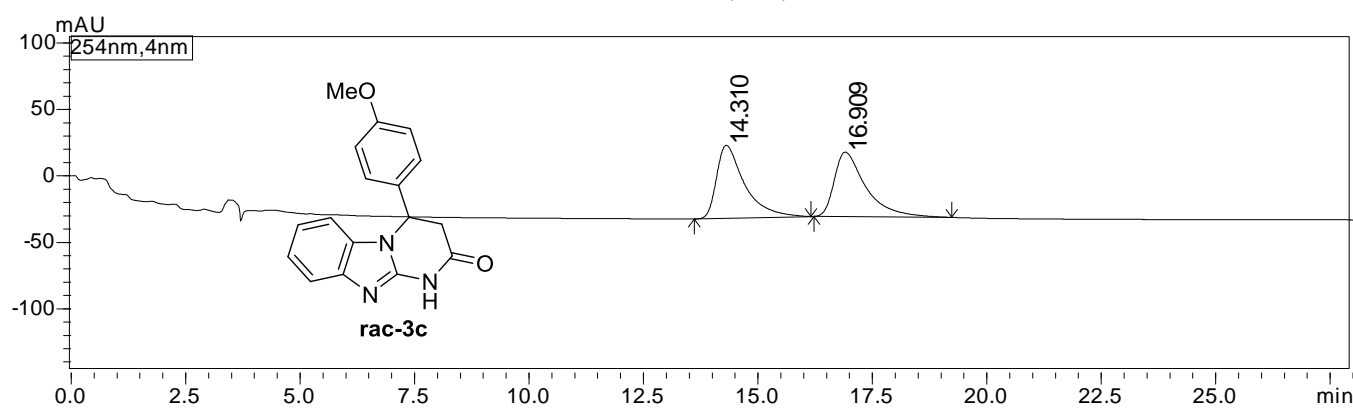

\begin{tabular}{|l|l|l|l|l|l|}
\hline Peak\# & Ret. Time & Area & Height & Area\% & Height\% \\
\hline 1 & 14.310 & 2340640 & 54864 & 50.079 & 53.036 \\
\hline 2 & 16.909 & 2333285 & 48582 & 49.921 & 46.964 \\
\hline Total & & 4673925 & 103446 & 100.000 & 100.000 \\
\hline
\end{tabular}

数据文件名:7-86-4-OMe-0.1M(IA80).Icd

样品ID:7-86-4-OMe-0.1M(IA80)

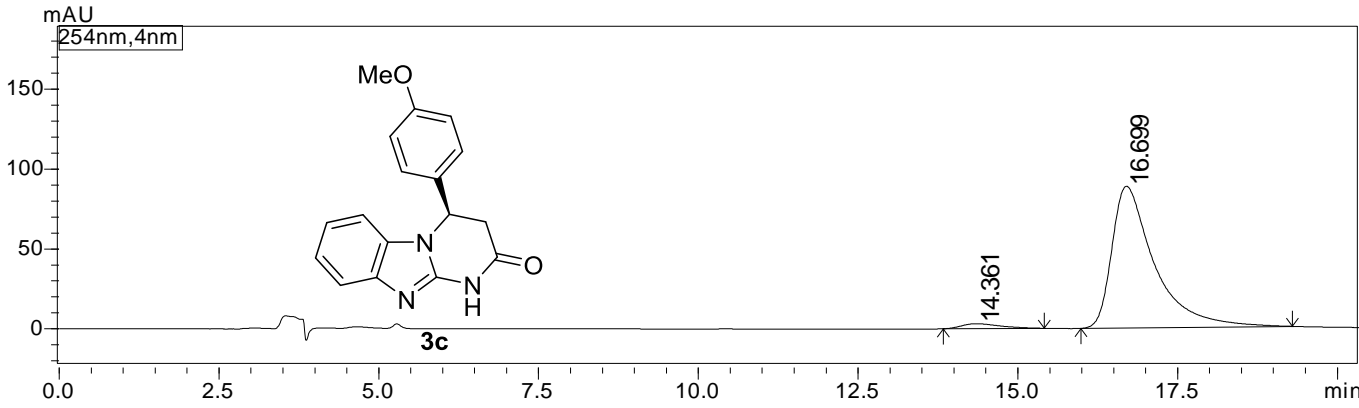

\begin{tabular}{|l|l|l|l|l|l|}
\hline Peak\# & Ret. Time & Area & Height & Area\% & Height\% \\
\hline 1 & 14.361 & 129311 & 3111 & 3.041 & 3.389 \\
\hline 2 & 16.699 & 4122988 & 88675 & 96.959 & 96.611 \\
\hline Total & & 4252298 & 91786 & 100.000 & 100.000 \\
\hline
\end{tabular}




\section{Compound 3d}

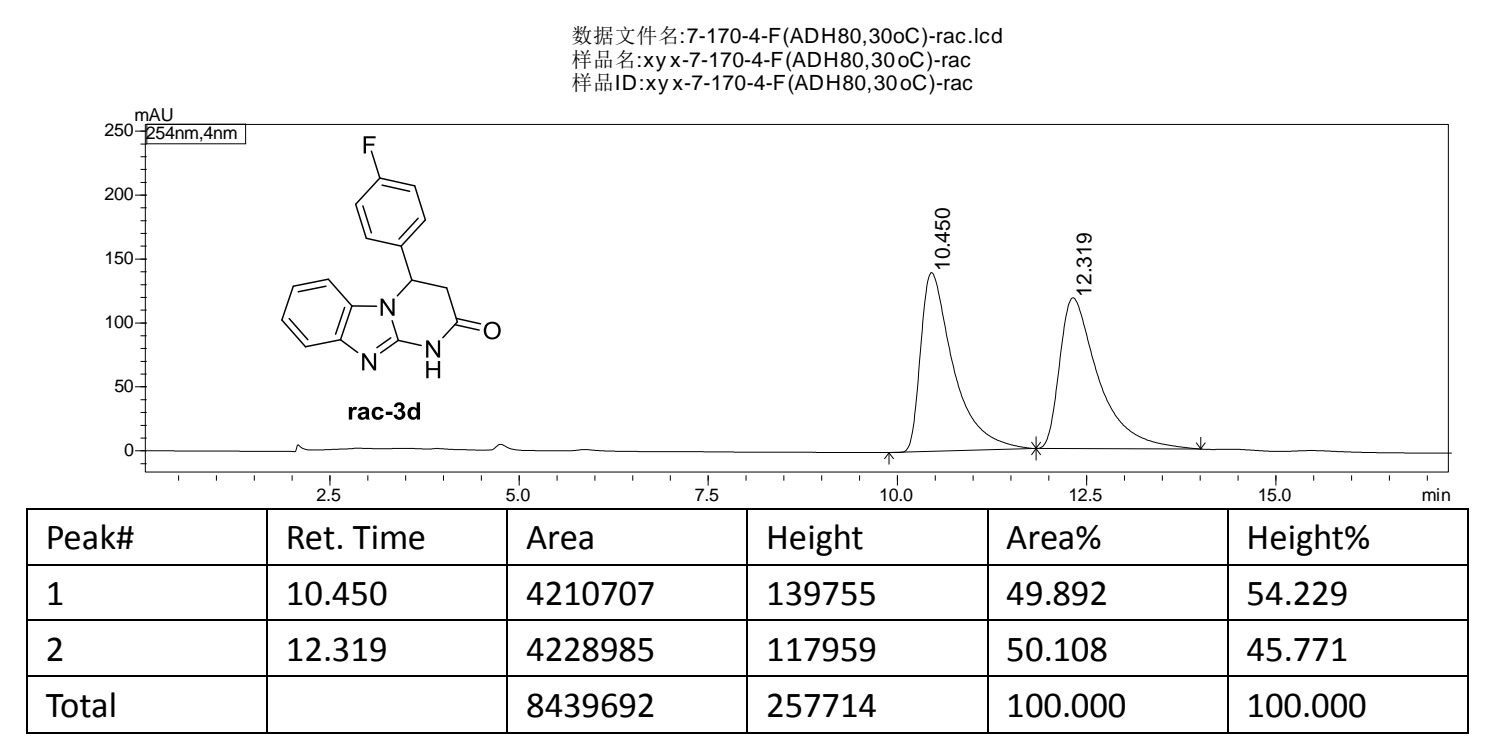

数据文件名: 7-170-4-F-chiral(ADH80,30oC). Ic d

样品名:7-170-4-F-chiral(ADH80,30oC)

\begin{tabular}{|l|l|l|l|l|l|}
\hline Peak\# & Ret. Time & Area & Height & Area\% & Height \\
\hline 1 & 10.285 & 213687 & 6533 & 3.909 & 4.552 \\
\hline 2 & 12.106 & 5252754 & 136987 & 96.091 & 95.448 \\
\hline Total & & 5466441 & 143520 & 100.000 & 100.000 \\
\hline
\end{tabular}




\section{Compound $3 e$}

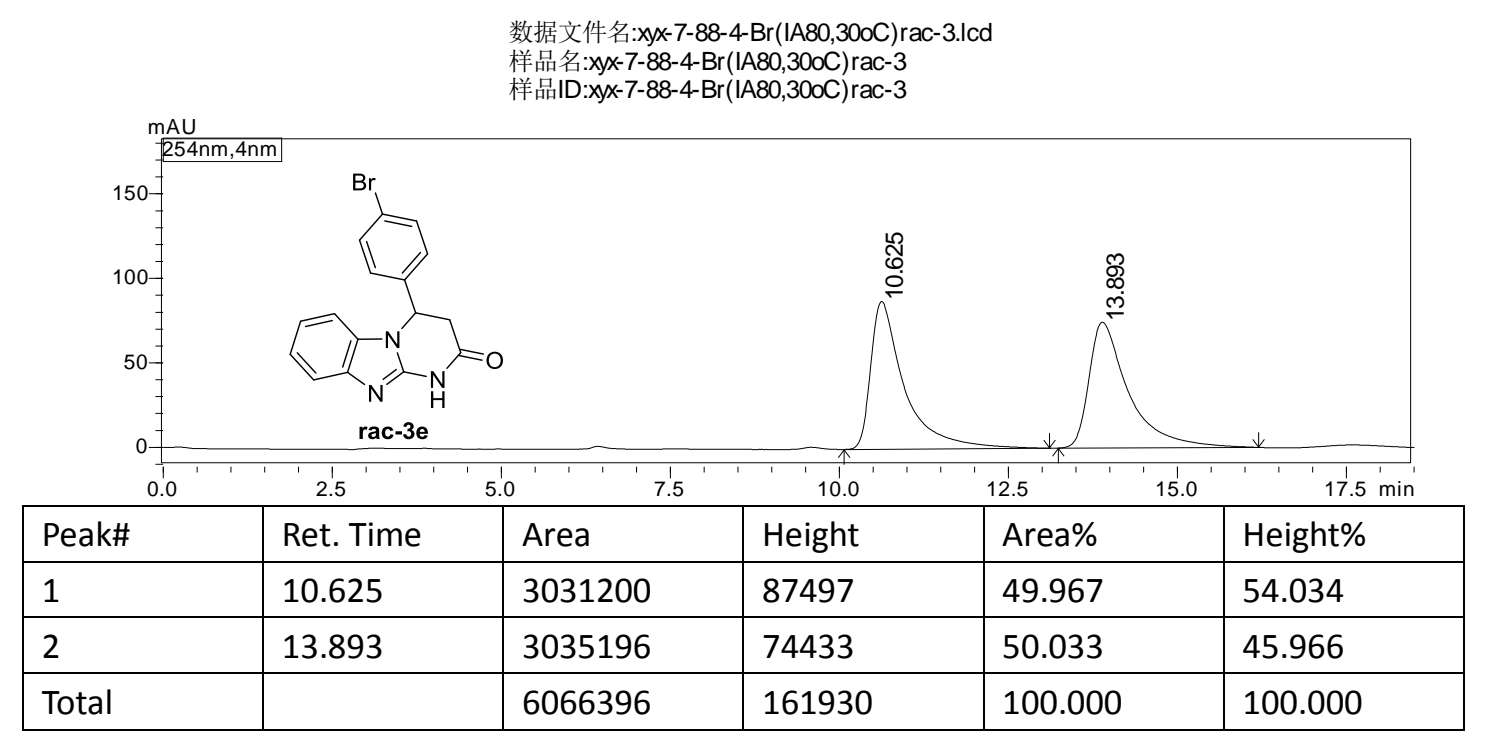

数据文件名:7-88-4- $\mathrm{Br}(\mathrm{IA} 80,30 \mathrm{oC}) \cdot \mathrm{Icd}$

样品名: $x y x-7-88-4-\mathrm{Br}(\mathrm{IA} 80,30 \mathrm{OC})$

样品ID:xyx-7-88-4-Br(IA80,30oC)

\begin{tabular}{|l|l|l|l|l|l|}
\hline Peak\# & Ret. Time & Area & Height & Area\% & Height\% \\
\hline 1 & 10.745 & 631095 & 19368 & 4.595 & 4.952 \\
\hline 2 & 13.840 & 13104680 & 371724 & 95.405 & 95.048 \\
\hline Total & & 13735775 & 391092 & 100.000 & 100.000 \\
\hline
\end{tabular}




\section{Compound $3 f$}
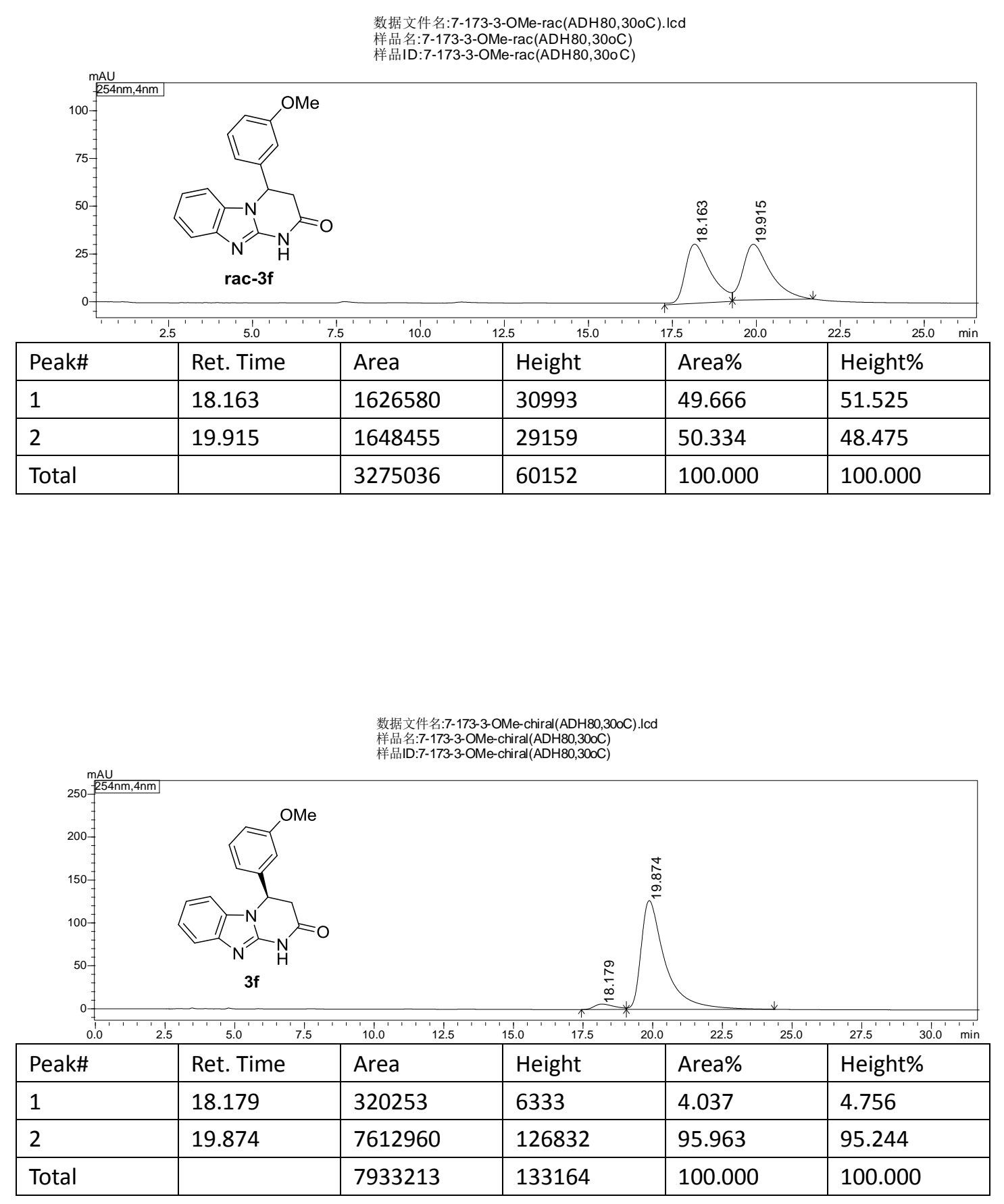


\section{Compound 3g}

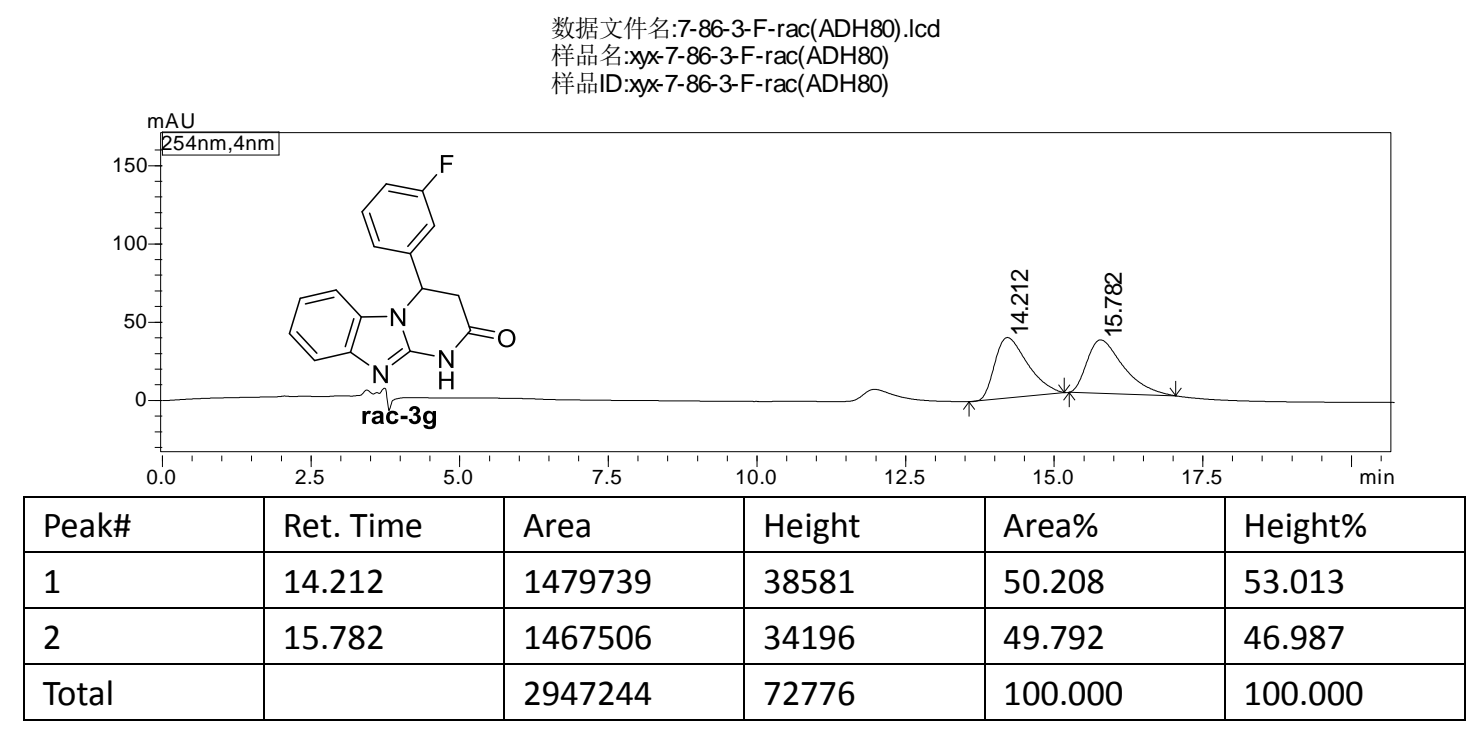

数据文件名:7-86-3-F(ADH80).Icd

样品名: $x y x-7-86-3-F(A D H 80)$

样品ID:Xyx-7-86-3-F(ADH80)

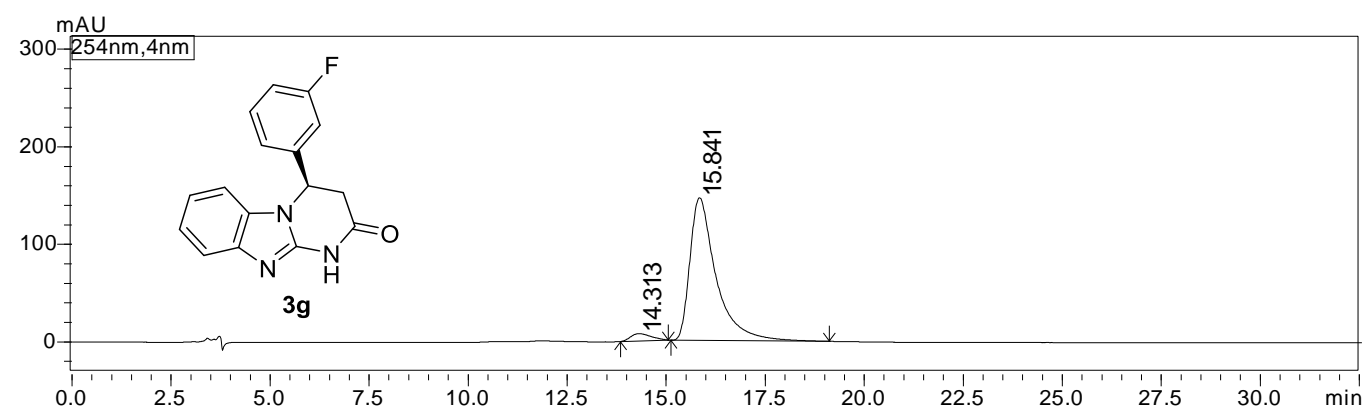

\begin{tabular}{|l|l|l|l|l|l|}
\hline Peak\# & Ret. Time & Area & Height & Area\% & Height\% \\
\hline 1 & 14.313 & 267888 & 7524 & 3.827 & 4.888 \\
\hline 2 & 15.841 & 6731590 & 146385 & 96.173 & 95.112 \\
\hline Total & & 6999478 & 153909 & 100.000 & 100.000 \\
\hline
\end{tabular}




\section{Compound 3h}
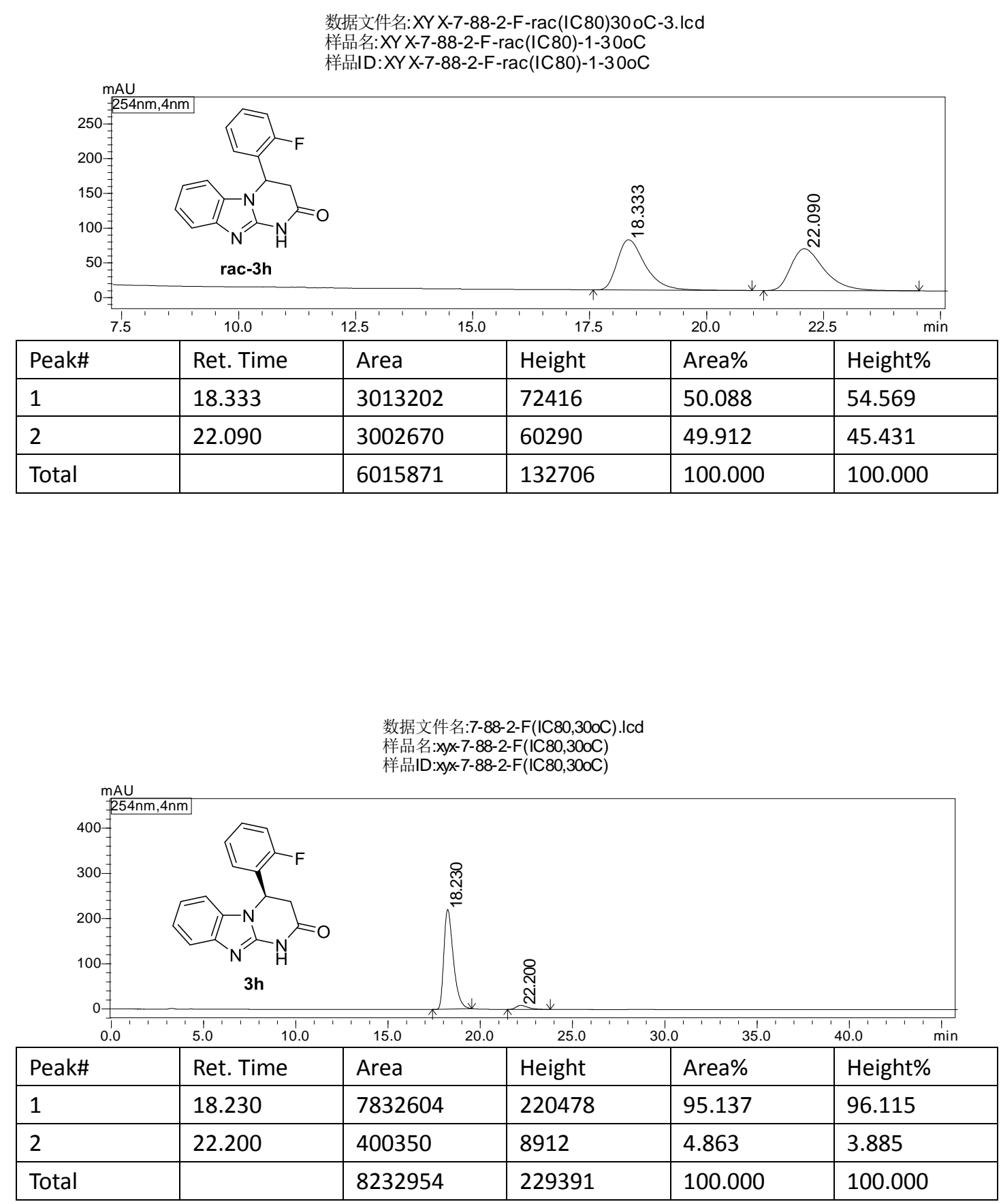


\section{Compound $3 \mathrm{i}$}

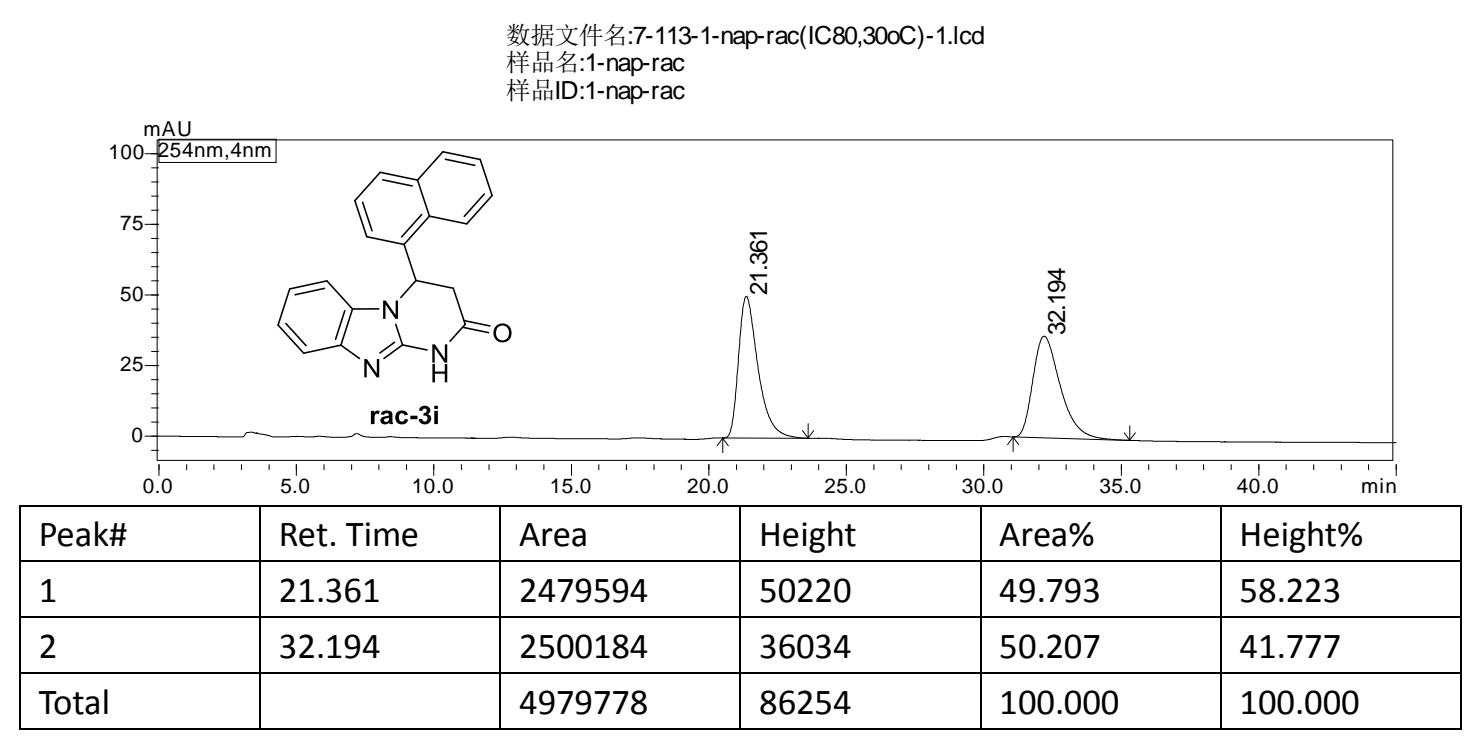

数据文件名:7-113-1-nap-CHIRAL(IC80,30oC)-1.Icd

\begin{tabular}{|l|l|l|l|l|l|}
\hline \multicolumn{1}{|c|}{ Peak\# } & Ret. Time & Area & Height & Area\% & Height\% \\
\hline 1 & 21.263 & 6159128 & 126817 & 93.006 & 94.970 \\
\hline 2 & 32.344 & 463174 & 6716 & 6.994 & 5.030 \\
\hline Total & & 6622302 & 133533 & 100.000 & 100.000 \\
\hline
\end{tabular}




\section{Compound 3j}

数据文件名:7-101-2-NAPZ-rac(ADH90)30oC.Icd

样品名:XYX-7-101-2-NAP-rac(ADH90)30oC

样品ID:XYX-7-101-2-NAP-rac(ADH90)30

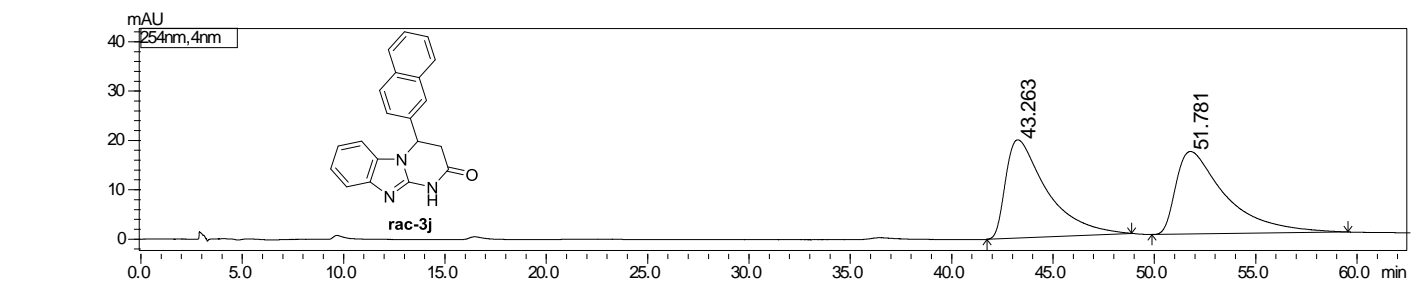

\begin{tabular}{|l|l|l|l|l|l|}
\hline Peak\# & Ret. Time & Area & Height & Area\% & Height\% \\
\hline 1 & 43.263 & 2818993 & 19921 & 49.671 & 54.336 \\
\hline 2 & 51.781 & 2856377 & 16742 & 50.329 & 45.664 \\
\hline Total & & 5675370 & 36663 & 100.000 & 100.000 \\
\hline
\end{tabular}

数据文件名:7-101-2-NAPZ-chiral(ADH90)30oC.Icd

样品名:XYX-7-101-2-NAP-chiral(ADH90)300C

样品ID:XYX-7-101-2-NAP-chiral(ADH90)30

\begin{tabular}{|l|l|l|l|l|l|}
\hline Peak\# & Ret. Time & Area & Height & Area\% & Height\% \\
\hline 1 & 42.216 & 35797536 & 283607 & 96.695 & 96.834 \\
\hline 2 & 51.449 & 1223377 & 9271 & 3.305 & 3.166 \\
\hline Total & & 37020913 & 292878 & 100.000 & 100.000 \\
\hline
\end{tabular}




\section{Compound 3k}

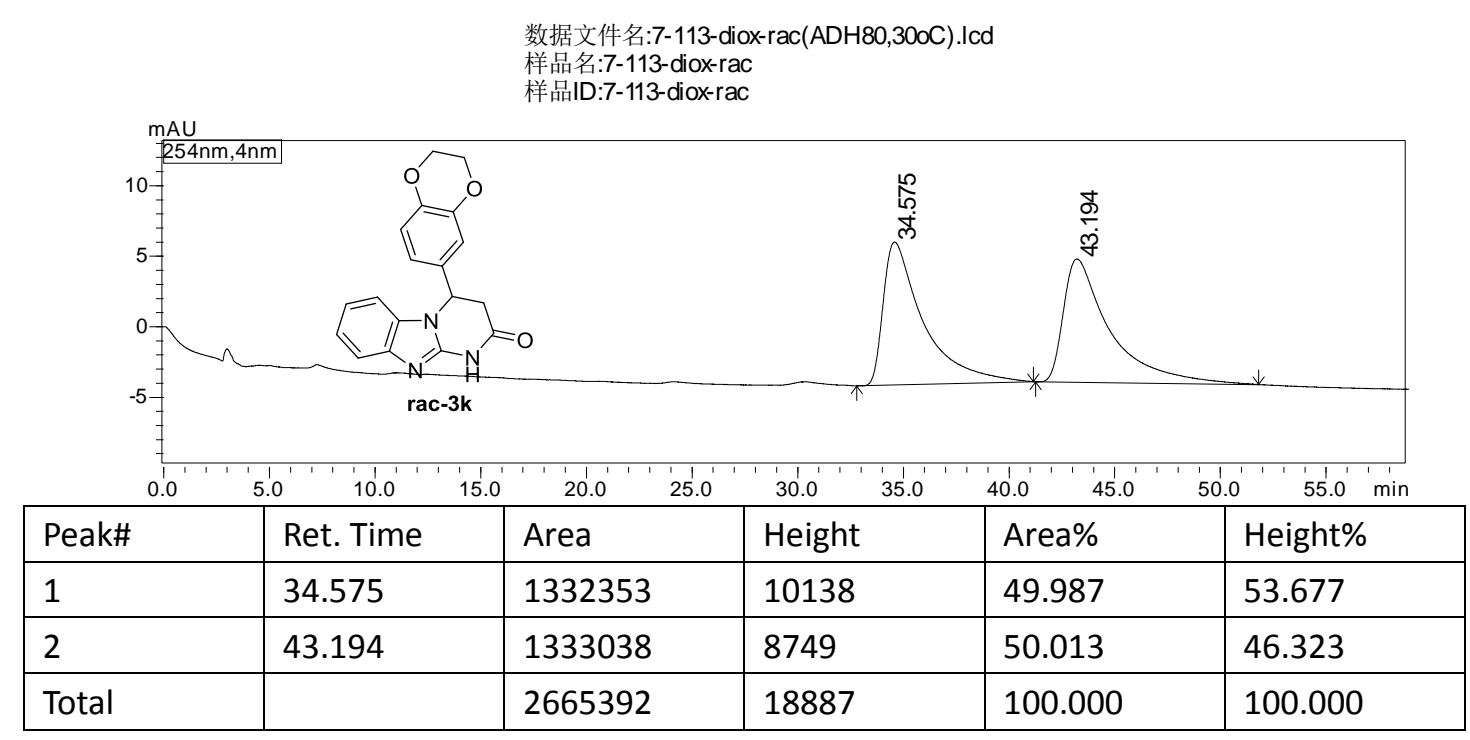

数据文件名:7-113-diox-chiral(ADH80,30oC).Icc

样品名:XYX-7-113-diox-chiral(ADH80,30oC)

样品ID:XYX-7-113-diox-chiral(ADH80,300

\begin{tabular}{|l|l|l|l|l|l|}
\hline Peak\# & Ret. Time & Area & Height & Area\% & Height\% \\
\hline 1 & 34.989 & 212809 & 2037 & 1.514 & 1.911 \\
\hline 2 & 43.125 & 13843586 & 104515 & 98.486 & 98.089 \\
\hline Total & & 14056395 & 106551 & 100.000 & 100.000 \\
\hline
\end{tabular}




\section{Compound 31}

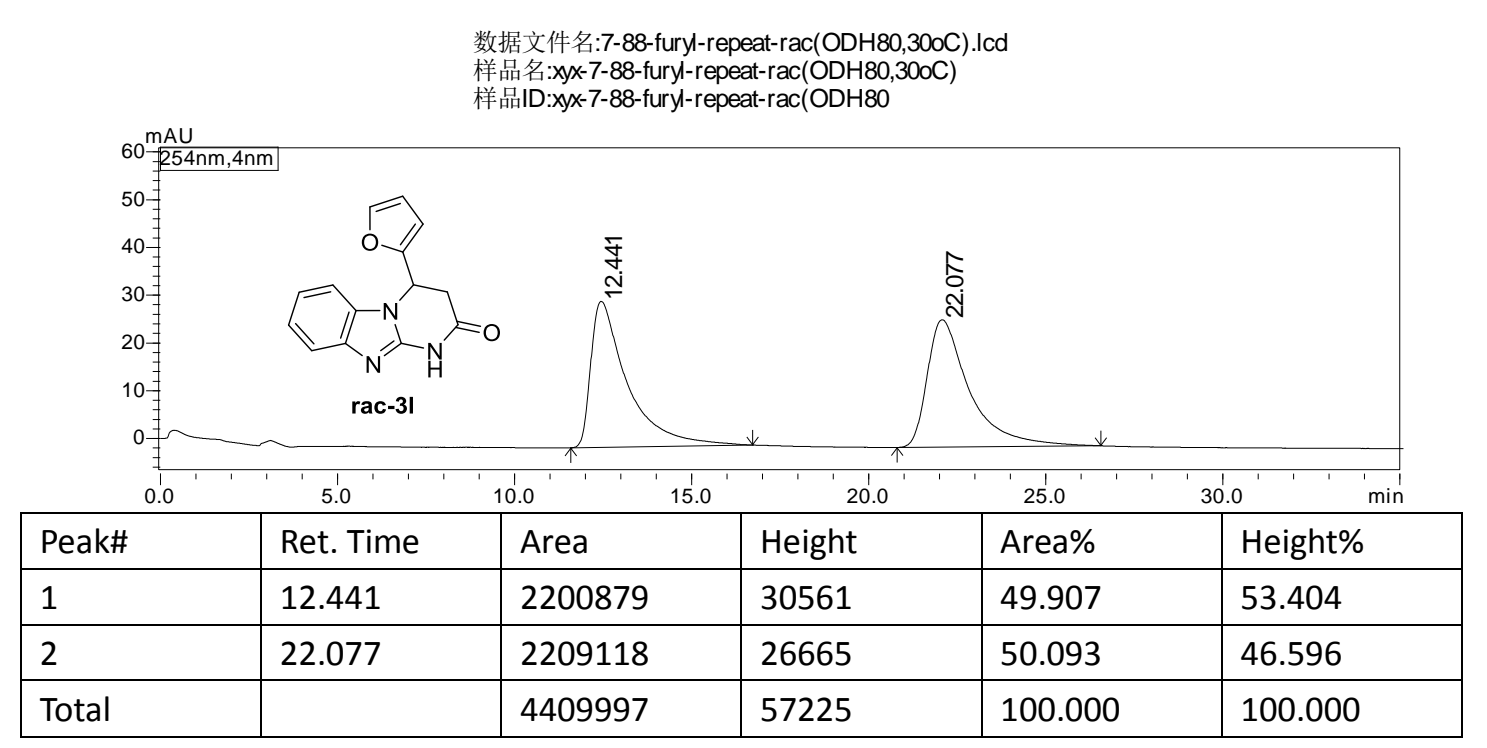

数据文件名:7-88-furyl-repeat-chiral(ODH80,30oC).Icd

样品名:xyx-7-88-furyl-repeat-chiral(ODH80,30oC)

样品ID:xyx-7-88-furyl-repeat-chiral(OD

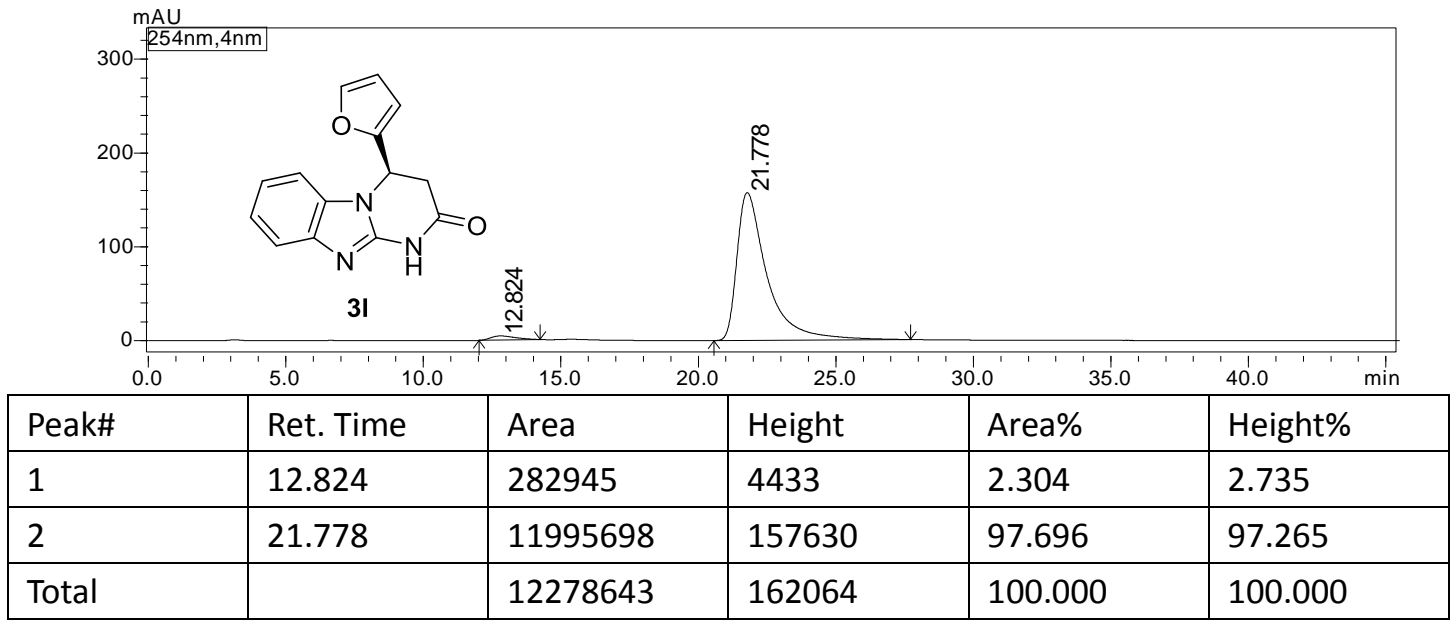




\section{Compound 3m}

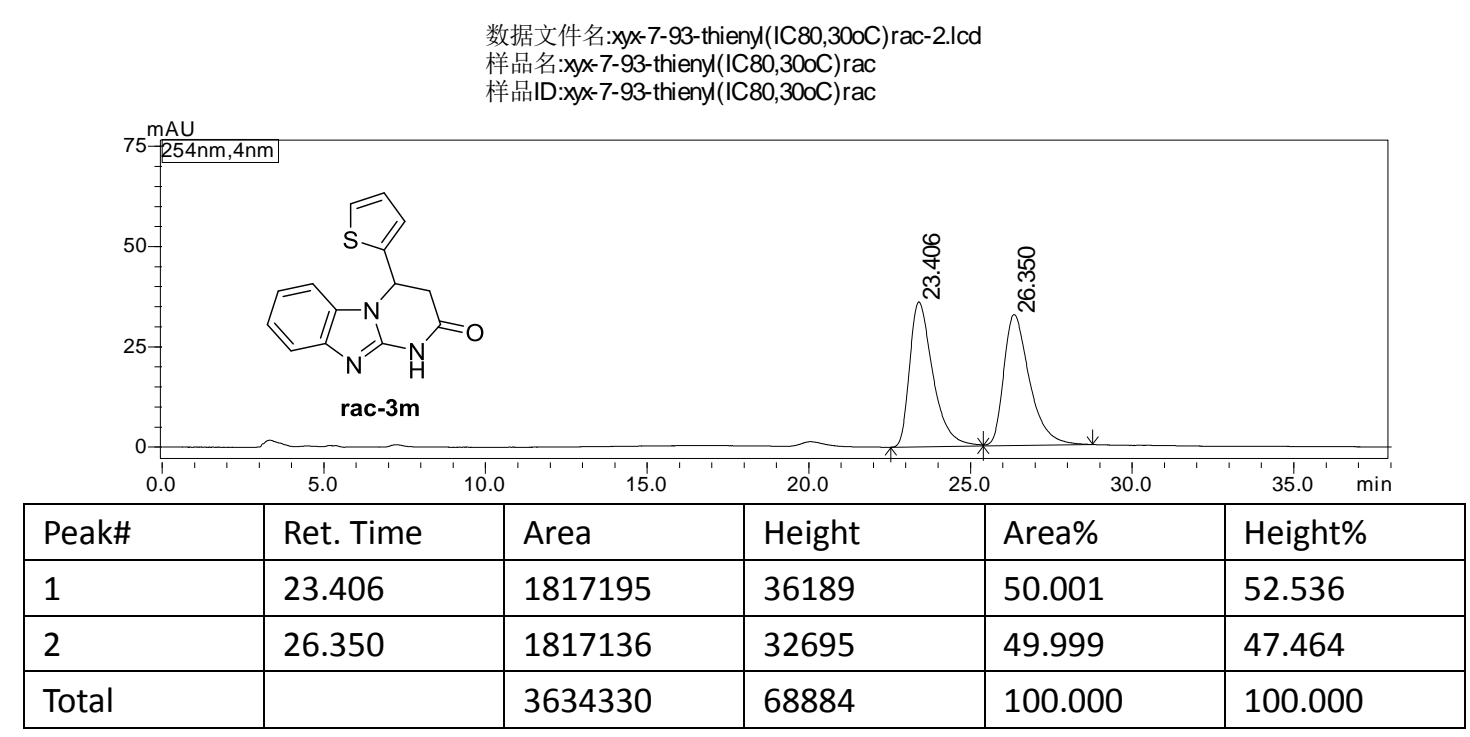

数据文件名:xyx-7-93-thienyl(IC80,30oC).Icd

样品名: xyx-7-93-thienyl(IC80,300C)

样品ID:xyx-7-93-thienyl(IC80,30oC)

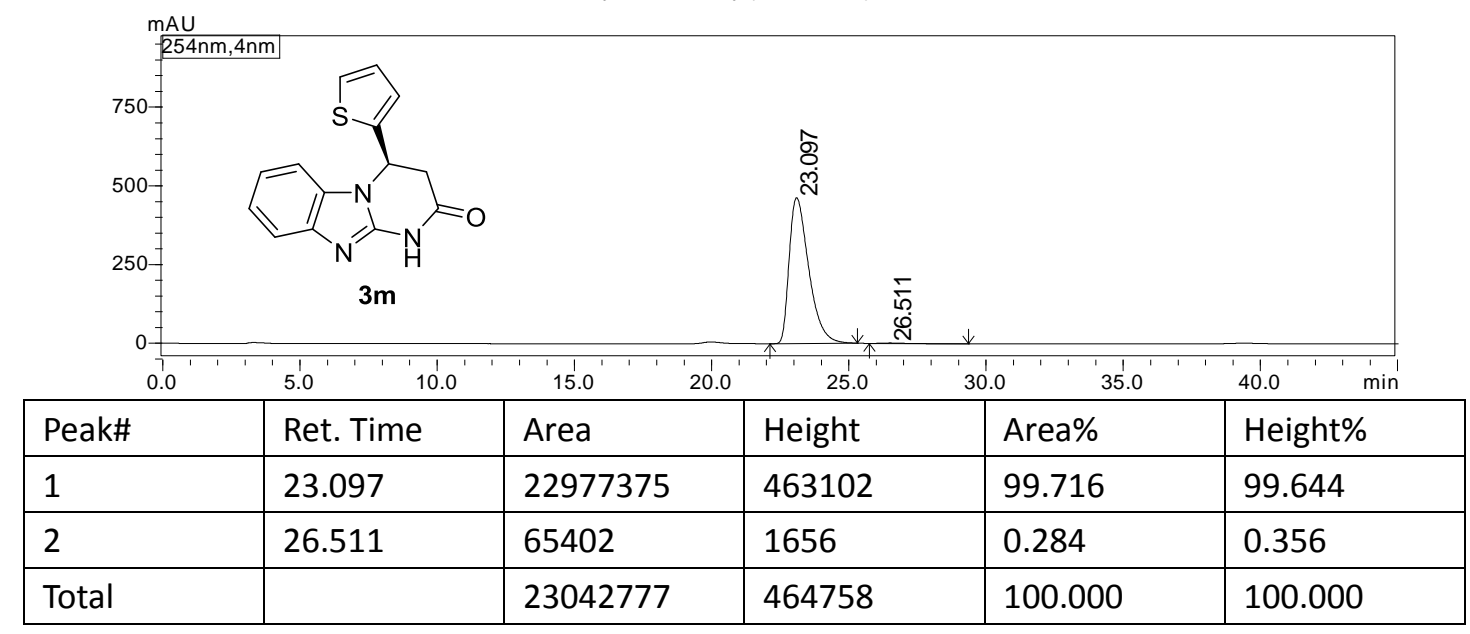




\section{Compound 3n}

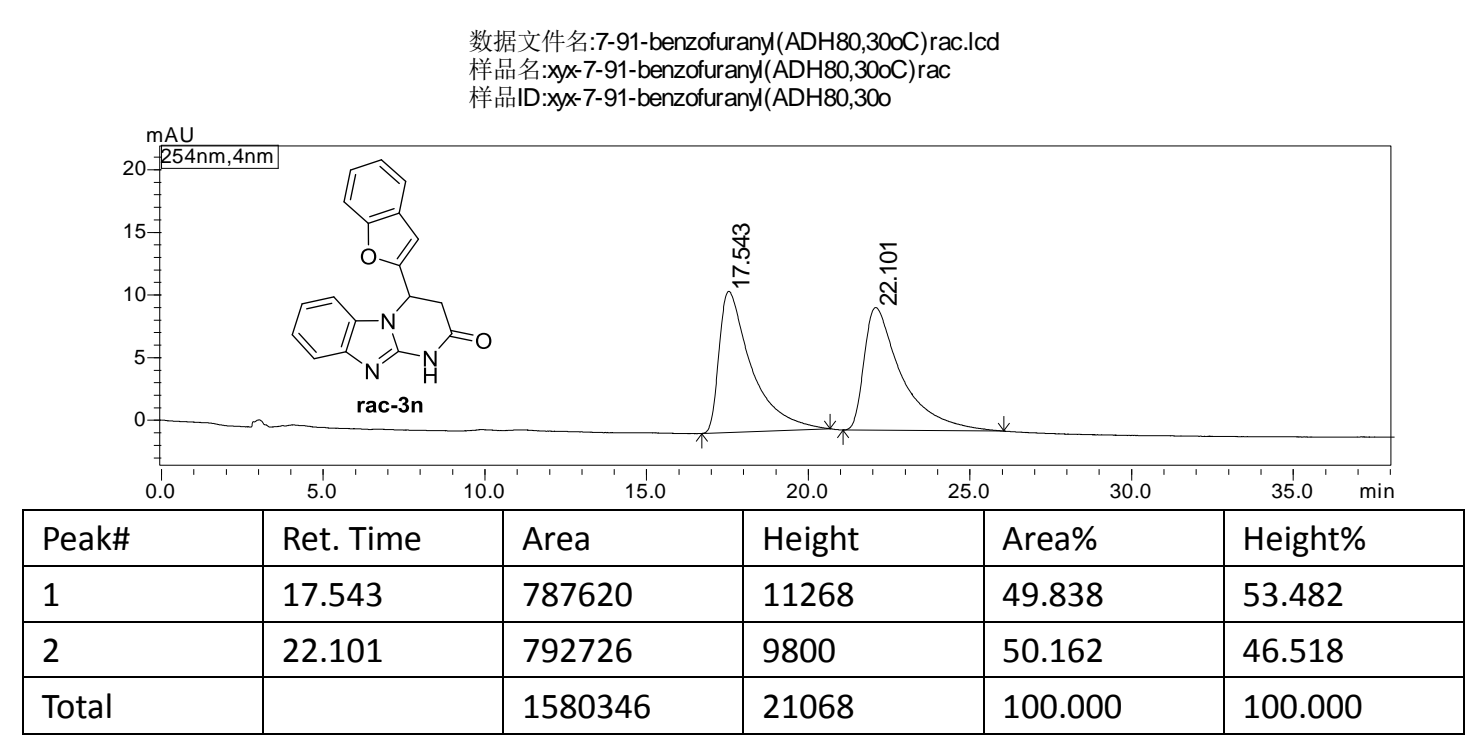

数据文件名:7-91-benzofuranyl(ADH80,30oC).Icd

样品名:xyx-7-91-benzofuranyl(ADH80,30oC)

样品ID:xyx-7-91-benzofuranyl(ADH80,30o

\begin{tabular}{|l|l|l|l|l|l|}
\hline \\
\hline Peak\# & Ret. Time & Area & Height & Area & Height \\
\hline 1 & 16.827 & 24383187 & 380816 & 95.897 & 95.479 \\
\hline 2 & 21.841 & 1043120 & 18034 & 4.103 & 4.521 \\
\hline Total & & 25426307 & 398850 & 100.000 & 100.000 \\
\hline
\end{tabular}




\section{Compound 3o}

数据文件名:7-118-CO2Et(ID80)-rac.Icd

样品名:CO2Et-rac

样品ID:CO2Et-rac

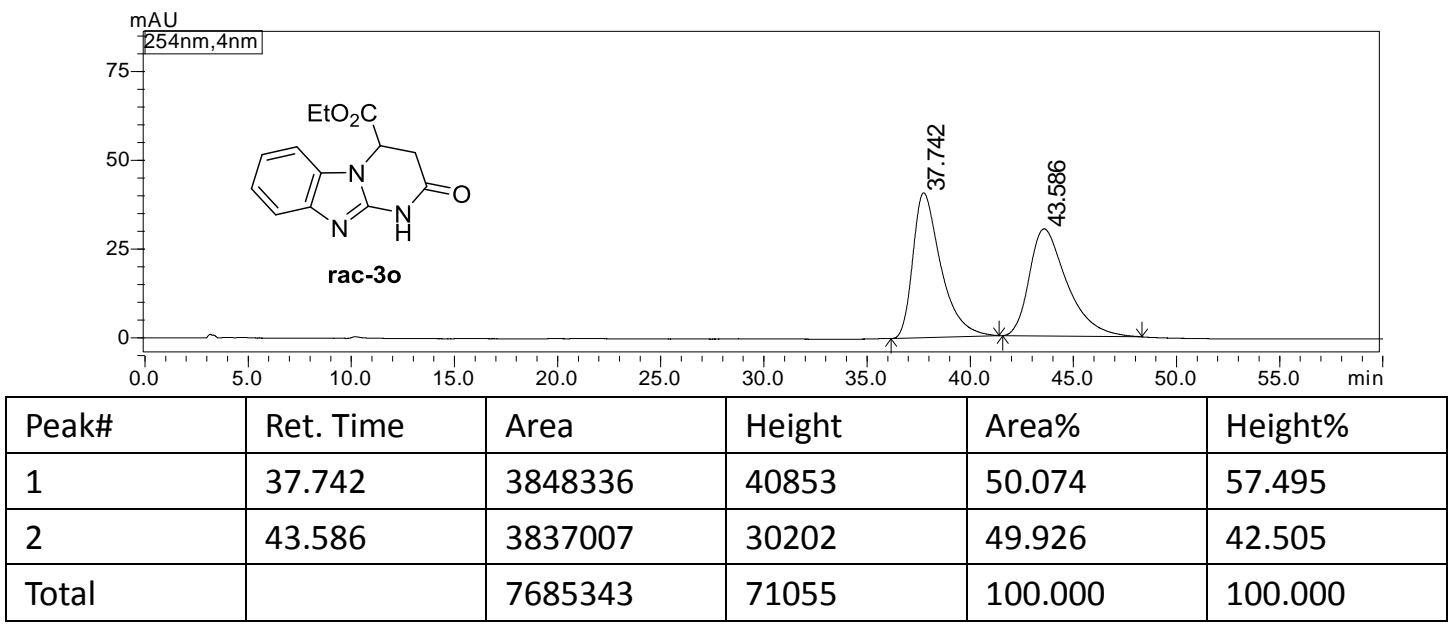

数据文件名:7-118-CO2Et(ID80)-chiral. Icd

样品名:CO2Et-chiral

样品ID:CO2Et-chiral

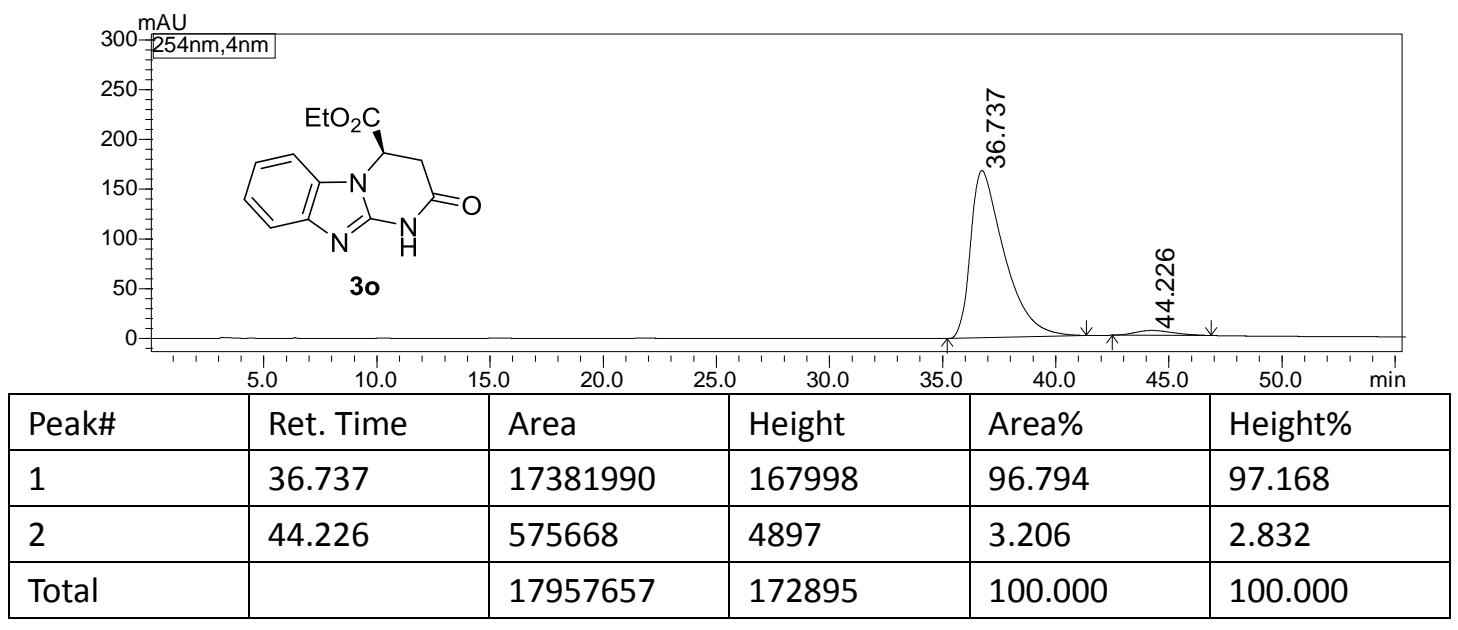




\section{Compound 3p}

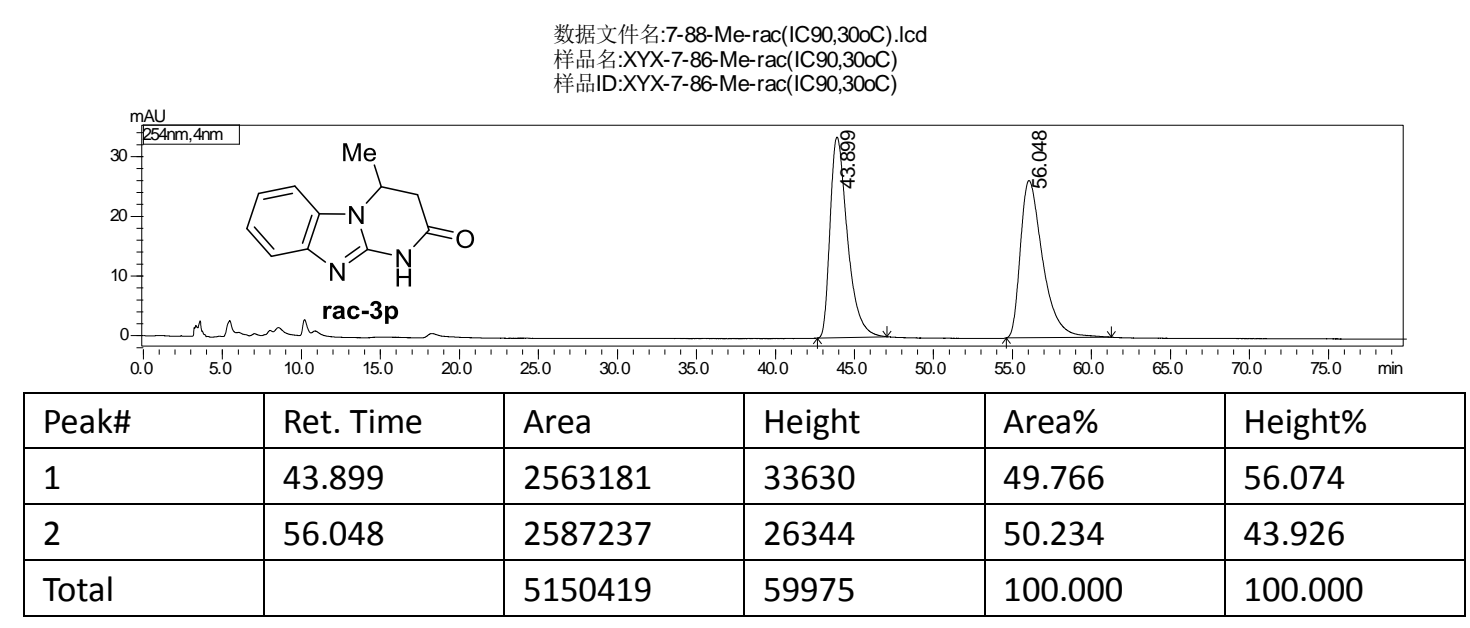

数据文件名:7-118-Me-chiral(IC90,30oC)-1.Icd

样品名:XYX-7-118-Me-chiral(IC90,300C)

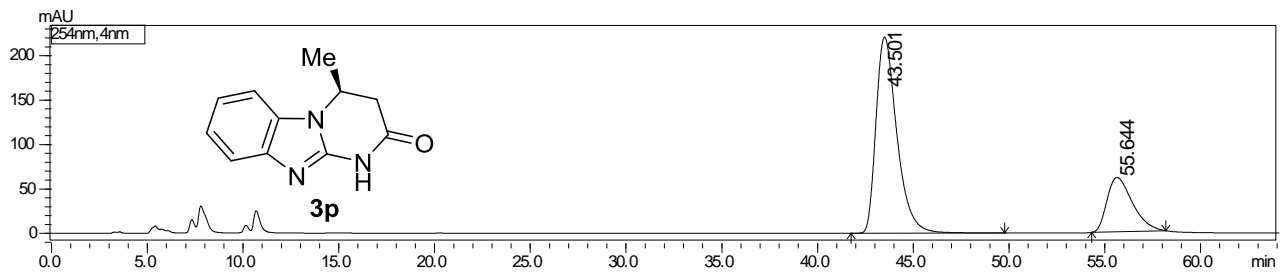

\begin{tabular}{|l|l|l|l|l|l|}
\hline Peak\# & Ret. Time & Area & Height & Area\% & Height\% \\
\hline 1 & 43.501 & 16740459 & 220969 & 74.699 & 78.290 \\
\hline 2 & 55.644 & 5670169 & 61276 & 25.301 & 21.710 \\
\hline Total & & 22410629 & 282245 & 100.000 & 100.000 \\
\hline
\end{tabular}




\section{Compound 4a}

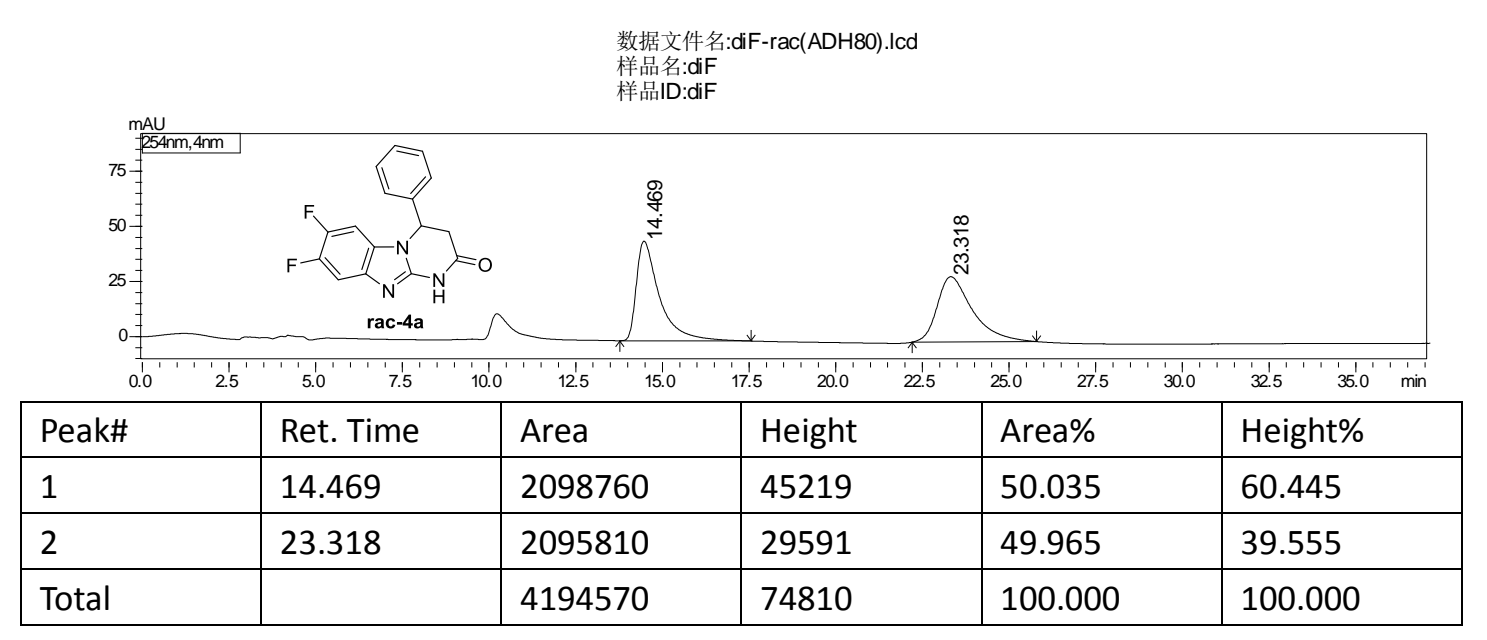

\begin{tabular}{|l|l|l|l|l|l|}
\hline Peak\# & Ret. Time & Area & Height & Area\% & Height\% \\
\hline 1 & 13.248 & 148183 & 5004 & 4.074 & 8.670 \\
\hline 2 & 22.442 & 3489303 & 52717 & 95.926 & 91.330 \\
\hline Total & & 3637485 & 57721 & 100.000 & 100.000 \\
\hline
\end{tabular}




\section{Compound 4b}

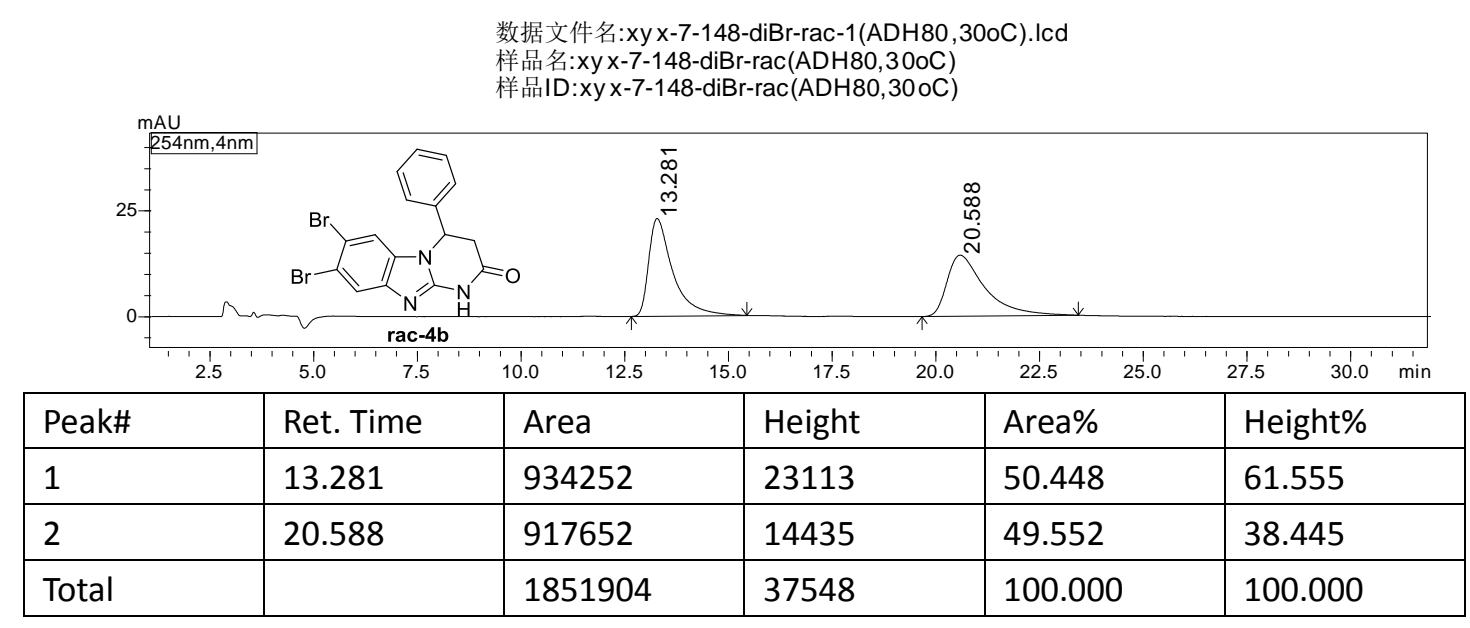

\begin{tabular}{|l|l|l|l|l|l|}
\hline Peak\# & Ret. Time & Area & Height & Area\% & Height\% \\
\hline 1 & 13.300 & 79186 & 2136 & 3.353 & 5.713 \\
\hline 2 & 20.472 & 2282465 & 35256 & 96.647 & 94.287 \\
\hline Total & & 2361652 & 37392 & 100.000 & 100.000 \\
\hline
\end{tabular}




\section{Compound 4c}

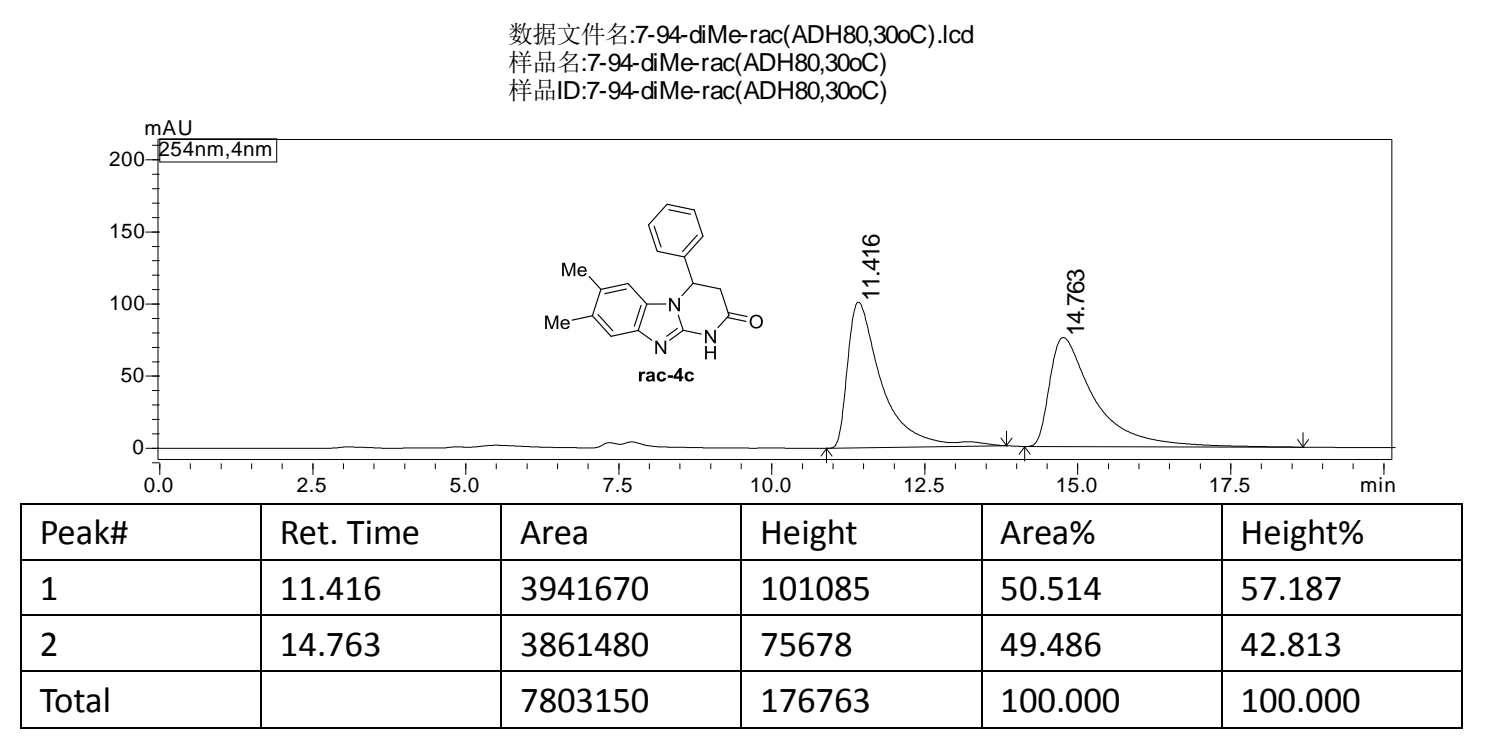

数据文件名:7-105-diMebenzoimidazole-chiRAL(ADH80,30oC).Icd

样品名:xyx-7-105-diMebenzoimidazole-chiRAL(ADH80,30oC)

样品ID:xyx-7-105-diMbenzoimidazole-chi

\begin{tabular}{|l|l|l|l|l|l|}
\hline Peak\# & Ret. Time & Area & Height & Area\% & Height\% \\
\hline 1 & 11.987 & 1553571 & 45629 & 5.947 & 7.943 \\
\hline 2 & 15.058 & 24570496 & 528857 & 94.053 & 92.057 \\
\hline Total & & 26124068 & 574486 & 100.000 & 100.000 \\
\hline
\end{tabular}




\section{Compound 4d}

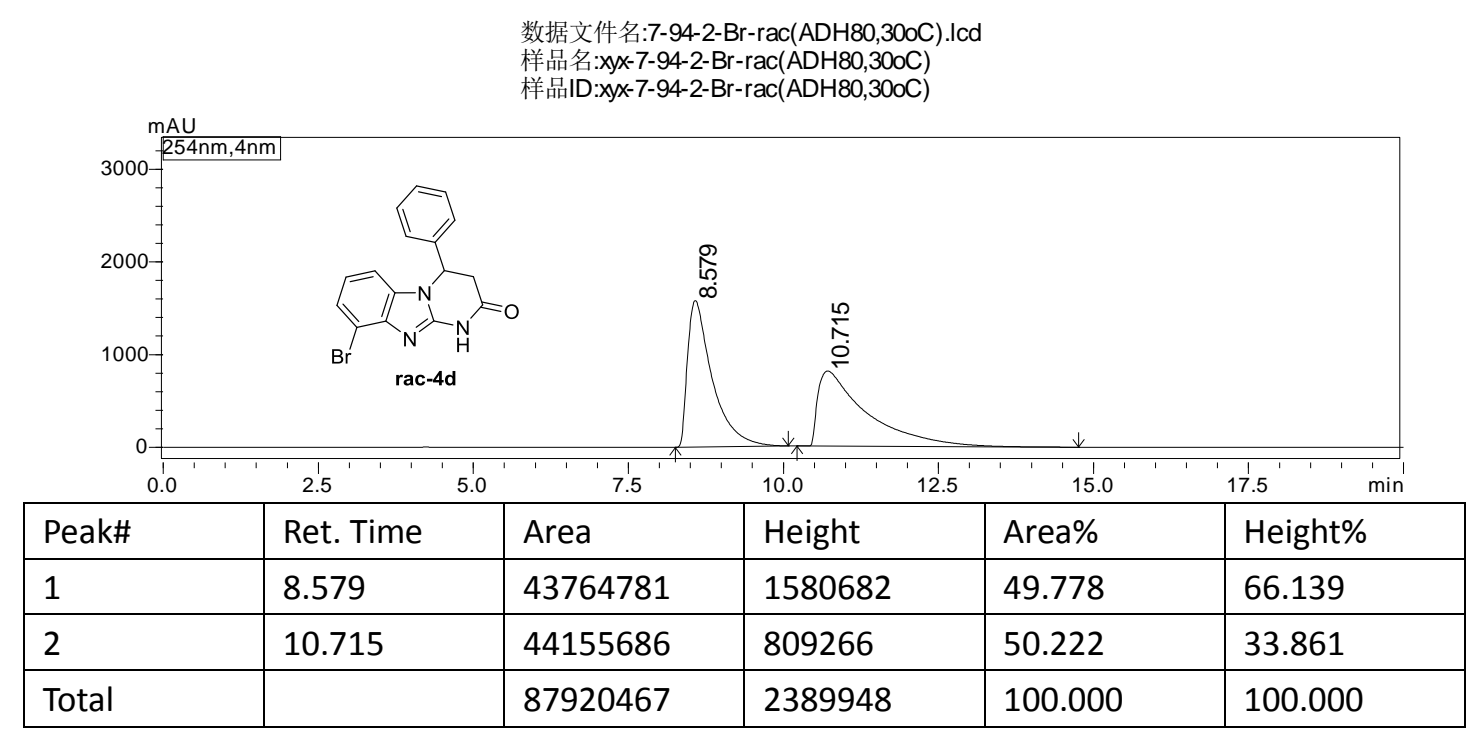

数据文件名:7-105-2-Br-chiral(ADH80,30oC).Icd

样品名:xyx-7-105-2-Br-chiral(ADH80,30oC)

样品ID:xyx-7-105-2-Br-chiral(ADH80,300

\begin{tabular}{|l|l|l|l|l|l|}
\hline Peak\# & Ret. Time & Area & Height & Area\% & Height\% \\
\hline 1 & 9.385 & 1814359 & 73305 & 3.829 & 7.810 \\
\hline 2 & 11.400 & 45566321 & 865248 & 96.171 & 92.190 \\
\hline Total & & 47380680 & 938553 & 100.000 & 100.000 \\
\hline
\end{tabular}




\section{Compound 4e}

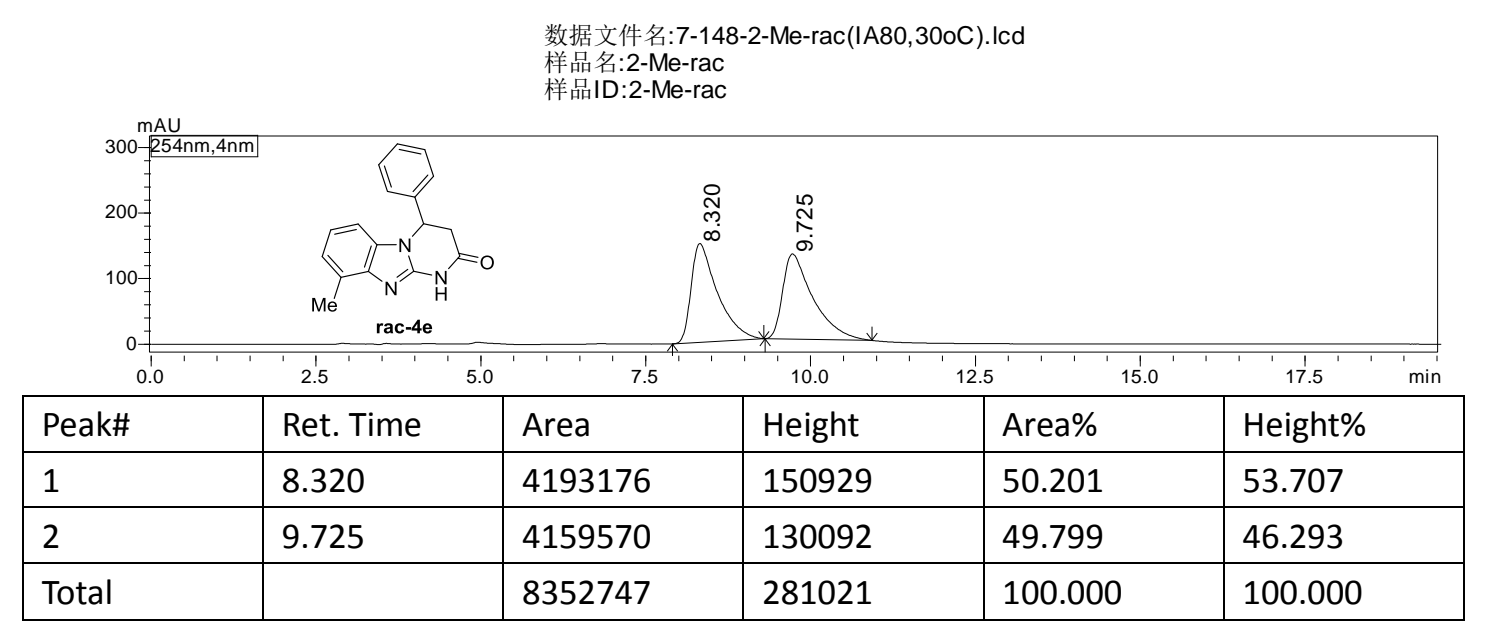

数据文件名:7-148-2-Me-chiral-1(IA80,30oC).Ic d

样品名:2-Me-chiral-1

样品ID:2-Me-chiral-1

\begin{tabular}{|l|l|l|l|l|l|}
\hline Peak\# & Ret. Time & Area & Height & Area\% & Height \% \\
\hline 1 & 8.386 & 242138 & 8929 & 3.412 & 4.276 \\
\hline 2 & 9.724 & 6855039 & 199878 & 96.588 & 95.724 \\
\hline Total & & 7097177 & 208808 & 100.000 & 100.000 \\
\hline
\end{tabular}




\section{Compound $4 f$}

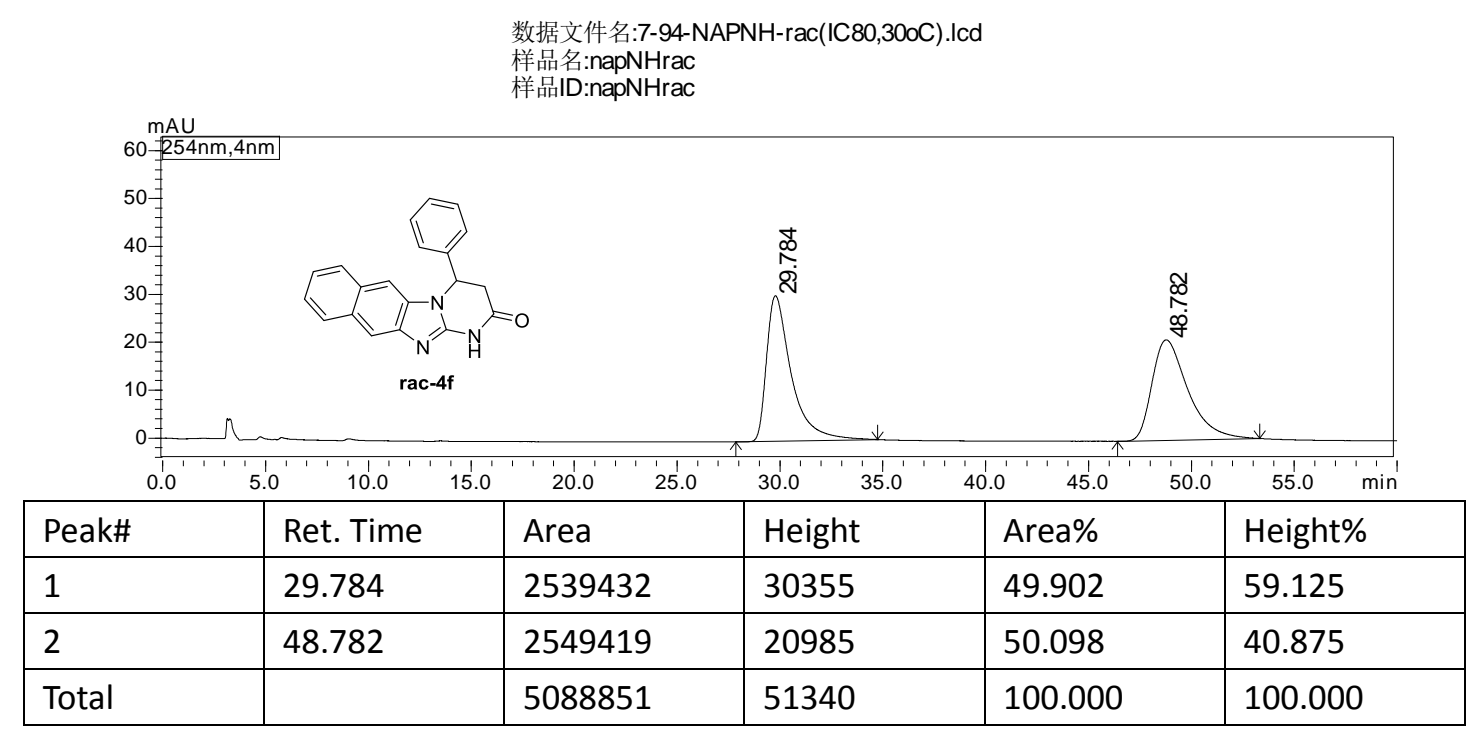

数据文件名:7-105-NAPNH-chiral(IC80,30oC).Icd

样品名:napNH

样品ID:napNH

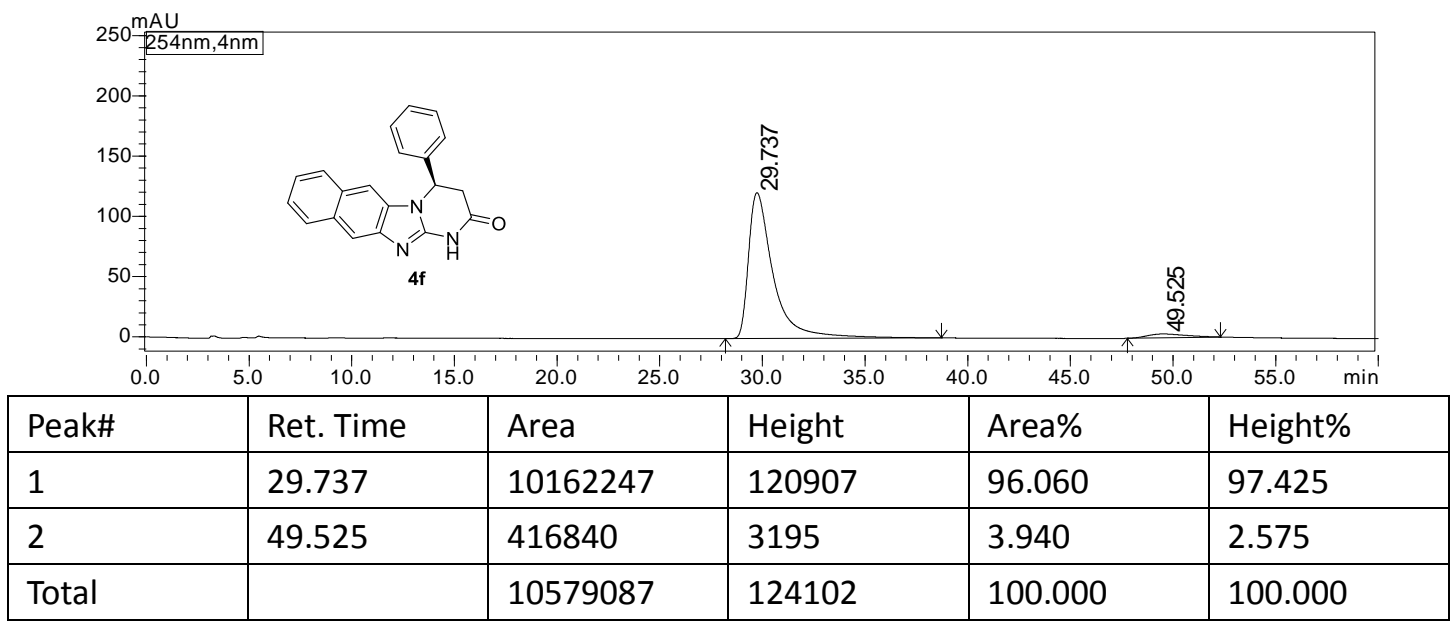




\section{Compound 4g}

\begin{tabular}{|l|l|l|l|l|l|}
\hline Peak\# & Ret. Time & Area & Height & Area\% & Height\% \\
\hline 1 & 27.511 & 3717404 & 42673 & 32.033 & 41.473 \\
\hline 2 & 32.616 & 2113852 & 20607 & 18.215 & 20.027 \\
\hline 3 & 38.078 & 2035417 & 17286 & 17.539 & 16.800 \\
\hline 4 & 53.450 & 3738164 & 22329 & 32.212 & 21.701 \\
\hline Total & & 11604838 & 102895 & 100.000 & 100.000 \\
\hline
\end{tabular}

数据文件名:7-105-3-Fbenzoimidazole-Chiral(ADH90,30oC).Icd

样品名:xyx-7-105-3-Fbenzoimidazole-chiRAL(ADH90,300C)

样品ID:xyx-7-105-3-Fbenzoimidazole-chi

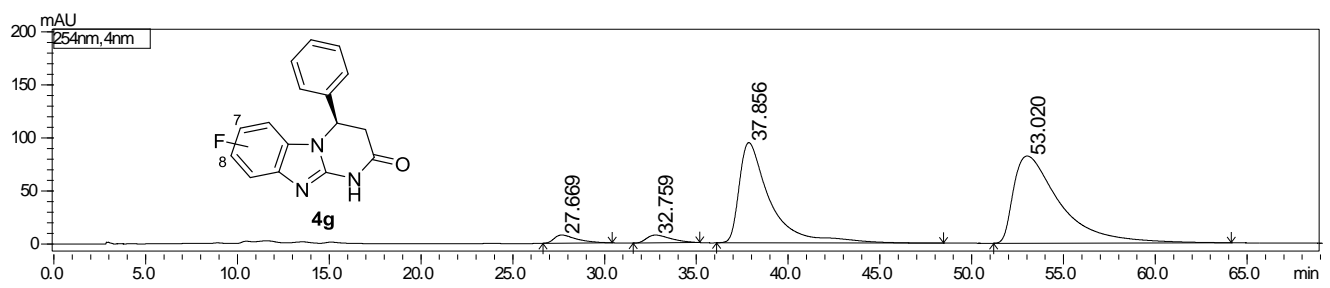

\begin{tabular}{|l|l|l|l|l|l|}
\hline Peak\# & Ret. Time & Area & Height & Area\% & Height\% \\
\hline 1 & 27.669 & 659919 & 7710 & 2.446 & 4.017 \\
\hline 2 & 32.759 & 690570 & 7475 & 2.560 & 3.895 \\
\hline 3 & 37.856 & 11115551 & 94537 & 41.203 & 49.258 \\
\hline 4 & 53.020 & 14511476 & 82199 & 53.791 & 42.830 \\
\hline Total & & 26977516 & 191921 & 100.000 & 100.000 \\
\hline
\end{tabular}




\section{Compound 4h}

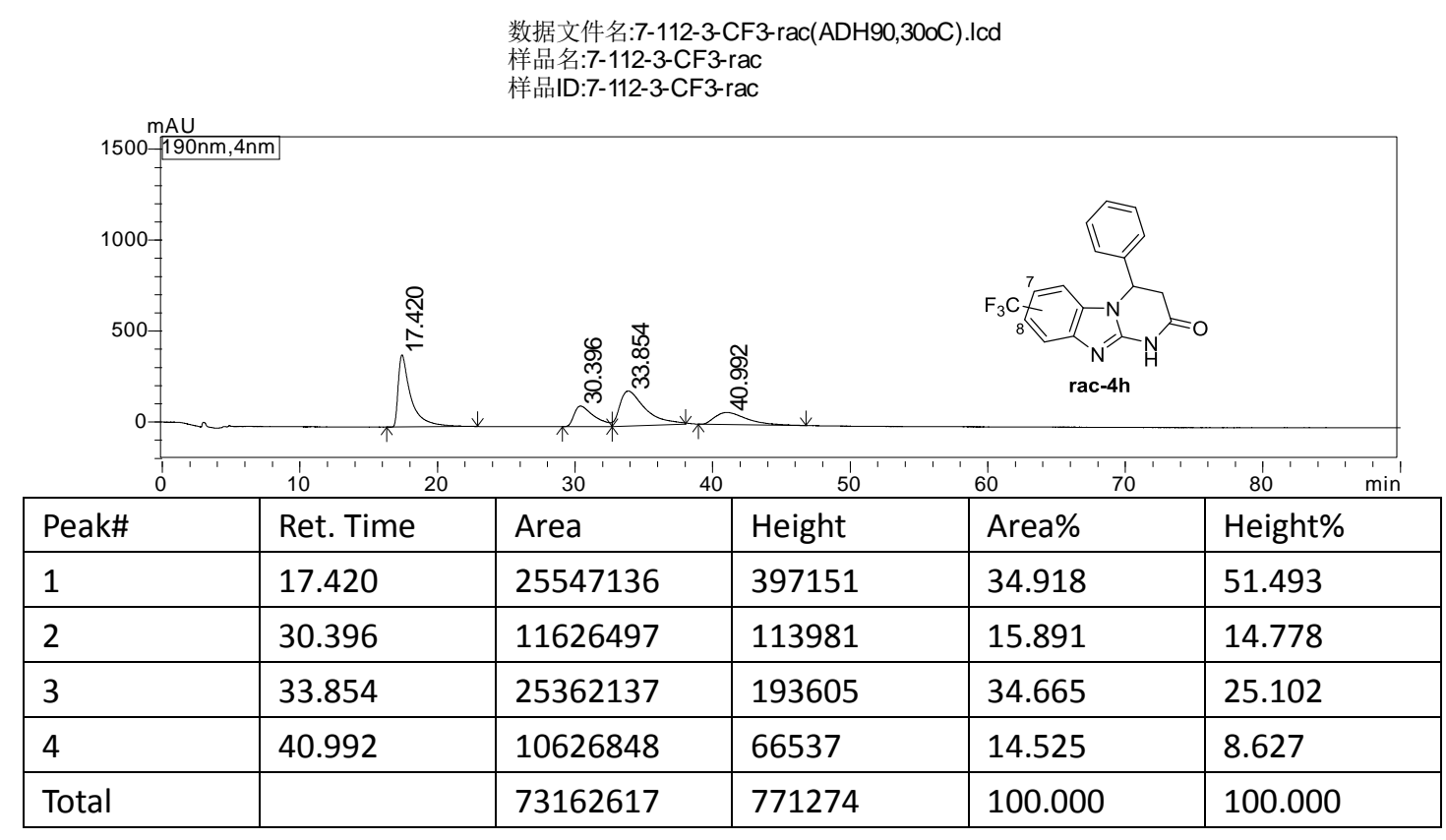

数据文件名:7-112-3-CF3-chiral(ADH90,30oC).Icd

\begin{tabular}{|l|l|l|l|l|l|}
\hline & Area\% & Height\% \\
\hline 1 & 17.957 & 625106 & 10588 & 1.985 & 3.935 \\
\hline 2 & 30.666 & 8822624 & 91436 & 28.023 & 33.977 \\
\hline 3 & 34.122 & 21837737 & 163616 & 69.362 & 60.798 \\
\hline 4 & 41.418 & 198190 & 3474 & 0.630 & 1.291 \\
\hline Total & & 31483657 & 269114 & 100.000 & 100.000 \\
\hline
\end{tabular}




\section{Compound 4i}

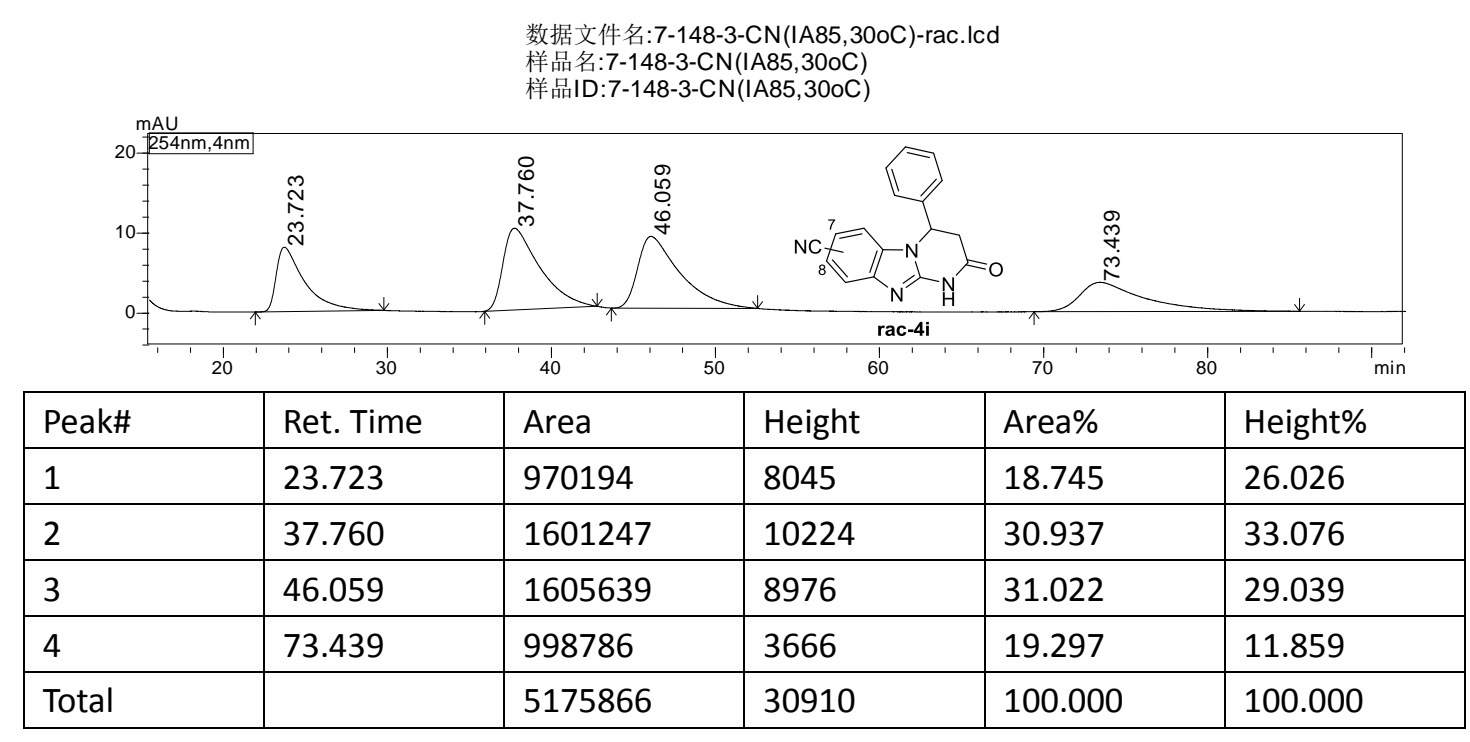

数据文件名:7-148-3-CN(IA85,30oC).Icd

样品名:7-148-3-CN(IA85,30oC)

样品ID:7-148-3-CN(IA85,30oC)

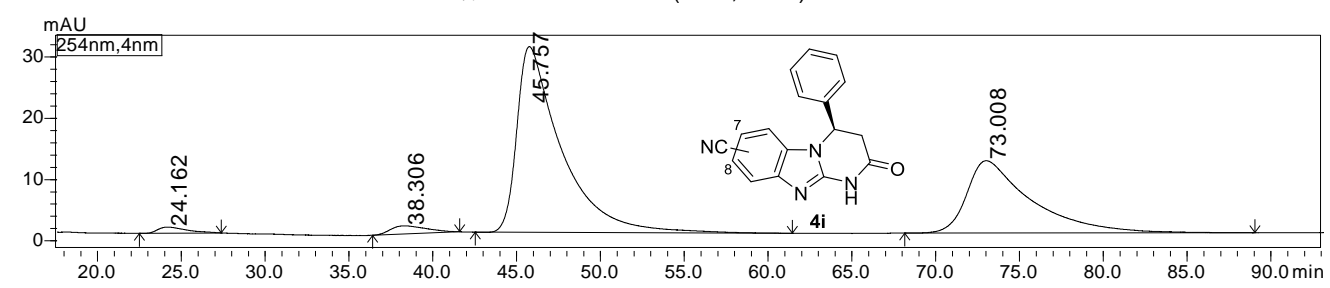

\begin{tabular}{|l|l|l|l|l|l|}
\hline Peak\# & Ret. Time & Area & Height & Area\% & Height\% \\
\hline 1 & 24.162 & 119565 & 1007 & 1.318 & 2.264 \\
\hline 2 & 38.306 & 198688 & 1345 & 2.190 & 3.024 \\
\hline 3 & 45.757 & 5610027 & 30315 & 61.824 & 68.169 \\
\hline 4 & 73.008 & 3145916 & 11804 & 34.669 & 26.543 \\
\hline Total & & 9074196 & 44470 & 100.000 & 100.000 \\
\hline
\end{tabular}




\section{Compound 4j}

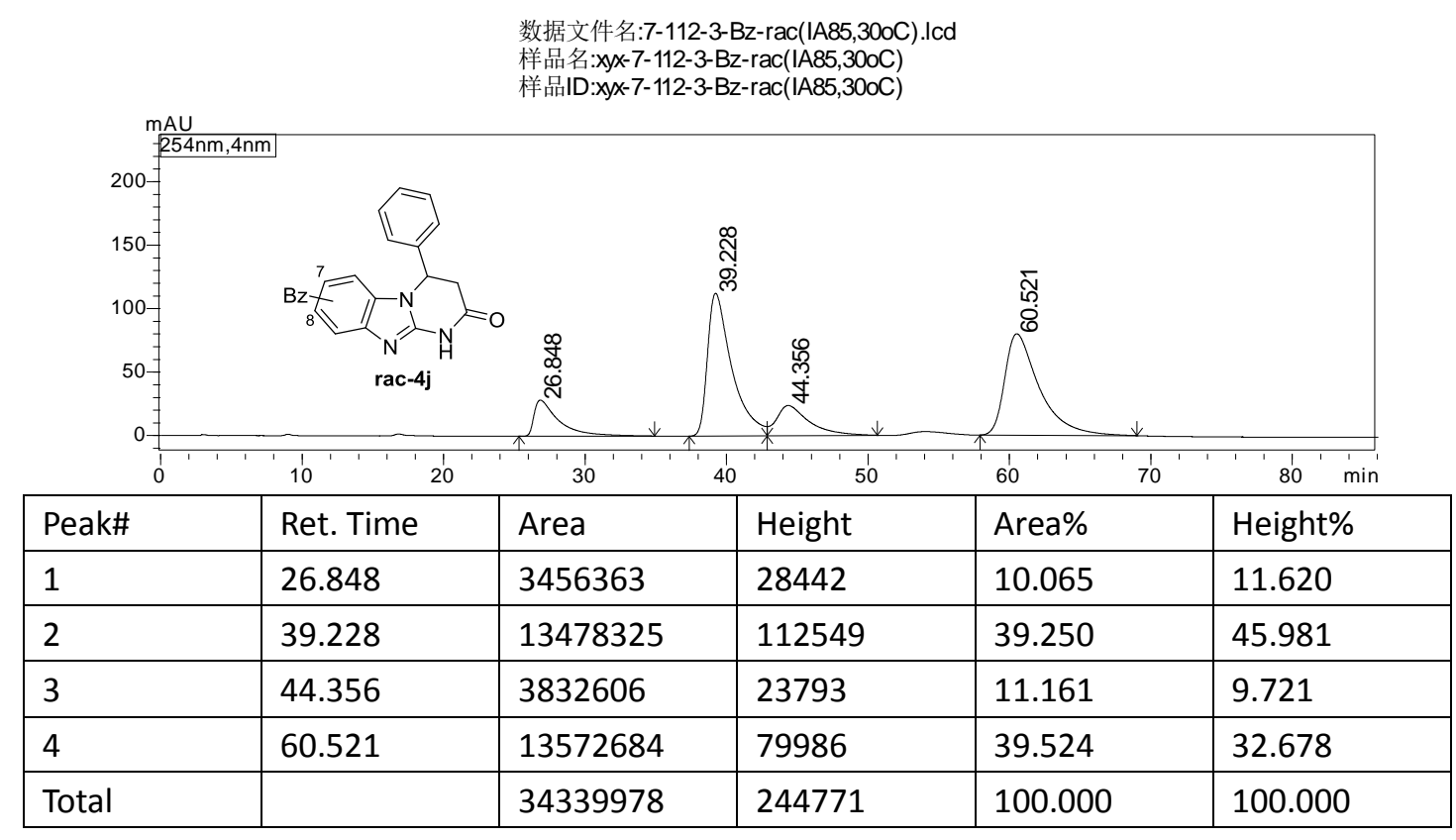

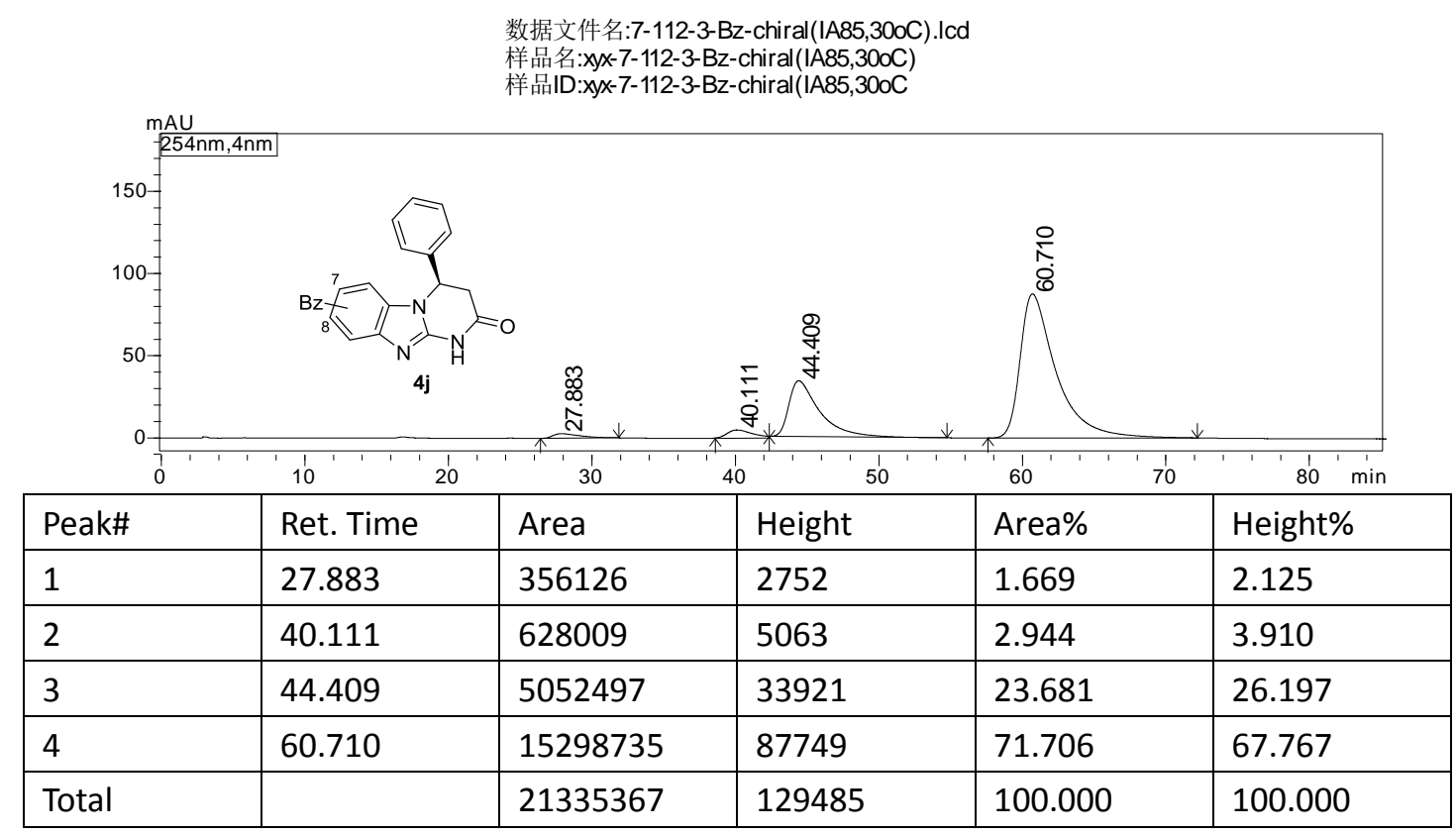




\section{Compound 4k}

\begin{tabular}{|l|l|l|l|l|l|}
\hline \multicolumn{2}{c|}{} \\
\hline Peak\# & Ret. Time & Area & Height & Area\% & Height\% \\
\hline 1 & 9.764 & 335392 & 7410 & 22.130 & 25.792 \\
\hline 2 & 11.376 & 425721 & 8229 & 28.090 & 28.643 \\
\hline 3 & 13.697 & 405055 & 7459 & 26.727 & 25.963 \\
\hline 4 & 15.605 & 349381 & 5632 & 23.053 & 19.602 \\
\hline Total & & 1515549 & 28730 & 100.000 & 100.000 \\
\hline
\end{tabular}

\begin{tabular}{|l|l|l|l|l|l|}
\hline \\
\hline Peak\# & Ret. Time & Area & Height & Area\% & Height\% \\
\hline 1 & 10.060 & 82018 & 1999 & 2.017 & 2.715 \\
\hline 2 & 11.688 & 79338 & 1995 & 1.951 & 2.711 \\
\hline 3 & 13.879 & 1937834 & 38385 & 47.646 & 52.148 \\
\hline 4 & 15.814 & 1968001 & 31229 & 48.387 & 42.426 \\
\hline Total & & 4067190 & 73609 & 100.000 & 100.000 \\
\hline
\end{tabular}




\section{Compound 41}

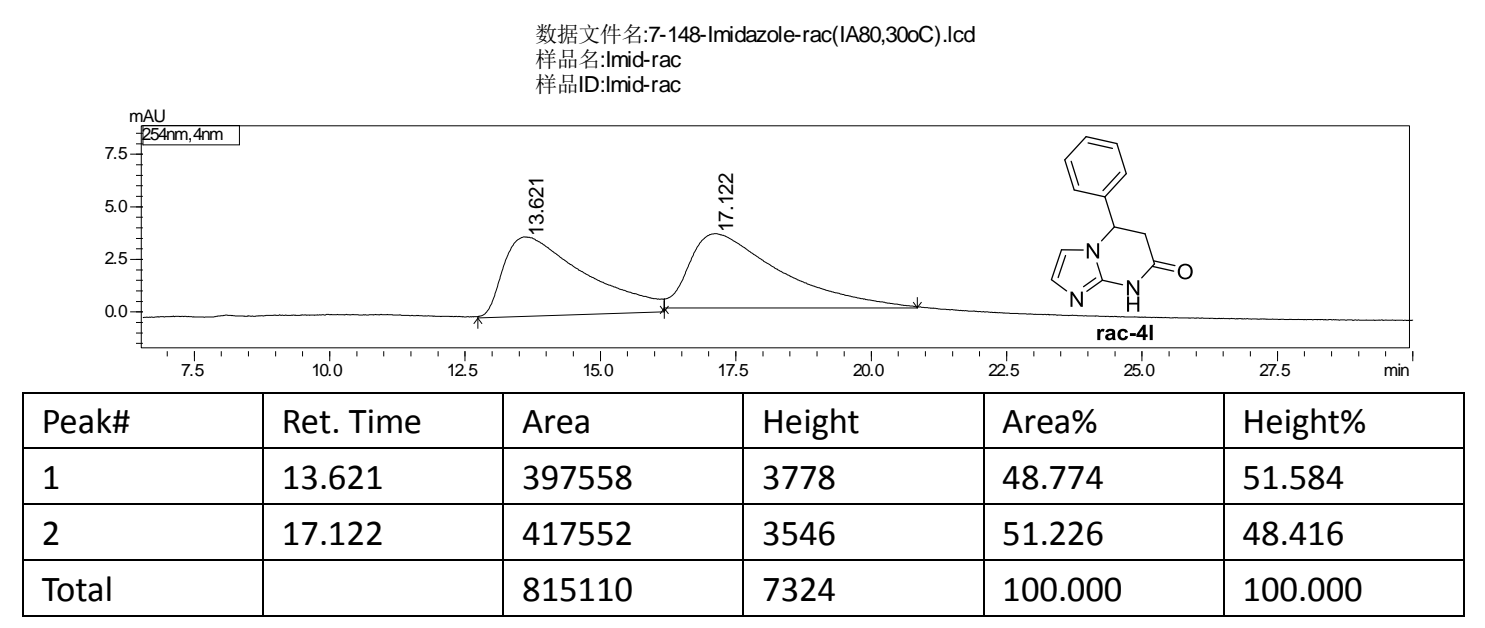

数据文件名:7-148-Imid-chiral-2(IA80,30oC).Icd

样品ID:Imid

\begin{tabular}{|l|l|l|l|l|l|}
\hline \multicolumn{1}{|c|}{} & & & \\
\hline
\end{tabular}




\section{Compound 5}

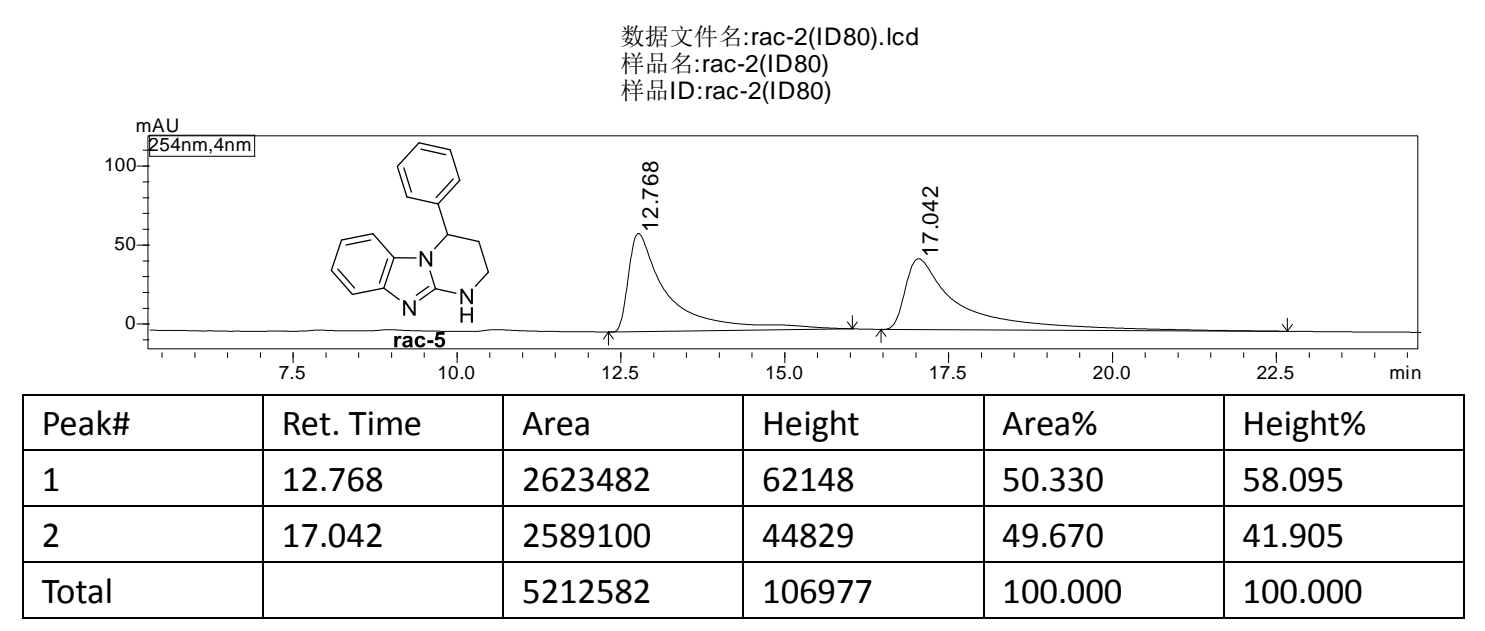

数据文件名:chiral-p0(ID80).Icd

样品名:chiralpO(ID80)

样品ID:chiral-p0(ID80)

\begin{tabular}{|l|l|l|l|l|l|}
\hline Peak\# & Ret. Time & Area & Height & Area\% & Height\% \\
\hline 1 & 13.188 & 599395 & 18176 & 3.808 & 5.217 \\
\hline 2 & 17.210 & 15142929 & 330228 & 96.192 & 94.783 \\
\hline Total & & 15742324 & 348404 & 100.000 & 100.000 \\
\hline
\end{tabular}

